\title{
The danger of innocence : common sense beliefs and misconceptions about false confessions
}

Citation for published version (APA):

Schell-Leugers, J. M. (2014). The danger of innocence : common sense beliefs and misconceptions about false confessions. [Doctoral Thesis, Maastricht University]. Universitaire Pers Maastricht. https://doi.org/10.26481/dis.20141215js

Document status and date:

Published: 01/01/2014

DOI:

10.26481/dis.20141215js

Document Version:

Publisher's PDF, also known as Version of record

\section{Please check the document version of this publication:}

- A submitted manuscript is the version of the article upon submission and before peer-review. There can be important differences between the submitted version and the official published version of record.

People interested in the research are advised to contact the author for the final version of the publication, or visit the DOI to the publisher's website.

- The final author version and the galley proof are versions of the publication after peer review.

- The final published version features the final layout of the paper including the volume, issue and page numbers.

Link to publication

\footnotetext{
General rights rights.

- You may freely distribute the URL identifying the publication in the public portal. please follow below link for the End User Agreement:

www.umlib.nl/taverne-license

Take down policy

If you believe that this document breaches copyright please contact us at:

repository@maastrichtuniversity.nl

providing details and we will investigate your claim.
}

Copyright and moral rights for the publications made accessible in the public portal are retained by the authors and/or other copyright owners and it is a condition of accessing publications that users recognise and abide by the legal requirements associated with these

- Users may download and print one copy of any publication from the public portal for the purpose of private study or research.

- You may not further distribute the material or use it for any profit-making activity or commercial gain

If the publication is distributed under the terms of Article $25 \mathrm{fa}$ of the Dutch Copyright Act, indicated by the "Taverne" license above, 


\section{The Danger of Innocence}

Common Sense Beliefs and Misconceptions about False Confessions 
(C) Jennifer Maria Schell-Leugers, 2014

Production: Datawyse | Universitaire Pers Maastricht

ISBN 9789461593870 


\title{
The Danger of Innocence
}

\section{Common Sense Beliefs and Misconceptions about False Confessions}

\author{
DISSERTATION \\ to obtain the degree of Doctor at Maastricht University, \\ on the authority of the Rector Magnificus, \\ Prof. dr. L.L.G. Soete \\ in accordance with the decision of the Board of Deans, \\ to be defended in public \\ on Monday 15 December 2014 at 12.00 hours \\ by \\ Jennifer Maria Schell-Leugers
}

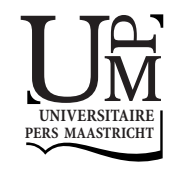




\section{Supervisors}

Prof. dr. H.J. Hospers

Prof. dr. H.L.G.J. Merckelbach

Prof. dr. S.M. Kassin (City University of New York, New York)

\section{Assessment Committee}

Prof. dr. G. Kok (chair)

Prof. dr. B. Englich (University of Cologne, Germany)

Dr. E. Meijer

Dr. K. van Oorsouw

Prof. dr. E. Rassin (Erasmus University Rotterdam) 
Dedicted to my beloved Opa Josef ( +2014$)$ who sadly passed away shortly before this thesis was finished 



\section{CONTENTS}

$\begin{array}{llr}\text { CHAPTER } 1 \text { General Introduction } & 9\end{array}$

CHAPTER 2 False Confessions: Why Innocent People Confess to Crimes 19 They Have Not Committed

CHAPTER 3 Common Sense of Confessions: What Do People Believe?

CHAPTER 4 Police Practices and Beliefs: A Survey of European

Investigators

CHAPTER 5 Not Acting According to Our Beliefs: The Dangers of

Waiving the Right to Remain Silent

CHAPTER 6 "I Would Never Do That": Exploring the Inconsistencies

CHAPTER 7 "Yes, I Have Sometimes Stolen Bikes": Blindness for Norm-

Violating Behaviors and Implications for Suspect

Interrogations

CHAPTER 8 Summary and General Discussion

References

Summary

Valorization

Acknowledgments

Curriculum vitae 

CHAPTER 1

General Introduction 
CHAPTER 1 


\section{Innocent Behind Bars - The Case of Ulvi Kulac}

Lichtenberg, located in Bavaria, Germany, is a small, beautiful, quiet village with around 1200 residents. It was a rather unspectacular place until it was shaken up by the disappearance of a little girl 13 years ago ${ }^{1}$. On May 7th 2001, nine year old Peggy went missing. After school she walked towards home with a friend. They arrived at her friends' house at $1.15 \mathrm{pm}$. Then Peggy kept walking home. She was seen by several witnesses on her way. Around $1.30 \mathrm{pm}$, she was seen by a friend who was driving by in a bus. By that time Peggy was close to her home. Her parents were at work but Peggy had a key and was used to being alone at home. Whether she actually went to her apartment or not is unknown. Maybe she went home and back out again later, but since no one was there, it is impossible to tell. Other witnesses reported still seeing her in the afternoon and evening in Lichtenberg. After her mother got home shortly after 8 pm that evening, she picked up Peggy's halfsister at the neighbors and only then realized that Peggy was not there. She called up several of Peggy's friends and went out to find her. After an unsuccessful search, she informed Peggy's stepfather and reported her daughter missing to the police shortly before $10 \mathrm{pm}$ that night.

In the days and weeks after Peggy's disappearance, a frantic search for her whereabouts started. Even though several witnesses came forward and stated that they had seen Peggy throughout the day and even days later, there was no sign of Peggy. The police initially stated that she was last seen around $7 \mathrm{pm}$ in the evening of May 7th, but later changed that time to $4 \mathrm{pm}$ in the afternoon and at a later point in the investigation to $1.30 \mathrm{pm}$. All searches in the village and in nearby woods stayed unsuccessful. No body, no clothes, no school bag, and no physical evidence the little girl literally vanished from the face of the earth. Not only the residents of Lichtenberg felt horrified by her disappearance, but throughout Germany people were shocked. How can a little girl just disappear in the middle of the day without any trace?

After Peggy went missing, Lichtenberg was swarmed with police and journalists. Different theories and speculations about what happened to Peggy appeared in the media on a daily basis. The police established a special commission to investigate what happened to the little girl. During the investigation information about Peggy's family was gathered. She lived with her mother Susanne, her Turkish stepfather Ahmet, and her younger half-sister Jessica in an apartment in Lichtenberg. Both parents worked during the day. Jessica was usually picked up from daycare and looked after by a neighbor, but Peggy was usually on her own. She would get ready for school by herself and after school walk home alone. Then usually she would spend the day playing outside with friends or wandering around Lichten-

\footnotetext{
1 All information about the case of Peggy Knobloch is derived from the website http://www.ulvikulac.de/ and the following book: Jung, I., \& Lemmer, C. (2013). Der Fall Peggy. Die Geschichte eines Skandals. [The case Peggy. The story of a scandal]. München: Droemer.
} 
berg, visiting neighbors but also local bars. Whether the parents were negligent or whether Peggy was just very self-reliant early on in her life is a point of disagreement between neighbors and friends of the family.

In the months before her disappearance, Peggy's behavior had changed. When Peggy entered third grade after the summer of 2000, she started having problems in school. Her performance deteriorated, her teacher noticed that she often seemed absent and was easily distracted. School friends also reported that they had seen bruises on Peggy, and claims emerged that she was beaten by her stepfather. But these accusations were never verified. Her mother also noticed a change in her daughter's behavior and took her to a doctor in April 2001. Peggy was first prescribed a homeopathic product and later a psychotropic drug. It is not known what exactly was going on in Peggy's life or why her behavior changed.

With the media reporting about the case regularly, the pressure on police increased with every day since the little girl vanished. Within the first eight weeks of Peggy's disappearance, the police received around 2500 leads about the case. At times there were 75 police detectives working around the clock to examine all clues that they had but many turned out to be unrelated and not helpful. The police looked into various theories - from Peggy running away from home because of familial problems to being sold in the Czech Republic for child prostitution to being kidnapped by her allegedly abusive stepfather and brought to Turkey. Several of these theories were followed thoroughly. Contacts were made to the Czech police and also to Turkey. Some leads seemed promising, but even after weeks and months of her disappearance any substantial evidence about what had happened to Peggy was still missing.

In addition to following up on tips that led abroad, police also questioned several residents of Lichtenberg. One of them was then 23 year old Ulvi Kulac. Born as a healthy baby in 1977, Ulvi contracted meningitis when he was just over two years old. He recovered, but the illness had caused permanent damage and the disease left him with an intellectual disability. He had to attend a special school and a therapeutic center. He was not able to keep a normal job and live alone. His parents, who ran a local restaurant, took care of him. He helped out in their restaurant. Ulvi was not capable of being on his own. Due to his mental status, Ulvi received a certificate of disability. He had an IQ of around 54, was socially awkward, his physical capacities were limited, and his mental status was that of a 10 year old. He was well known by everyone in the village as an odd fellow. Even though he had problems finding friends because of his disability, he was well liked by most locals and known to be harmless. However, at times Ulvi could also be annoying, especially when he was out of money. Then he would ask several locals for money, cigarettes or alcohol. Even though this might have been annoying, he was easy to get rid of by waving him off. Girls were generally not attracted to Ulvi, and he had never had a girlfriend. He could be described as a boy stuck in the body of a man. He was often unable to cope with his sexual drive and at one point diagnosed with psychosexual retardation. At times he would act out sexually by running around naked in the village. 
Some kids also said that Ulvi tried to touch them inappropriately or wanted them to touch him. Others liked to tease him and asked him to show his genitals to them and then would run off. Of course, some kids told their parents about these occasions.

In June 2000, Ulvi got into trouble for such behavior for the first time. The mother of one of the local boys called Ulvi's mother and told her that Ulvi had asked her son to watch him masturbate. Ulvi's mother was furious and lectured her son about his actions. He took his mother's words seriously and one night after visiting a disco and drinking he called the police to confess what he had done. The incident was investigated and an expert was asked to evaluate Ulvi's criminal responsibility. His report stated that he suffered from organic brain damage, obvious mental impairment, emotional and social immaturity, a lack of social competencies and selfconsciousness, all limiting legal accountability. In addition to these issues it was reported that it was likely that he was under the influence of alcohol and cannabis at the time of the incident. Based on these observations, it appeared that he could not be held responsible for his actions at the time and the case was closed. Even though there were no legal consequences, Ulvi's mother took this incident seriously and arranged for Ulvi to visit a therapist. Life went on like normal in Lichtenberg after this incident.

At the end of May 2001, shortly after Peggy disappeared, Ulvi was questioned by the police about his whereabouts on the day the girl was last seen. He was able to provide a bullet proof alibi and so the police were no longer interested in him. This changed in September 2001. After another incident of Ulvi's exhibitionism, the police got involved again and questioned him. His mother agreed with the police that Ulvi needed more help and arranged for inpatient treatment starting on September 10, 2001. However, once the police detectives who worked on Peggy's case heard about the incident with Ulvi, they went to see him and accused him of being involved in her disappearance. Four days before his therapy was scheduled to start, he was questioned by the police twice in one day - four hours in the morning and another five hours in the afternoon. He was alone, no parent or lawyer present. He eventually admitted that he had touched Peggy inappropriately, but firmly denied having anything to do with her disappearance. The detectives suspected that Ulvi had abused Peggy sexually, killed her, and then disposed her body in order to cover up the sexual abuse. He denied this accusation rigorously and since there was no body or even a shred of physical evidence, there was nothing the police could do.

Ulvi was sent to the closed unit of a psychiatric hospital. At the same time, Peter $\mathrm{H}$., a criminal and criminal informant to the police was also staying at the same hospital. Later, Peter H. would claim that detectives had visited him and offered him a deal: if he would talk to Ulvi and try to find out more about what happened to Peggy, they would in return help him get out. Of course, such a deal is illegal and the police detectives denied arranging it. Over the next weeks and months, Peter H. reported back to the police that Ulvi had confessed the murder of Peggy to him. This confirmed the detectives' suspicion that Ulvi had something to do with the 
missing girl. It provided a great - and long needed - breakthrough in the case. Even though the informant reported different stories and locations of Peggy's body (in which her body was not actually found), the police believed him. Parallel to investigating Ulvi's possible involvement in the case, the police still examined other theories as well. But Ulvi was the prime suspect for most of the police detectives. Over weeks and months, Ulvi was repeatedly questioned and interrogated but kept maintaining that he had nothing to do with Peggy's disappearance. However, the informant kept reporting that Ulvi had opened up to him and gave more details to the police. The mind of the detectives was set, Ulvi was the perpetrator. Now they just needed to prove it.

In April 2002, the police came up with a Tathergangshypothese (a hypothesis about the circumstances of the crime). This hypothesis stated that Ulvi had raped Peggy and then strangled her a few days later to make sure that she kept quiet. It also included the possibility that Ulvi did not mean for it to happen. The final interrogation - in which the detectives hoped Ulvi would finally confess to them as well and not only to Peter $\mathrm{H}$. in private conversations - was planned well in advance. It was decided that one of the older, male detectives would 'play' a father figure for Ulvi during the interrogation, while one of the younger, male detectives would confront him with the allegations. The interrogation was scheduled for July and it was decided that it was best to only audio tape it to avoid the distractions of a camera.

On July $2^{\text {nd }} 2002$, Ulvi was picked up by the police for the interrogation. During the interrogation at which his lawyer was present, Ulvi kept denying any involvement in Peggy's disappearance. Even after police told him that they found blood on some of his clothes (which was not true), Ulvi stuck to his story. Once the official interrogation was over, Ulvi's lawyer left, but when Ulvi was brought to the car he allegedly said that he wanted to tell the police more and so he was brought back to the interrogation room. Then he confessed to murdering Peggy and disposing of her body. He gave the police a detailed description of everything that happened and explained where they could find the body. Ulvi's lawyer was not present during the confession and no audiotape was made. The police claimed that the audiotape device stopped working and they only wrote a Gedächstnissprotokoll (memory minutes). At the end of the interrogation, the detectives were relieved - their suspect had confessed as expected and the case could finally be closed.

However, Peggy's body was not found in the indicated location. And in the following two interrogations, Ulvi changed many details of his confession. He gave different accounts of what happened, where the body was, and who helped him dispose the body. The detectives kept searching the different locations identified by Ulvi, but Peggy's body was found in none of these. They also investigated the various accomplices that Ulvi mentioned - who all allegedly helped him hide the body. However, every single one of them had a bullet proof alibi. In August, a well-known expert witness got involved with the case. The the expert witness - a leading forensic psychiatrist - was asked to evaluate the authenticity of Ulvi's confession. Yet, during his first session with Ulvi, Ulvi denied being a murderer. In all three ses- 
sions, he maintained his innocence. He did, however, admit that he confessed to the police. He explained that they were getting on his nerves and he just wanted to be left alone but that he was innocent. Allegedly one of the detectives also told Ulvi right before he confessed that he should just say he murdered Peggy and that he would not go to jail because of his low IQ. In addition to the sessions with Ulvi, the expert witness also received information from the police. Based on his conversations with Ulvi and the information from the police, the expert witness stated that he had no reason to doubt the credibility of Ulvi's confession and reported that there was no reason to believe that Ulvi could have falsely confessed. Looking at the inconsistencies in Ulvi's story, including the inconclusive statements about accomplices, that no body was found where Ulvi told the police he had put it, his mental status, and the fact that he recanted his confession, it is unclear how an expert witness could have reached such a conclusion.

A recanted confession from the main suspect and an alibi for the day of Peggy's disappearance, still no body, or physical evidence, or any clue of where Peggy could be - but the police still believed that Ulvi was the perpetrator and the case went to trial. Ulvi was charged with sexually abusing Peggy and then murdering her. By the time the trial started, Ulvi had been interrogated 42 times by the police, often longer than four hours and in total 18 times without his lawyer being present. But he only admitted to the murder of Peggy in three of these interrogations. Once the case went to trial, he had long recanted his confession and firmly claimed that he had nothing do to with Peggy's disappearance. In April 2004, after a lengthy trial, Ulvi was convicted of the murder of Peggy based on his initial confession, the report of the expert witness, and the witness Peter H. who claimed that Ulvi admitted to murdering Peggy to him. Ulvi received a life sentence. Simultaneously, the judge ordered his admission to a forensic hospital for the time of his sentence.

After the trial, Peggy's mother was glad that the nightmare was finally over and that justice had been served, even though Peggy was still not found. But not everyone was pleased with the outcome of the trial. The guilty verdict was harshly critiqued by the media and by many residents of Lichtenberg and people from all over Germany. Many people believed that the verdict was scandalous. Ulvi was convicted only on the basis of circumstantial evidence. A number of people believed that he was innocent and that he had falsely confessed to the crime. Ulvi's lawyers appealed the verdict but their request was denied, the verdict stands, and Ulvi is behind closed doors in a forensic hospital. ${ }^{2}$ Even though the case was closed with a guilty verdict, countless questions remain: How can a mentally handicapped young man commit a perfect crime? And how can someone be convicted for murder without a body or any shred of hard evidence? Could Peggy still be alive? Is Ulvi innocent and the victim of a miscarriage of justice? Is it possible that he is innocent but

\footnotetext{
${ }^{2}$ In 2013, after a new appeal with a new lawyer, a retrial was granted. The new hearing was held in April 2014, the outcome is described in the final chapter of this thesis (Chapter 8).
} 
admitted to murdering Peggy because of police pressure? Did Ulvi falsely confess to a crime he has not committed?

False confessions are not an unheard-of phenomena. Although counterintuitive, they do exist and cause wrongful convictions around the world (Huff \& Killias, 2008), also in Germany (Friedrichsen, 2010; Friedrichsen, 2011; Otto, 2006). Most documented cases stem from the United States, such as the following case example: In 1989, a young woman was severely beaten, raped, and left for dead in New York's Central Park. Shortly thereafter, five 14-16 year-old Africanand Hispanic-American boys were arrested, interrogated, and ended up confessing to the horrible crime. They all were convicted despite the fact that each boy recanted his confession and professed his innocence. More than a decade later, Matias Reyes, a prison inmate, confessed that he had committed the crime and DNA evidence confirmed his account (Kassin, 2005). The question that comes to mind when reading about this case is why these five boys falsely confessed to a crime they had not committed and risked serving years in prison? Most people cannot imagine that they would ever falsely confess to something they have not done, especially to such a violent crime as the Central Park jogger case.

In 1765, Voltaire said that "common sense is not so common" and the Central Park jogger case, which is only one example of many false confession cases, proves his point. Confessing to a crime one has not committed goes against common sense. According to the Oxford dictionaries, common sense can be defined as "good sense and sound judgment in practical matters." For example, if you see a red traffic light, you know you have to stop to avoid an accident. That is what your common sense tells you to do. If it is snowing outside, you know you have to dress up in warm clothes to protect yourself from the cold. Again, you use your common sense knowledge. If you are accused of a crime you have not committed, your common sense tells you to not admit any guilt. But why do people act against their common sense and admit guilt for crimes for which they are not responsible?

A confession is one of the most powerful types of evidence that exists. If somebody confesses to a crime that usually means the person did it. This logic is based on the simple heuristic that humans do not make decisions against their own selfinterest. There is a related issue that plays a critical role here: the fundamental attribution error (Zimbardo \& Leippe, 1991): if we learn that someone confesses to a crime, we assume that the confession derives from internal factors - the person must feel guilty - rather than external factors (e.g., the person must have been subjected to bad interrogation techniques). That is why we find it hard to believe that there is a thing called false confession. Contradicting this belief is the number of proven false confessions that have surfaced in the last decade.

Indeed in their 50 Great Myths of Popular Psychology, Lilienfeld and colleagues (2007) list the common belief that false confessions are a rare phenomenon. Over the past few years, analysis of wrongful conviction cases as well as laboratory studies have made it plain that false confessions do arise in normal adults. There is now a solid scientific corpus on false confessions, which is addressed in the next chapter. 
The existing literature, however, has been mainly dealing with the question which psychological maneuvers during interrogations raise the risk of false confessions. The current dissertation mainly focuses on the stage that precedes interrogation: with what beliefs do people enter an interrogation situation and how does that affect their vulnerability to false confessions? As we will see, the sheer fact that one is innocent poses a risk, a point that has also been eloquently made by Kassin (2005).

\section{Outline of the thesis}

The primary purpose of this dissertation is to investigate common sense beliefs and misconceptions about false confessions, their impact on false confessions elicited during interrogations, and the risks they constitute for innocent suspects. ${ }^{3}$ With this in mind, the research described in this thesis addressed the following issues:

(1) common sense beliefs and police practices about confession-related legal issues;

(2) how misbeliefs about false confessions pose a risk for innocent suspects;

(3) the relationship between people's beliefs and their behavior during police custody.

This thesis entails eight chapters. Apart from the first two chapters - a case example and general introduction, respectively - , the seventh chapter (describing an avenue for future research), and the last chapter (a general summary, discussion, and conclusion), this thesis is divided in two main parts. Part one, which includes Chapter 3 and 4, addresses the following issues: What are lay peoples' beliefs about legal issues related to false confessions? (Chapter 3). And what are common practices and beliefs of European police investigators (Chapter 4)? Part two consists of Chapters 5 and 6. Chapter 5 addresses the issue of whether there is a discrepancy between beliefs and behavior of suspects in custody. Specifically, it investigates the relationship between predicted and actual behavior regarding suspects' rights to remain silent. While Chapter 6 explores inconsistencies between beliefs and behavior regarding confession rates during interrogations.

\footnotetext{
${ }^{3}$ The thesis mostly focuses on the situation in the United States and Germany. Most available literature resources are from the American system but will be applied to the German system/situation when possible.
} 



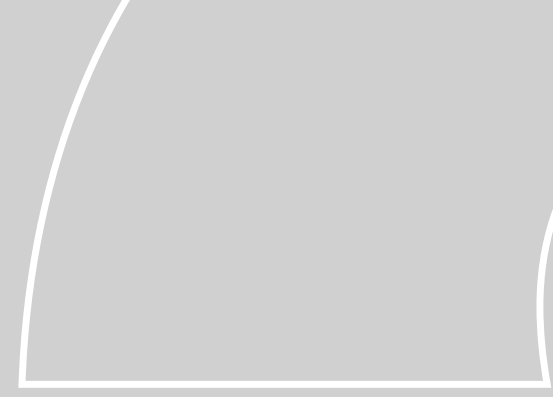

\section{CHAPTER 2}

\section{False Confessions:}

\section{Why Innocent People Confess to Crimes They Have Not Committed}

This chapter is an adapted, extended, and translated version of the following two articles: Schell, J. M. (2010). False confessions and its pitfalls: The dilemma of applying research findings to practice. In P. Santtilla (Ed.), The applicability of psycho-legal research: Sexual interest, deception and suggestibility. Proceedings of the Third Joint Nordic PhD course in Legal and Investigative Psychology (pp. 73-88). Oslo: Nordforsk.

Schell, J. M., \& Merckelbach, H. (2011, May). Falsche Geständnisse: Warum unschuldige Menschen Verbrechen gestehen, die sie nicht begangen haben [False confessions: Why innocent people confess to crimes they have not committed]. In-Mind Magazine, 1/2011. Retrieved from http://de.in-mind.org/ 
CHAPTER 2 


\section{Introduction}

A confession can be defined as "a detailed written or oral statement in which a person admits to having some transgression, often acknowledging guilt for a crime" (Kassin \& Gudjonsson, 2004, p. 35). A false confession, in contrast, can be defined as a detailed written or oral statement in which a person admits to being guilty of a crime that the he/she did not commit. Most people cannot imagine confessing to something they did not do. Meanwhile, several miscarriages of justice show that false confessions do exist. Innocent people do confess to crimes, they have not committed. The phenomenon of false confessions is illustrated in the following two case examples.

\section{Case 1: New York, USA 1989/2006}

On November 15th, 1989 15-year old Angela C. went out after school to take pictures for one of her school projects. She never came home. Two days later, police dogs found her naked body. She had been beaten, raped, and strangled. Jeffrey Deskovic was in the same class as Angela and became suspicious to the police because he was late to school the day after she went missing. Furthermore, he seemed distraught by her dead and visited her wake three times. The police talked to him eight times in the following months. Meanwhile, Deskovic had started doing his own investigation and provided the police with information about possible suspects. The police asked him whether he would be willing to participate in a polygraph session and he agreed. Deskovic hoped that the police would finally let him help find the real perpetrator after he passed the test. Deskovic participated in several polygraph sessions and was interrogated in between. Neither his lawyer nor his parents were there. He got coffee the whole day but no food. After six hours, three polygraph sessions, and several intensive interrogations Deskovic finally confessed. He cried while confessing and at the end he was sobbing and lying under the table in the fetal position.

Shortly after admitting to the murder, Deskovic recanted his confession. On the body of the girl DNA (sperm \& hair) had been found. During the interrogation, Deskovic was told by the detectives that he would be cleared if the DNA would not be his. The results of the DNA analysis showed that it was not a match to Deskovic's DNA. Instead of clearing Deskovic, the prosecution charged him with murder, based on his confession. In January 1991, Deskovic was convicted of murder and sent to prison for life. While in prison he fought for his freedom and claimed that he was innocent (for more information about the case of Jeffrey Deskovic: www.jeffreydeskovicspeaks.org). In January 2006, the DNA was retested and the real perpetrator was found. Jeffrey Deskovic's conviction was overthrown and he was released from prison. He had served almost 16 years in prison for a crime he had not committed (Johnson \& Drucker, 2009). 


\section{Case 2: Bavaria, Germany 2001/2011}

In 2001, the farmer Rudi Rupp, went missing after he went out to a bar. After five beers he left the bar, but according to his family he never made it home. The police started investigating the case without any success. In 2003, the farmer was still missing and the police found evidence suggesting that he actually had come home after his night at the bar. The police asked his wife, his two daughters, and his son-in-law to come to the police for another witness testimony. During the individual questioning of the witnesses, all four confessed that they had murdered the farmer. According to their statements, they waited for him to come home and then beat him over the head with a hammer. Allegedly, the unconscious farmer was carried to the basement, beaten again, and then his body was cut into pieces and fed to the dogs (Juettner, 2009a).

The case seemed crystal clear. However, no physical evidence (DNA, blood, body parts) was ever found and all defendants recanted their confessions before the trial, insisting that the farmer had never made it home that night. In 2005, despite missing material proof and the withdrawn confessions, all four defendants were convicted and received sentences between 2.5 and 8.5 years (Juettner, 2009a).

In March 2009, a Mercedes Benz including the skeletonized but 'whole' body of the farmer was found at the bottom of a lake near the farm. Allegedly, the body was sitting the other way around on the driving seat. Preliminary examinations of the body did not reveal blunt trauma or forceful injury marks. This constellation of findings suggested that there was no foul play involved. Furthermore, it confirmed the relatives' statements that the farmer never came home that night and it proves that their initial confessions were false. He was neither cut into pieces nor fed to the dogs. Despite the new evidence, the prosecution was hesitant to reopen the case. They maintained that the relatives murdered the farmer; the new evidence only showed that they did not hack him into pieces. According to the prosecution, their initial confessions would prove that they murdered him (Juettner, 2009b).

Eventually the case was reopened and ended with acquittals for the family members in February 2011. Probably it will be never known what exactly happened to farmer Rupp. But it is clear that the initial confessions of the family members - that they had hacked him into pieces and fed him to the dogs - had been false (“Getöteter Landwirt," 2011).

Both case examples illustrate the danger of wrongful convictions due to false confessions. They also demonstrate that confessions are a strong form of evidence and often lead to convictions, even in the absence of any other evidence or the presence of exonerating evidence. Of course, the question remains why somebody would ever falsely confess to a criminal act and admit guilt, when he/she is in fact innocent. 


\section{False Confessions in Court}

False confessions are not a new phenomenon in the legal arena. During the Salem witch trials of 1692 in the US around 50 women confessed to using witchcraft, which demonstrates that false confessions have occurred for more than 300 years (Karlsen, 1989 as cited in Kassin, Drizin, Grisso, Gudjonsson, Leo, \& Redlich, 2010). The first documented case of a false confession in Germany dates back to 1813, when 15-year old Justine Heller confessed to setting fire to a house. She was convicted and sentenced to 10 years in jail, mostly based on her confession. Four years after she finished her sentence, she appealed the verdict and produced witnesses who were able to prove that she was nowhere near the village in which the fire happened that night. The court acquitted her retroactively (Otto, 2003).

Researchers have been aware of the problem of false confessions for decades. In 1908, Hugo Münsterberg in his book 'On the Witness Stand' wrote a whole chapter about Untrue Confessions (Kassin et al., 2010). In Germany, Karl Peters and colleagues examined appellate German court cases from the 1950's and 1960's and found that $7 \%$ of these cases involved a false confession (Peters, 1970).

In the last two decades, the emergence of DNA profiling has challenged the forensic sciences and has introduced a new scientific paradigm in the forensic field (Saks \& Koehler, 2005). DNA profiling serves as "a model for a scientifically sound identification science" (Saks \& Koehler, 2005, p. 892) and has helped to uncover several wrongful convictions, in which false confessions played a key role. These cases highlight the powerful impact a confession has on the judge and the jury during a trial. Through the help of the Innocence Project and similar organizations, over 300 innocent people have been successfully released from prison. Shockingly, it turns out that approximately $25 \%$ of these wrongful convictions involved false confessions (http://innocenceproject.org).

Furthermore, research has shown that confessions are still powerful even after they have been proven to be false. Archival analyses of criminal justice statistics show that when false confessors plead not guilty and proceeded to trial, the conviction rates were between 73 percent (Leo \& Ofshe, 1998) and 81 percent (Drizin \& Leo, 2004). As a result of these studies, Drizin and Leo (2004) characterize confession evidence as "inherently prejudicial and highly damaging to a defendant, even if it is the product of coercive interrogation, even if it is supported by no other evidence, and even if it is ultimately proven false beyond any reasonable doubt" (p. 959). This suggests that there is no effective safety net able to protect false confessors from wrongful convictions.

\section{Prevalence}

Most people cannot imagine why anyone would falsely confess to a crime he/she did not commit. Unfortunately, during the last two decades it has become obvious that false confessions do exist. Most documented cases surfaced in the US and in 
England. But since there is no government or private institution keeping track of false confession cases, it is impossible to estimate how many people have falsely confessed and how many innocent people are still in prison because of a false confession (Kassin et al., 2010). The earlier mentioned percentages of DNA exonerations suggest that false confessions are much more common than usually thought and it might well be that they represent the tip of the iceberg (Drizin \& Leo, 2004). One problem is that it is often hard, if not impossible, to establish a 'ground truth' for a case. Even if there is a suspected false confession, often evidence (such as exonerating DNA evidence) is missing or it is difficult to get access to the police reports and other official documents of a case. This, of course, makes it complicated to prove that a defendant made a false confession (Kassin et al., 2010). Therefore, it is also not known how many guilty defendants only claim to have falsely confessed.

While it is difficult to come up with a precise estimation of false confessions prevalence in the US, it is even more difficult to assess the situation in other countries. Although documented cases have appeared around the world, for example, in Canada (Meissner, Horgan, \& Albrechtsen, 2009), Norway (Gudjonsson, 2003), Finland (Santtila, Alkiora, Ekholm, \& Niemi, 1999), Germany (Otto, 2006), Ireland (Inglis, 2004), Australia (Egan, 2006), New Zealand (Sherrer, 2005), China (Kahn, 2005), Japan (Onishi, 2007), Singapore (Mokhtar, 2001), and the Netherlands (Wagenaar, 2002), most studies and documented cases are from the US and England. While some European scholars (e.g., Rentschler, 2007) recognize that there has not been a systematic investigation of potential false confessions within their jurisdiction, it is not seen as a danger to their justice system.

More recent studies have used self-report instruments to identify the frequency of false confession cases. Kassin and colleagues (2007), for example, surveyed over 600 North American police interrogators and they reported an average of $4.8 \%$ of innocent people who confess. Schell and Kassin (2009; see Chapter 3) surveyed 575 lay people in seven countries and asked them if they could imagine that they would ever confess to a crime not committed. Surprisingly, $10 \%$ of the participants indicated that could imagine this. Gudjonsson, Sigurdsson, and Sigfusdottir (2009) surveyed 24627 high school students in seven countries in Europe and in this sample, $1.6 \%$ claimed to have made false confessions to the police. Collectively, these studies give a rough indication of the frequency of false confessions. The data of these studies suggest that false confessions are, indeed, a low base rate phenomenon in terms of percentages. Still, if one would use these percentages as a jumping off point for an extrapolation to high volume criminal statistics, this would amount to thousands of cases. It has to be taken into account, however, that all of the above mentioned studies share one limitation: all are based on self-reports and include alleged false confessions and not proven or corroborated false confessions.

It is difficult for investigators, prosecutors, police detectives, jurors, and judges to distinguish between true and false confessions. Of course, one would assume that it is widely known that people lie sometimes. But what is less obvious is that some people are prone to lie under specific conditions (Kassin, 2007) and, of course, a 
false confession can be conceptualized as a special case of lying. Research has also shown that people in general, no matter if they are working in law enforcement or not, do poorly at discriminating between truth and deception. Even training does not improve deception detection skills reliably (Granhag \& Strömwall, 2004; Memon, Vrij, \& Bull, 2003).

\section{Interrogations}

In the US, much attention has been giving to the so-called Reid technique of interrogations, which is named after its founder John E. Reid. The Reid technique consists of nine steps. First, the investigator confronts the suspect with the fact that there is no doubt that he/she is guilty of the crime. In the next step, investigators develop a theme which offers a 'moral excuse' for the suspect's crime. In the third step, investigators should interrupt any kind of denial from the suspect and in the fourth step objections of the suspect need to be overcome. In the next step, investigators need to make sure that the suspect stays attentive and does not withdraw from the situation, while the sixth step offers sympathy and understanding from the investigators for the crime. The seventh step provides a 'face-saving' alternative for the suspect for why he/she committed the crime. In the eight step suspects are encouraged to verbally admit to (at least parts of) the crime and the goal of the last step is to transform a verbal confession into a written one (Inbau, Reid, Buckley, \& Jayne, 2001).

The Reid technique is a widely used method by law enforcement to judge suspect's credibility. While Reid interrogation training manuals claim that the use of verbal and nonverbal deception cues can lead to a detection accuracy level of 85\% (Inbau et al., 2001), an empirical review of deception literature established a baseline of 54\% (47\% for lies, $61 \%$ for truths), which comes close to flipping a coin (Bond \& DePaulo, 2006). Furthermore, several studies have shown that police detectives are not more accurate than lay people, but they are more confident in their judgment (Kassin, Meissner, \& Norwick, 2005; Meissner \& Kassin, 2002). One influential study was conducted by Christian Meissner and Saul Kassin (2002). They presented videotapes of innocent and guilty suspects, both claiming to be innocent, to students and police officers. The task was to figure out who was lying (guilty suspects) and who was telling the truth (innocent suspects). Students were barely able to differentiate between the two groups. Police officers were confident that they were able to perform at superior levels. Interestingly, the results showed that the accuracy of distinguishing between truth and deception was identical for police and students. There was, however, one important difference between the two groups. The police officers were more inclined to judge innocent suspects as guilty compared to the students. False confessors might believe that police will eventually be able to differentiate between true and false confessions. Therefore, people might falsely confess for opportunistic reasons (e.g., they want to go home), assuming that the police will eventually uncover the truth (Meissner \& Kassin, 2002). Instead, it is more likely that they will be charged for the crime they confessed to because the police will not be able to recognize that they falsely confessed. 


\section{Deception Detection}

The question arises whether lay people are aware of actual deception detection accuracies. A recent survey by Schell and Kassin (2009) of lay people's beliefs about deception detection asked participants in seven different countries (Germany, US, Canada, Australia, New Zealand, South Korea, and the UK) about their own accuracy level at judging between truths and lies. They were also asked about the accuracy level of the average person and specially trained police officers. Participants estimated their own deception detection skills at a $66 \%$ detection level compared to $60 \%$ for the average person and $76 \%$ accuracy level for specially trained police officers. These findings indicate that people overestimate their own skills because their estimations exceed human lie detection performance.

Interestingly, participants believed they are better than the average person, but worse than specially trained police officers. These findings illustrate the common misconception of lay people that training can improve deception detection skills and that there is a difference between lay people and police officers in terms of these skills, although there is not. As said before, the overestimation of deception detection skills by police detectives poses a potential risk for innocent suspects because they may believe in the police detectives' ability to accurately judge between truths and lies. Most people are not aware of the fact that a police detective's judgment accuracy and everybody else's is barely better than flipping a coin. Fascinatingly, there were no significant differences between the seven countries, indicating that this is a universal misconception (Schell \& Kassin, 2009).

\section{Three Types of False Confessions}

In 1985, Kassin and Wrightsman identified three types of false confessions: voluntary false confession, coerced-compliant false confession, and coerced-internalized false confession. Voluntary confessions are made freely by a person, without any pressure or coercion. Several motives might drive a voluntary false confession. To gain fame is one of them. For example, when the Charles Lindberg baby was kidnapped in 1932 that event was broadly covered in the media and more than 200 people confessed to the crime. Another motive for a voluntary false confession is to protect the real criminal. Günther Kaufman, a German actor, confessed to killing his tax consultant and was convicted in 2002 and sentenced to prison. After being in prison for several years already, it turned out that his wife had murdered the tax consultant. His wife was dying of cancer and therefore Kaufman confessed to the murder to protect his wife (Handel, 2003). There are also cases in which mentally disabled persons confess because they cannot differentiate between reality and fantasy (Kassin \& Gudjonsson, 2004).

Coerced-compliant confessions are confessions that originate from pressure during the police interrogation. The confessors in this category know that their 
story is incorrect, but admit to the crime in order to 'get-out-of-there'. Basically, the person calculates that the more desirable option is to confess to a crime not committed rather than staying in the interrogation room. For example, in Brown v. Mississippi (1936), three black farmers admitted to a murder after being physically tortured. Nowadays, most cases of coerced-compliant confessions in Western jurisdictions do not include physical torture though. However, isolation, long lasting interrogations, sleep deprivation and confrontational interrogation techniques may trigger false confessions as well.

Coerced-internalized confessions by contrast are believed to be true by the confessor after the police have exposed him or her to misinformation. In such situations, the suspect actually believes to be the real perpetrator due to the pressure and suggestiveness of the interrogation process. Since memory is malleable, this poses a great risk because the suspect might not be able to identify the truth anymore. Often coerced-internalized confessions are made by vulnerable, naïve, young, low intelligence suspects in combination with false evidence (Kassin, 1997). False evidence often makes suspects sceptical of their own memory. Such a state of memory distrust may occur, for example, when suspects are told that their fingerprints were found at the crime scene (Meissner \& Russano, 2003). A study conducted by Van Bergen, Merckelbach, Horselenberg, Jelici, and Zuidberg (2011) found that the introduction of false evidence (in the form of negative feedback) did not increase false confession rates in general, but it did raise the number of internalized false confessions. The authors warned that their findings of an overall nonincreased false confession rate might not apply to the real life situation, since there the false information is combined with anxiety, sleep deprivation, isolation, and the pressure of the interrogation. Their results indicate the risk of manipulating suspect's memory by introducing false evidence. If innocent suspects come to believe that their confessions are true, they are unlikely to withdraw their statements. This can have dramatic repercussions, as the following case examples demonstrate. In the US, Paul Ingram, a deputy sheriff, was charged with satanic ritual abuse of his daughter. He contested the accusations, but after several months of repeated interrogation (including hypnosis, suggestive questioning, and hints with false evidence), he avowed himself and confessed. He firmly believed that he had been involved in a satanic gang. He was convicted and sentenced to 20 years in prison. After extensive investigations, it turned out that the satanic ritual abuse never happened (Meissner \& Russano, 2003). In Germany in 2006, Wolfgang Schwertz had been pressured by the police until he confessed to murdering his ex-girlfriend 20 years ago. He believed that his 'evil ego', the 'wolf' inside of him had committed the murder (Friedrichsen, 2010).

The Kassin and Wrightsman (1985) taxonomy of false confessions has been reiterated and refined in many subsequent papers (eg., Conti, 1999; Gudjonsson, 2003). Meanwhile, it remains unclear what exactly triggers an innocent person to admit guilt. By looking at documented cases, it seems that often a combination of several factors led to a false confession. The chain of reactions starts with a crime 
that has been committed and the search by the police for suspects. Once a possible suspect has been found, he or she is brought to the police station for a preinterrogation interview. In general, the purpose of such an interview is to find out whether the person is being truthful or not. If judged as being truthful, the person is no longer a suspect. If judged as being deceptive, the suspect will be interrogated. This constellation already poses a risk for innocent suspects. As discussed earlier, police detectives are not better than anybody else at deception detection and hence an innocent suspect's chances of being evaluated as truthful or deceptive are at best fifty-fifty. Moreover, if detectives operate on the basis of a guilty bias, which they often do (e.g., Meissner \& Kassin, 2002), then their chances of being approached as an innocent citizen are less than $50 \%$.

If judged guilty, the suspect has to be informed about the constitutional rights to silence (Miranda v. Arizona, 1966) before the interrogation can begin. The Miranda rights are supposed to function as a safeguard for suspects in the US. In Germany, article 136 of the Code of Criminal Procedures describes similar rights (STPO, 2008). In the Netherlands, Article 29 of the Dutch Code of Criminal Procedure (CCP) informs suspects before an interrogation that they are not obligated to answer questions (Hirsch Ballin, 2012). Unfortunately, there are several problems with these safeguards. First, not everybody has the mental capacity to fully understand what it means to have the right to remain silent and to have a lawyer present. Second, police have found ways to trick suspects into waiving their rights. Third, a discrepancy between attitude and behavior puts innocent people at risk. Laboratory studies have shown that $81 \%$ of innocent suspects involved in mock crimes waive their rights (Kassin \& Norwick, 2004). In Kassin et al.'s police survey (2007), police detectives also reported an overall waiver rate of $81 \%$. In contrast to these findings, in a recent survey of lay people's beliefs, participants estimated a waiver rate of $16 \%$ for themselves, which is highly inconsistent with previous findings (Schell \& Kassin, 2009; see Chapter 3). A reason for such low waiver rates could be that people are usually poor at judging their future behavior (Fazio \& RoskosEwoldsen, 1994).

If suspects waive their rights, the interrogation process starts. Although tactics including, for instance, inflicting physical or mental pain, are no longer allowed, the modern interrogation is still a powerful one. As mentioned above, only 'believedguilty' suspects are interrogated, which makes the interrogation a guiltpresumptive process. Obviously, if the interrogator already believes that the suspect is guilty, his interaction is influenced by that believe. Additionally, several social influence methods are used, for example, isolating the suspect in a barely furnished, soundproof, small room (Kassin \& Gudjonsson, 2004). Often interrogations take several hours. The average interrogation length of documented, proven false confessions is 16.3 hours (Drizin \& Leo, 2004). Furthermore, the nine-step Reid technique is often used by police, which is a confrontational interrogation technique mainly used in the US (Inbau et al., 2001), but elements of it are also employed by the German police (Jung \& Lemmer, 2013). 


\section{False Confessions in the Lab}

In order to find out more about the causes of false confessions, several laboratory experiments have been conducted. One of the most influential ones was developed by Saul Kassin and Katherine Kiechel (1996). The so-called Computer Crash paradigm was introduced to the participants as a reaction time experiment. The task was to type letters on a keyboard. These letters were read out by a confederate who pretended to be a regular participant. Before the experiment began, participants were instructed not to touch the ALT key because this would lead to a crash of the computer. After one minute the manipulated computer crashed and the participants were falsely accused of hitting the ALT key. Participants were divided in two groups: one fast group (in which the confederate read out the letters in fast pace) and one slow group (in which the confederate read out letters in slow pace). A further manipulation was that in half of the times in each group, the confederate claimed to have witnessed the participant hit the ALT key which in effect, is a form of false evidence. In total there were four different conditions: slow/false witness, slow/no false witness, fast/false witness and fast/no false witness. The authors wanted to investigate how many participants would be willing to sign a confession, even though all participants were innocent.

\section{ALT Key Paradigm (Kassin \& Kiechel, 1996)}

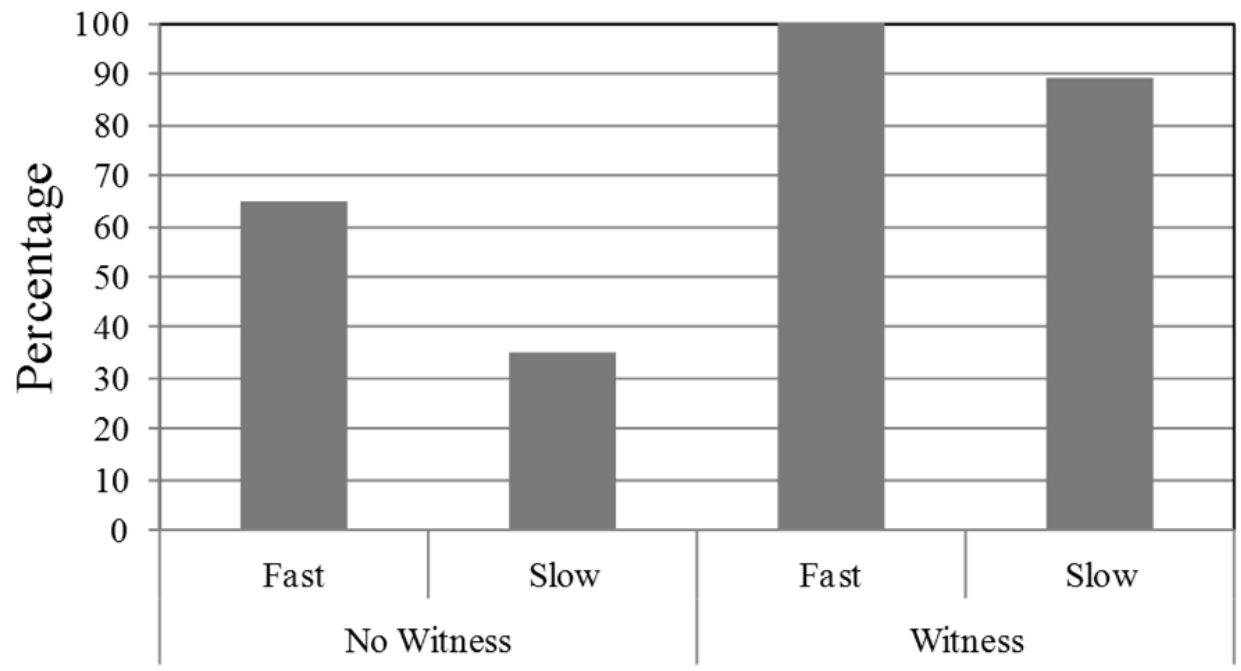

Figure 1. Results of Kassin and Kiechel's (1996) ALT key experiment.

The basic results are summarized in Figure 1.Overall, 69\% of the participants signed a (false) confession and admitted to have hit the forbidden ALT key. As can be seen, the fast pace, but also the false witness manipulation significantly in- 
creased the rate of false confessions. In the fast/false witness condition, $100 \%$ signed, while only $35 \%$ signed in the slow/no false witness condition. Furthermore, the researchers tested whether the participants internalized guilt and developed confabulations. Examples of confabulations justifying the false confessions are: "Yes, I hit the ALT key because I had too much coffee this morning" or "Yes, I hit the ALT key with my right hand after the letter A was read out." In the end, 28\% really believed that they had touched the ALT key and 9\% gave reasons and explanations why. In reality, all participants were innocent. This study illustrates that it is possible to elicit false confessions in the lab and that certain influences, such as false evidence, can increase false confessions.

The by now classic ALT key experiment has been replicated many times. A PsycINFO search with key words "false confessions" and "computer" yielded a total of eight studies that replicated the ALT key experiment ${ }^{4}$. Table 1 summarizes the main results of the replication studies. Several conclusions can be drawn from this overview. First, it can be seen that most studies had rather high rates of false confessions, even though participants were from intelligent student populations. Based on this overview, an overall false confession rate of $59 \%$ can be calculated compared to the original $69 \%$ confession rate that was obtained in the Kassin and Kiechel (1996) study. Second, not only college student population display rather high false confession rates, but they are also evident in other samples, for example children. Third, false confession rates are also evident when they have serious consequences (e.g., Horselenberg et al., 2006) showing that it is not the case the high false confession rates are a byproduct of a low stake lab situation.

However, many have criticized that touching an ALT key is not comparable to committing a 'real' crime (e.g., Levesque, 2006) and that there were no severe consequences (e.g., Horselenberg et al., 2006). Furthermore, this paradigm only involved innocent suspects, which makes it impossible to compare true and untrue confessions and to establish diagnosticity (Russano, Meissner, Narchet \& Kassin, 2005). In order to address some of the shortcomings of the computer crash paradigm and improve ecological validity, Russano and colleagues (2005) developed a novel paradigm, the so called cheating paradigm. In this study, undergraduate students were asked to participate in problem solving tasks, either alone or together with a confederate (who posed as a participant). In half of the cases, the confederate asked the participant for help. If the participant helped the confederate - this was against the rules - it was an act of cheating and the person was considered as guilty. The other half of the participants were not asked to break the rules and hence were in the innocent condition. Afterwards all participants were accused of cheating, interrogated, and asked to sign a statement admitting that they had cheated. The consequence of not signing the statement was that the professor would get involved.

${ }^{4}$ This search was conducted in March 2012. 
Table 1. Overview of Kassin \& Kiechel (1996) replication studies

\begin{tabular}{lllcccc}
\hline Study & Year & Location & Sample & Age & $\begin{array}{c}\text { Overall Confession Internalization } \\
\text { Rate (\%) }\end{array}$ & (\%) \\
\hline Forrest et al. & 2002 & US & 56 & College Studens & 61 & 36 \\
$\begin{array}{l}\text { Redlich \& Good- } \\
\text { mann }\end{array}$ & 2002 & US & 96 & Teenagers \& College & 69 & 39 \\
Horselenberg et al. & 2003 & Netherlands & 34 & College Students & 82 & 42 \\
Candel et al. & 2005 & Netherlands & 50 & Children & 36 & 89 \\
Forrest et al. & 2006 & US & 98 & College Students & 82 & 59 \\
Horselenberg et al. & 2006 & Netherlands & 56 & College Students & 68 & 26 \\
Klaver & 2008 & US & 219 & College Students & 43 & 10 \\
Perillo \& Kassin & 2011 & US & 71 & College Students & 61 & 10 \\
\hline
\end{tabular}

By creating innocent and guilty conditions the researchers were able to study the influence of two interrogation techniques (minimization and promise of leniency) on true and untrue confessions. Not surprisingly, results showed that overall guilty participants were more likely to sign a confession compared to the innocent participants. If no interrogation techniques were used, $46 \%$ of the guilty participants confessed compared to $6 \%$ of the innocent ones. Using both techniques, confession rates from guilty participants rose up to $87 \%$ and went up to $43 \%$ for innocent participants. Apparently, the techniques work to increase true confessions, but also untrue confessions and hence the risk of false confessions has to be taken into account when using minimization and leniency techniques (Russano et al, 2005).

Perillo and Kassin (2011) used a variant of the cheating paradigm to investigate the influence of false evidence on confession rates. Specifically, they were interested in studying the bluff tactic that is often used by interrogators. This tactic is used to make a suspect believe that there is evidence that connects them to the crime, while in reality no such evidence exists. The overall set-up was similar to the original study done by Russano and colleagues (2005). Participants had to solve problems either individually or with a confederate (who was pretending to be a participant). In half of the cases the confederate asked the participant for help and if the participant did help, it was seen as cheating and hence he/she was in the guilty condition. After a few rounds all participants were asked by the experimenter to follow her into another room and there they were accused of sharing information with the other participant. All participants were asked by the experimenter to sign a handwritten statement admitting that they had cheated and would lose credit. The bluff tactic was used with half of the guilty participants and half of the innocent participants. They were told that there was a camera that had recorded the whole session. They were told that once the video technician came in, the experimenter could check whether they had cheated or not. 
Overall, $57.6 \%$ of all participants signed the statement. Of the guilty participants in the control group, $87 \%$ truthfully signed the statement. The number of true confessions increased in the bluff condition to $93 \%$. In the innocent control group none of the participants signed the statement; hence no false confessions were elicited. However, once the bluff was introduced, the number of innocent participants signing the statement - and hence falsely confessing to something they did not do - rose to $50 \%$. Interestingly, $88 \%$ of false confessors and $75 \%$ of non-confessors used the same reason as to why they confessed or did not confess: the camera. False confessors used it to explain that they signed the statement even though they were innocent because the camera would exonerate them. Non-confessors said it made it easier for them not to sign because the camera would prove their innocence. This study demonstrates the detrimental effect that the bluff tactic can have on innocent suspects (Perillo \& Kassin, 2011).

The previously described research studies have shown how false confessions can easily be produced in a laboratory setting. Of course critics still object that such experiments cannot be compared to real life police interrogations and hence lack ecological validity (Inbau et al., 2001). But these results help to understand better why innocent suspects would ever confess to something not done. Furthermore, using a laboratory approach, different interrogation techniques can be examined in the realm of ethically acceptable limits.

\section{Applicability Issues in Psychology and Law}

We know that false confessions are a potential danger for causing miscarriages of justice. Although the corpus of knowledge needs further articulation, we also know the various causes of false confessions and the risks that they pose for innocent suspects. Still, false confessions occur and there is no safety net for false confessors. Even though much has been researched about this topic, the need to implement the knowledge to practice and, if necessary, change certain rules and regulations still exists. Of course, one problem is that it is impossible to determine a prevalence rate for false confessions. Most people do not see the danger of falsely confessing to a crime as a great danger to society and innocent suspects, but rather as a small side effect of the criminal justice system. Also, most people believe that it would not happen to them, which stems from the belief in a just world (Lerner, 1980). It is believed that false confessions are the exception and not a danger to every innocent suspect. Case studies as well as field and laboratory studies indicate the contrary that the risk of a wrongful conviction due to a false confession can happen to anyone.

Based on several years of empirical research, we now know that human lie detection performance is barely better than flipping a coin. Thus, police detectives are not able to accurately differentiate between lies and the truth. Still, the preinterrogation interview is often claimed to be used to distinguish between the 
truthfulness and deception of a suspect. It raises the question of why the police do not incorporate such research findings into their practices and abolish this part of their interrogation. On the one hand, it can be argued that this would be even more dangerous because then more suspects will be interrogated, innocent and guilty ones. Additionally, it is often claimed that laboratory based findings lack ecological validity and therefore cannot be applied to the practice. On the other hand, by abolishing such an interview process the guilt presumptive bias could be reduced. If everybody is interrogated, the police detectives might be less convinced of the suspect's guilt already before the interrogation even started. This could improve the situation for innocent suspects during interrogations. Also, it would prevent guilty suspects from 'getting away' after being judged as truthful during the initial interview.

One related issue is the controversy over human lie detection skills. While several empirical studies have provided a baseline of 54\% (e.g., Bond \& DePaulo, 2006), there are still authors who criticize these findings. Opponents argue that accuracy rates are higher than flipping a coin in high stake situations (e.g., Van Hippel \& Trivers, 2011). For example, as mentioned previously, Reid and colleagues claim to have an accuracy rate of $85 \%$ (Inbau, Reid, Buckley, \& Jayne, 2001). Reid interrogation seminars are given on a daily basis to law enforcement officials, and also private detectives. This worsens the situation for innocent suspects, because the 'wrong' knowledge is being promoted, meaning that law enforcement officials are trained incorrectly. That illustrates one big problem of applying research findings to practice: often research findings are seen as controversial because different opinions exist. Therefore, it is hard to establish a 'ground truth' for research findings. Usually, acceptance by the scientific community is necessary to establish the truth of a research result. But who exactly is involved in the scientific community? Who decides what pseudoscience is and what is not? And how do non-scientific parties, such as the police, decide upon whom to believe? There are indications that law enforcement representatives are often sensitive to pseudoscience (e.g., criminal profiling; Lilienfeld \& Landfield, 2008). Hence, it is a rather difficult process to apply research findings to practice, in this case the results of deception detection studies.

\section{Miranda Rights}

Miranda rights were highly criticized when they were first implemented because law enforcement claimed that confession rates for guilty suspects would decrease and hence convictions as well. Problematic is that only results of self-reports and laboratory findings are known. Therefore, it cannot be argued that confession and guilty verdicts decreased, because it is not documented how the situation changed after Miranda v. Arizona (1966). What is known is that several case studies and laboratory findings show that not everybody has the mental capability to fully understand the right to silence and that police uses certain tactics to overcome Miran- 
da. A reform is needed to improve the situation. In Great Britain, the 'appropriate adult' rule exists, which means that in cases involving juveniles or mentally vulnerable persons, a guardian or parent has to be present to make sure the person understands what is happening (Home Office, 2003).

Currently, the empirical data base of false confessions is experimental studies. But how much ecological validity do these studies have with regard to the right to remain silent? Will a participant in a lab experiment react like an innocent suspect brought into a police station? Without knowing the validity of such studies, it is hard to convince the responsible parties of the relevance and to motivate them to apply the findings to practice. Also, what is often ignored is the important role Miranda rights actually play in false confession cases. The rights could serve as safeguards if used properly.

Interrogation is a rather uncomfortable process of confrontations by an authority figure - an (armed) police detective - in which innocent suspects often only try to achieve one outcome: to get out of it. What is often ignored by an innocent suspect is the long-term consequence of going to trial after falsely confessing to crime just to end an interrogation. In order to improve the interrogation process and make it 'safer' for innocent suspects, several recommendations have been made by researchers and forensic psychologists (e.g., Lilienfeld \& Byron, 2013): the interrogation process should be aimed at finding out the truth and getting guilty suspects to confess, but not innocent suspects. This can be done by prohibiting certain techniques, for example, bluffing about evidence which is allowed in the US, but not in most European countries. Furthermore, minimization techniques such as promises of leniency should not be allowed. Also, currently there is no time limit to interrogation, which should be set in order to protect suspects from hours-long interrogations. Great Britain implemented the Police and Criminal Evidence Act of 1984 (PACE), which could be used as an example for the US and other countries (Home Office, 2003).

The obstacle is - again - that the interrogation process is not seen by the police as inherently dangerous for innocent suspects. Therefore, it is difficult to apply the findings to the procedure in order to change and improve it because the need for change and improvement is not realized by the responsible parties. Awareness and flexibility would be needed, but if you do not see a problem - why change anything? Implementing research findings into practice sounds easier than it actually is. One would think that everybody wants to improve the system and avoid wrongful convictions. The trouble is that not everybody acknowledges false confessions as a problem and danger to innocent suspects. Furthermore, the legal ruling 'innocent until proven guilty' seems often to be reversed in false confession cases to 'guilty until proven innocent.' 


\section{The Psychology \& Law Movement}

The implementation of false confession research findings to improve the legal system is also hindered by the overall interaction between psychology and law. The psychology and law movement had its beginnings at the turn of the $20^{\text {th }}$ century with pioneers such as Hugo Münsterberg, Alfred Binet, and William Stern. The question remains why the interaction of psychology and law has had a relatively small influence on the law so far. Ogloff (2002) examined the relationship between these two fields and stated there have been improvements over the last ten decades but not as many as one would expect there could be after a century of research.

Costanzo (2004) described the interaction of psychology and law as a clash of cultures. Both fields are different in nature and have other aims. While psychologists try to explain why people behave in a certain manner, the law tries to control the behavior of people with limits and restrictions set through the rule of law. One has to realize that although both aim at different goals, the interaction can be helpful to reach these goals. If one wants to control behavior, one has to understand why people behave in a certain way. In order to explain behavior, one also needs to know the causes. Obviously, there also exist major differences between the fields: psychology relies on falsifiable theories, while law uses fixed rules. This complicates matters (Costanzo, 2004).

False confession research is one small domain within the field of psychology and law. As discussed above, the level of awareness and interaction between these disciplines has not reached yet the level it should have after 100 years of research in the field. Naturally, this obstructs the application of false confession research in the sense that the whole area of psychology and law is not established far enough. Additionally, research applicability problems are strong in countries with barely any false confession research, such as, for example, Germany or the Netherlands. As far as the latter is concerned, the situation is illustrated well by a bill of former Minister of Justice Piet Hein Donner that intends to regulate criminal cases with confessions such that these cases are given a faster procedure (Van Koppen, Merckelbach, Jelicic, \& de Keijser, 2010).

\section{Working Toward a Better Future}

False confession cases highlight the inability of the justice system to avoid wrongful convictions. The trouble starts when innocent suspects are held by the police and assumed to be guilty. The protection of Miranda rights is often misunderstood and then rights are waived. This automatically expedites innocent people to the interrogation process, which poses the risk of a false confession. The next step - a trial will also not provide a safety net for innocent defendants because judges, juries, and others are not able to distinguish between true and false confessions. As Kassin 
and Gudjonsson (2004) put it: "It is all too easy, however, to mistake illusion for reality and not realize that a police-induced confession is like a Hollywood drama: scripted by the interrogator's theory of the case, shaped through questioning and rehearsal, directed by the questioner, and enacted by the suspect" (p. 59).

The dilemma arises of how the situation can be changed. How can the system be improved and wrongful convictions due to false confessions be avoided? Many have argued that new reforms of interrogation practices are needed (e.g., Kassin et al., in press; Leo, 2009). Such reforms call for the exclusion of introducing false evidence, threats of harm, promises of leniency, Miranda violations, and introducing time limits to interrogations, and mandatory video- and audio recording of interrogations. All of the above mentioned improvement suggestions are supported by research and will by all means improve the system and reduce false confessions.

However, the problem remains how to implement these changes. This poses the biggest issue when it comes to applying research findings to practice. Reforms are essential, but it is more important to find a way to implement the reforms into practice. This can only be done by educating the new generation of lawyers and psychologists better. Research studies indicate that it is often hard to change somebody's initial view or opinion. Keeping that in mind, how likely will it be to change a system that is inhabited by law enforcement officials that have been in the system for decades? The answer is - not likely at all. What is needed in order to improve the criminal justice system in regard to false confessions is to include psychology courses into law schools and police academies. Educate the new generations of law enforcement as early as possible by making them aware of the possible risks and pitfalls of wrongful convictions and teaching them ways for improvement. 


\section{CHAPTER 3}

\section{Common Sense of Confessions: What Do People Believe?}

Schell-Leugers, J. M., \& Kassin, S. M. (2009). Common sense of confessions: What do people believe? Manuscript in preparation. 


\begin{abstract}
The main purpose of this study was to examine lay people's beliefs about confession issues and whether those beliefs are universal or specific to culture. Five hundred and seventy three participants from seven different countries (Australia, Canada, Germany, Great Britain, New Zealand, South Korea, and the USA) filled out an online questionnaire assessing their beliefs about deception detection capabilities, the use of the right to remain silent, and the likelihood of true and false confessions. The results show that participants overall estimated that they were $66 \%$ accurate at truth and lie detection, while they reported the average person at a $58 \%$ level and trained police officers at 76\% accuracy. Overall, $4.5 \%$ of the participants stated that they would waive their rights if guilty, and $15.9 \%$ of the participants would waive their rights if innocent. As for self-reported estimates of confessions, 87.9\% participants felt that they would confess to a crime committed, while $10.8 \%$ thought they would confess if innocent. The findings show that participants universally exhibited a relative lack of knowledge about confessions and the factors that put innocent people at risk. The results are discussed in light of what is known from previous surveys, experimental studies, police interrogation, and false confession cases.
\end{abstract}




\section{Introduction}

A confession is one of the most powerful types of evidence that exists. Over 100 years ago Hugo Münsterberg already established that untrue confessions occur. According to the US based innocent project, around 25\% of their 311 DNA exonerated cases involved false confessions (http://innocenceproject.org). However, false confessions are not an American phenomenon, cases have been documented around the world (for example in Australia (Egan, 2006), Canada (Meissner, Horgan, \& Albrechtsen, 2009), China (Kahn, 2005), Finland (Santtila, Alkiora, Ekholm, \& Niemi, 1999), Germany (Otto, 2006), Great Britain (Gudjonsson, 2003), Japan (Onishi, 2007), the Netherlands (Wagenaar, 2002), New Zealand (Sherrer, 2005), Norway (Gudjonsson, 2003), and South Korea (Rahn, 2008)). Furthermore, various empirical research studies have substantiated the occurrence of false confessions and examined risk factors, causes, and consequences (e.g., Drizin \& Leo, 2004; Kassin \& Gudjonsson, 2004; Kassin \& Kiechel, 1996; Kassin et al., 2010; Russano, Meissner, Narchet, \& Kassin, 2005).

The case of Rudi Rupp illustrates the dangers of admitting to a crime when innocent. The German farmer went missing in 2001. Four of his close relatives confessed to killing him, cutting his body into pieces, boiling the body parts, and feeding the remains to the farm animals. No physical evidence was found and the family recanted their confessions, claiming that they had been caused by police pressure. Despite any supporting evidence, Rupp's relatives got convicted for murder. When his car was found at the bottom of a lake in 2009, including his (complete) skeleton and no proof of foul play, it was proven that the absurd story of hacking him in pieces and feeding him to the farm animals was false. In 2011, the convictions were finally overthrown and his family members acquitted (Friedrichsen, 2011; "Getöteter Landwirt [Killed farmer]", 2011). The question remains why they falsely confessed. Why did they come up with such a bizarre and brutal story? Shouldn't they have known that this will put them in jail?

Even though the existence of false confessions has been documented and acknowledged, many people still find it hard to understand why they occur. A confession is an indication of guilt and this is based on the simple principal that humans do not make decisions against their own self-interest. A related issue plays a critical role here: the fundamental attribution error (Zimbardo \& Leippe, 1991): if someone confesses to a crime, it is assumed that the confession derives from internal factors - the person must feel guilty - rather than external factors (e.g., the person must have been subjected to bad interrogation techniques). Another reason why it is difficult to comprehend why people falsely confess is that it is hard to imagine what it would be like in an interrogation. As Davis and Leo (2012) stated it might be because of "our inability to walk in the skin and shoes of the accused: to truly understand the forces facing them, the personal context in which those forces operate on them, and the mechanisms through which these forces exert their effects" (p. 737). 
Research has shown that confessions are still powerful even after they have been proven to be false. The results of archival analyses of American criminal justice statistics indicated that when false confessors plead not guilty and proceeded to trial, the conviction rates were between 73 percent (Leo \& Ofshe, 1998) and 81 percent (Drizin \& Leo, 2004). As a result of these studies, Drizin \& Leo (2004) characterize confession evidence as "inherently prejudicial and highly damaging to a defendant, even if it is the product of coercive interrogation, even if it is supported by no other evidence, and even if it is ultimately proven false beyond any reasonable doubt" (p. 959). To make matters worse, it is difficult for police investigators, prosecutors, judges, and jurors to distinguish between true and false confessions. All this leads confession experts in court to argue that lay people need their assistance since they know little about confessions as a matter of general knowledge (Fulero, 2004; Kassin, 2007).

To date several studies have examined lay people's attitudes and beliefs about false confessions in the United States (Blandon-Gitlin, Sperry \& Leo, 2011; Chojnacki, Cicchini, \& White, 2008; Costanzo, Shaked-Schroer, \& Vinson, 2010; Henkel, Coffman, \& Dailey, 2008; Leo \& Liu, 2009). They indicated that many participants incorrectly believe that police are more accurate at distinguishing between truth and deception and that deception detection skills improve with training (Chojnacki, Cicchini, \& White, 2008; Costanzo, Shaked-Schroer, \& Vinson, 2010), and that poor memory is not a risk factor for falsely confessing (Chojnacki, Cicchini, \& White, 2008; Henkel, Coffman, \& Dailey, 2008). Also, many stated that they acknowledge the existence of false confessions, but they thought it was unlikely for them personally to confess if innocent (Henkel, Coffman, \& Dailey, 2008). Furthermore, confessions of innocent suspects were seen as counter-intuitive (Leo \& Liu, 2009) and participants thought that psychologically coercive interrogation tactics were unlikely to elicit them (Blandon-Gitlin, Sperry \& Leo, 2011; Leo \& Liu, 2009). These results offer proof that lay people may not be able to comprehend the dangers of psychologically coercive interrogations and fail to see how such techniques can cause false confessions (Blandon-Gitlin, Sperry \& Leo, 2011; Leo \& Liu, 2009). Moreover, most participants thought that expert testimony would be very helpful to hear in cases with potentially false confessions (Chojnacki, Cicchini, \& White, 2008; Costanzo, Shaked-Schroer, \& Vinson, 2010). Overall, the studies showed that false confession related issues are outside of the common knowledge of laypersons and that such misconceptions can be dangerous for innocent defendants who have falsely confessed (Chojnacki, Cicchini, \& White, 2008).

The findings we have summarized reveal some intriguing aspects of layperson's beliefs about false confessions, namely they show the misbeliefs that average citizens have about the risk of false confessions. However, the data represents the perception and attitudes of Americans only. We want to not only add to the existing knowledge by collecting American data, but we want to take this line of research a step further and survey lay people in various countries to investigate whether such beliefs are universally accepted or specific to the American culture. Another gap in 
the aforementioned literature is that most of the studies mostly ask participants to estimate, for example, confession rates of innocent suspects or rate statements, while our research not only asked participants to rate their own behavior but also in comparison to that of others. To address these gaps in the literature of common knowledge and perceptions and attitudes about confession related items and add to the existing research, we investigated lay layperson's beliefs in seven different countries.

\section{The Present Study}

The primary purpose of this study was to examine the beliefs of lay people about the likelihood of true and false confessions, the waiver rates of the right to remain silent and the right to counsel, and the perception of the ability to distinguish between truth and perception. Furthermore, we wanted to investigate whether these beliefs were universal or culture specific. Once we have data on people's beliefs about confessions, it is possible to educate law enforcement and jurors about the risk of false confessions. This could help to establish a safety net for innocent defendants to better detect false confessions by, for example, enabling defendants to introduce expert testimonies about false confessions. We predicted that participants will exhibit a relative lack of knowledge about: (1) the ability to detect truth and deception, (2) the right to remain silent, (3) the likelihood of falsely confessing, and (4) that such misconceptions are identical across different countries.

\section{Method}

\section{Participants}

A total of 573 jury eligible individuals participated in this study: 383 females $(66.84 \%)$ and 190 males (33.16\%). Their overall age average was $31.03(S D=$ 13.18) years. The breakdown of participants' gender, age, and sample size by country is presented in Table 1. Subjects were recruited through the internet and via email using snowball techniques. Only participants over the age of 18 were allowed to take part in the online survey.

\section{The Questionnaire}

The questionnaire consisted of ten questions relating to confession issues and three items relating to demographic information (age, gender, nationality). The questionnaire covered questions concerning layperson's beliefs about lie detection, the right 
to remain silent, and confessions. The questionnaire was specifically designed for the current study.

Following the demographic questions, participants were asked about confession issues of innocent and guilty persons. Subjects were also asked if they would ever confess to a crime they had committed and if they would ever confess to a crime they had not committed. Also, the subject's judgment about their own likelihood of confessing and that of others during an intense, but legal police interrogation when guilty and when innocent was questioned.

Table 1. Distribution of Age and Gender in the Sample

\begin{tabular}{lcccc}
\hline & Females (\%) & Males (\%) & Age $(M)$ & Sample Size $(n)$ \\
\hline Australia & 70 & 30 & 27.7 & 50 \\
Canada & 56 & 44 & 34.5 & 50 \\
Germany & 61 & 39 & 35.4 & 100 \\
Great Britain & 65 & 35 & 29.1 & 43 \\
New Zealand & 64 & 36 & 25.9 & 57 \\
South Korea & 69 & 31 & 23.0 & 99 \\
United States & 72 & 28 & 35.5 & 174 \\
\hline
\end{tabular}

Furthermore, issues with regard to the right to remain silent were covered. Subjects were asked if they would give up their right to remain silent and agree to answer questions without a lawyer present when they were innocent and when guilty. Moreover, participants were inquired to estimate how many guilty and innocent people give up their rights, agreeing to be questioned without a lawyer and how many do not give up their rights, refusing to be questioned without a lawyer.

With regard to deception detection, subjects were asked to estimate how accurate they are, the average person, and specially trained police detectives in making truth vs. lie judgments. Participants were informed that they would be correct $50 \%$ of the time by guessing.

\section{Results}

Mean, median, range, and standard deviation are presented where appropriate. Due to missing data, sample sizes were different for each item. Therefore, sample sizes are reported separately for each question. Participants who only responded to the demographic items were completely omitted from the analysis. 


\section{Truth and Lie Detection}

To determine how lay people think about lie detection abilities, participants were asked to estimate the percentage of accuracy about their own truth vs. lie detection judgment. Furthermore, participants were asked how accurate the average person and specially trained police detectives are in making truth vs. lie judgments. Participants estimated their deception detection skills were 66.1\% (Mdn $=70$; Range $=5$ to $100 ; S D=15.28 ; N=525$ ) accurate, while they found the average person to be accurate $58.9 \%(\mathrm{Mdn}=60$; Range $=10$ to $100 ; S D=14.18 ; N=525)$ of the time, and police detectives $76 \%(\mathrm{Mdn}=80$; Range $=5$ to $100 ; S D=14.18 ; N=526)$. Country specific results are presented in Figure 1.

A 7 (Australia, Canada, Germany, Great Britain, New Zealand, South Korea and the USA) by 3 (participants, average person, police detectives) mixed ANOVA yielded a significant main effect for lie detection judgment, $F(2,517)=433.74 ; p<0.01)$, but no significant interaction was found, $F(1,517)=1.88 ; p=.08$ ) (see Figure 2). The analysis moreover showed that there were no statistically significant differences between the seven samples, $F(2,517)=1.59 ; p=.15$.

\section{Estimated Deception Detection Skills}

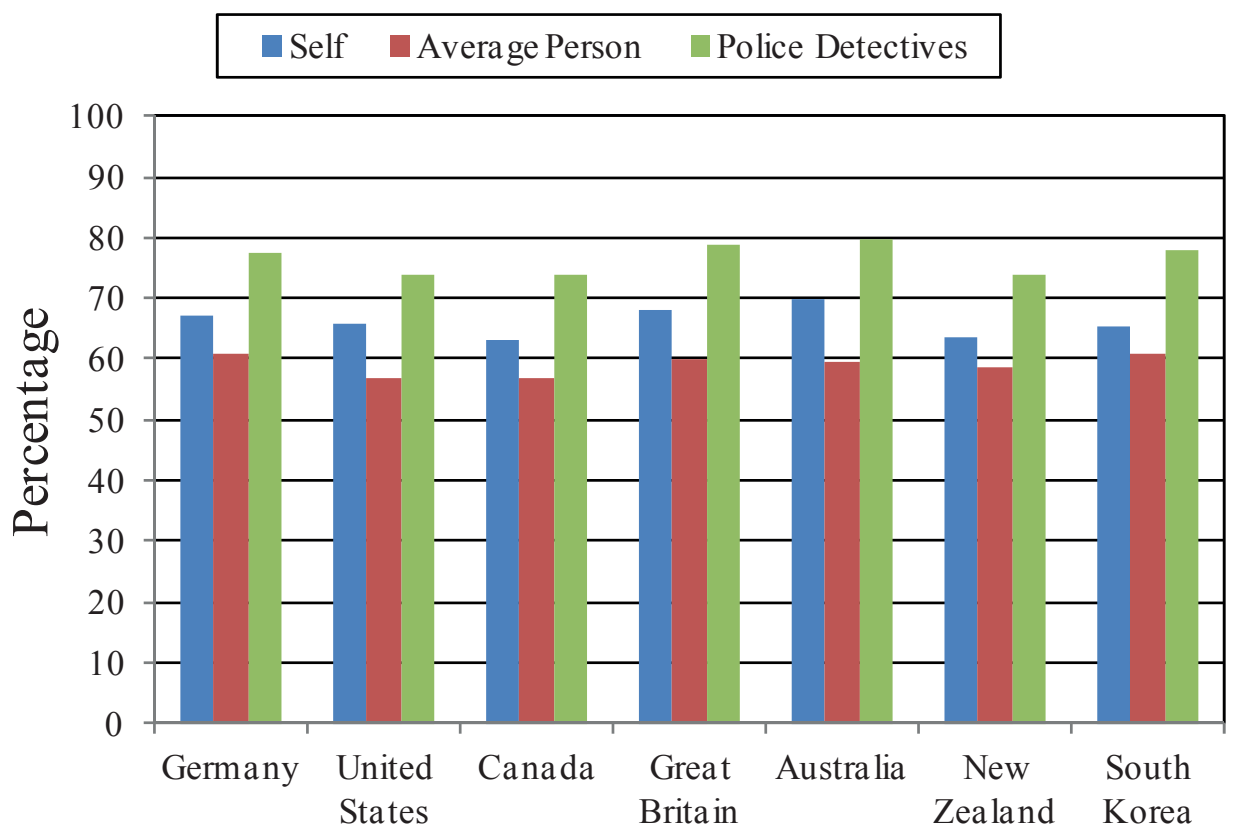

Figure 1. Estimated Deception Detection Skills across Countries 


\section{The Right to Remain Silent}

Participants were asked to imagine that they are brought into a police station and be informed that they have the right to remain silent and the right to have a lawyer present. They were then asked to indicate whether or not they would sign a waiver and agree to answer questions without a lawyer present, assuming they were guilty and assuming they were innocent. Furthermore, they were asked about guilty vs. innocent suspects who are brought in for questioning. Innocence led to significantly higher waiver rates (15.7\%) than guilt $(4.5 \%), \chi^{2}(d f=1, N=525)=16.21, p<0.01$. Participants estimated waiver rates for others (48.3\% vs. 30.1\%) higher than for themselves (15.7\% vs. 4.5\%). Country specific results are shown in Table 1 and show that results are comparable in all countries, except for South Korea.

A 7 between-group factors (Australia, Canada, Germany, Great Britain, New Zealand, South Korea and the USA) by 2 within-subjects (guilt, innocence) mixed ANOVA model examined the waiver rates. The main effect for waiver estimates for the different countries was significant, $F(1,513)=12.38 ; p<0.01$. An additional, post hoc Bonferroni correction revealed that South Korea deviated $(p<0.01)$ from the other countries. Furthermore, a significant main effect for waiving rights was obtained, $F(1,513)=184.83 ; p<0.01$. Also, a significant interaction was obtained $F$ $(1,513)=7.55, p<0.01$.

\section{Confession issues}

Participants were asked to separately estimate confession rates for suspects who were guilty and innocent. Then, they were asked if they would ever confess to a crime, again separately - if innocent and if guilty. On the question whether the participants would confess to a crime they had not committed, $10.8 \%$ of the participants answered yes, while they stated that $17.7 \%$ of innocent suspects would confess. The next question, whether they themselves would confess to a crime they had committed, $87.9 \%$ indicated they would confess, while they estimated that $45.6 \%$ of guilty suspects in general would. Table 4 shows the breakdown by country. 
Table 1. Estimated Waiver Rates (reported in \%)

\begin{tabular}{lcccc}
\hline & \multicolumn{2}{c}{ SELF } & \multicolumn{2}{c}{ OTHERS } \\
\cline { 2 - 5 } & Guilty & Innocent & Guilty & Innocent \\
\hline Germany & 3.2 & 11.6 & 30.7 & 50.4 \\
United States & 2.4 & 15.1 & 36.5 & 55.3 \\
Canada & 0 & 17.1 & 27.6 & 57.8 \\
Great Britain & 5.3 & 21.6 & 22.7 & 44.5 \\
Australia & 2.2 & 20 & 25.7 & 52.1 \\
New Zealand & 5.6 & 20.4 & 36.6 & 51.8 \\
South Korea & 14.4 & 22.5 & 25.5 & 26.6 \\
MEANS & $\mathbf{4 . 5}$ & $\mathbf{1 5 . 7}$ & $\mathbf{3 0 . 1}$ & $\mathbf{4 8 . 3}$ \\
\hline
\end{tabular}

Participants were also questioned whether they would confess during an intense, but lawful interrogation if innocent and if guilty. Confession rates if innocent were estimated at $12.1 \%(\mathrm{Mdn}=5$; Range $=0$ to $100 ; S D=20.62 ; N=546)$, while rates if guilty were at $70.4 \%$ (Mdn $=80$; Range $=0$ to $100 ; S D=27.87 ; N=547)$.

A 7x2 mixed-model ANOVA was used to examine a between-groups factor (Australia, Canada, Germany, Great Britain, New Zealand, South Korea and the USA) and a within-subjects factor (guilt, innocence). On estimation confession rates, the main effect for country was significant, $F(1,536)=7.83, p<0.01$. An additional, post hoc Bonferroni correction revealed that South Korea deviated $(p<0.01)$ from the other countries. A significant main effect for guilt and innocence was obtained as well, $F$ $(1,536)=497.53 ; p<0.01$. Estimated confession rates were higher for guilty suspects $(M=45.7 ; S D=23.27)$ than for innocent suspects $(M=17.7 ; S D=18.43)$. A significant interaction was also obtained, $F(1,536)=4.99, p<0.01$.

Table 2. Confession Estimates (reported in \%)

\begin{tabular}{lcccc}
\hline & \multicolumn{2}{c}{ SELF } & \multicolumn{2}{c}{ OTHERS } \\
\cline { 2 - 5 } & Guilty & Innocent & Guilty & Innocent \\
\hline Germany & 94.7 & 7.3 & 49 & 9.5 \\
United States & 85.6 & 14.3 & 42.8 & 19.4 \\
Canada & 85.1 & 8.7 & 40.8 & 13.4 \\
Great Britain & 100 & 7.7 & 43.2 & 13.7 \\
Australia & 89.1 & 6.5 & 53.3 & 28.7 \\
New Zealand & 94.6 & 12.5 & 48.5 & 18 \\
South Korea & 76 & 12 & 36.7 & 16.2 \\
MEANS & $\mathbf{8 7 . 9}$ & $\mathbf{1 0 . 8}$ & $\mathbf{4 5 . 6}$ & $\mathbf{1 7 . 7}$ \\
\hline
\end{tabular}




\section{Discussion}

This online survey of common beliefs of confession was designed to get layperson's perspectives about various aspects of confessions issues. Several interesting findings were obtained - some were consistent with past research, others were not. Moreover, similarities and differences were found between the seven countries Australia, Canada, Germany, Great Britain, New Zealand, South Korea and the USA. One reason for obtained differences in the seven samples could be due to differences in their legal systems. By and large, our findings illustrate the widespread belief that it is the guilty individual, who refuses to waive his/her rights and ultimately confesses.

On the subject of deception detection, participants were asked about their own accuracy level at judging between truths and lies. Moreover, they were asked about the accuracy level of the average person and specially trained police officers. Research studies have shown that people in general, no matter if they are working in the law enforcement or not, do poorly at judging between truth and deception. Even training does not improve deception detection skills reliably (Granhag \& Strömwall, 2004; Meissner \& Kassin, 2002, Memon, Vrij, \& Bull, 2003). While Reid training manuals claim that verbal and nonverbal deception cues can lead to an accuracy level of 85\% (Inbau et al., 2001), an empirical review of deception literature established a baseline of $54 \%$ ( $47 \%$ for lies, $61 \%$ for truths) (Bond \& DePaulo, 2006). Furthermore, several studies have shown that police detectives are not more accurate than lay people, but they are more confident in their judgments (Meissner \& Kassin, 2002).

Concurring with existent research (Chojnacki, Cicchini, \& White, 2008; Costanzo, Shaked-Schroer, \& Vinson, 2010), participants in this study overestimated deception detection skills. They overrated their own skills (66.1\%) and those of police officers $(76 \%)$, while thinking that they were better than the average person (58.9\%). The ratings of police officers are consistent with reported estimations of police detectors, which rated their own deception detection skills at a 77\% level of accuracy (Kassin et al., 2007). Interestingly, participants believed they are better than the average person, but worse than specially trained police officers. These findings prove the common misconception of lay people that training can improve detection deception skills and that there is a difference between laypeople and police officers, although there is not.

The overestimation of deception detection skills of police detectives pose a potential risk for innocent suspects because they believe in the police detectives to accurately judge between truths and lies, hence to accurately tell that they (the innocent suspects) are telling the truth. Most people are not aware of the fact that a police detective's judgment accuracy and everybody else's is barely better than flipping a coin. Interestingly, there were no differences found across countries, which means that this misbelief is universal. 
Before an interrogation, police has to warn suspects that they have the right to remain silent and to have a lawyer present. These warnings have been established in all seven countries surveyed in this study. In regard to these rights, participants were asked if they would waive their rights, if innocent and if guilty. Furthermore, participants estimated how many of guilty and innocent subjects would waive their rights. Only $4.5 \%$ of the participants stated that they would waive their rights if guilty. Concerning innocence, only $15.9 \%$ of the participants reported that they would waive their rights if innocent. These findings are inconsistent with previous research findings. In Kassin (2007) et al.'s police survey, police detectives reported an overall waiver rate of $81 \%$, which was consistent with earlier research findings. Furthermore, laboratory based findings claim an $81 \%$ waiver rate for innocent people compared to $36 \%$ for guilty ones (Kassin \& Norwick, 2004). Previous findings suggest that such rights may not fully protect those citizens who need it the most, while the current findings contradict this argument.

An explanation for such low waiver rates could be that people actually think they would refuse to waive, but in reality do not. Future predicting studies have shown that people are usually poor at judging their future behavior (Fazio, \& Roskos-Ewoldsen, 1994). Another explanation for the low waiver rates could be that the question used the rather broad term 'crime' instead of asking for a specific crime (like theft, rape or murder) or specifying the seriousness of the crime.

Relating to estimations of innocent and guilty suspects, participants estimated that $29.3 \%$ of guilty suspects would waive. Concerning innocent suspects, participants reported a waiver rate of $48.3 \%$. The results for guilty suspects are somewhat consistent with Kassin and Norwick's (2004) findings, while the innocent suspect's waiver rate is still highly underestimated. Again, innocent suspects were more likely estimated to waive their rights than guilty suspects. Interestingly, participants' waivers estimation of other people was much higher than compared to their own waiving estimate.

Regarding similarities and differences across countries, an intriguing finding emerged. Results were consistent across all countries, except for South Korea. While all other countries show lower waive rates for guilt compared to innocence, South Korea's estimates are stable across conditions (guilt vs. innocence and self vs. others).

When it comes to the outcomes of interrogations, participants rated that $45.7 \%$ of guilty suspects would confess compared to $17.9 \%$ of innocent suspects. Comparing the results to Kassin et al.'s (2007) police survey, outcomes differ greatly. Police interrogators reported on average a $69 \%$ confession rate for guilty suspects, which is far higher than the estimations of lay people. For innocent suspects, police reported an average of $4.8 \%$.

Looking at the results, it is obvious that lay people, compared to police interrogators, underestimate the confession rates of guilty suspects, while they overestimate false confessions done by innocent suspects. These findings imply that lay people, who are possible jurors, are aware of the danger of innocent people con- 
fessing to a crime they have not committed. Interestingly enough, reality seems to show a different picture. Several cases of false confessions, for example, the Central Park jogger case, the Michael Crowe case, the Marty Tankleff case, and the Jeffrey Deskovic case have shown that a recanted false confession can still lead to a guilty verdict leading to several years in prison being innocent (Kassin et al., 2007). Therefore, results of this lay people's survey about common sense of confessions suggests that people think that they are aware of false confessions, but apparently react to them in a different way when they surface in courts. Another reason for rather high innocent confession rates could be, again, the rather broad term 'crime'. It was not specified what kind of crimes or the level of seriousness, so it is not known what kind of crimes participants had in their mind when making these estimations.

Regarding the issue whether the participants would confess to a crime they had committed, $87.9 \%$ of the participants reported that they would, while $10.8 \%$ of participants reported they would confess when being innocent. These findings, for the assumption of guilt and innocent, are highly inconsistent with the above mentioned findings of Kassin et al. (2007). Our results suggest higher confession rates compared to what police estimated, especially surprisingly high for innocence.

An interesting finding emerged when asked about the likelihood of confessing during an intense, but lawful interrogation. The confession rate when innocent barely increased, but the rates for guilt did rise. These results support earlier discoveries that the average citizen may not be able to understand the impact that an intense interrogation can have on innocent suspects (Leo, 2001; Leo \& Liu, 2009), while believing that true confession rates increase through intense interrogations.

\section{Conclusion and Limitations}

Conclusively, it can be said that some interesting findings emerged from the current study. Our prediction that lay people would exhibit a lack of knowledge regarding truth and deception detection skills was fully supported. Results regarding the right to remain silent were inconsistent with previous studies and our hypothesis, and actually portrayed that lay people do recognize them as safeguards. Our third forecast was maintained by the outcomes of this survey, lay people display a lack of knowledge when it comes to confession rates. Furthermore, our data shows that such misconceptions are consistent across countries and not culture specific. Based on these findings it can be argued that common sense knowledge of confessions is not that common and that expert witnesses should be allowed in court.

While the present research revealed interesting results, there are limitations that restrict the generalizability of the findings. First, although participants were selected randomly via email snowball techniques, the number of participants in several countries was rather small. Ultimately a survey including larger number of participants should be conducted. Second, participants were asked in several ques- 
tions how they would react in several situations, hence, they were asked to predict their behavior. Studies have shown that there is an inconsistency between predicting future behavior and actually reacting to certain situations exists (Fazio, \& Roskos-Ewoldsen, 1994). Therefore, collecting behavioral data in combination with a pre-survey would be a future research study goal. A third limitation was the use of the word 'crime'. The term is rather broad and was not specified. Therefore, it is not possible to generalize the waiving of rights and confession estimations. A follow-up study of this survey could include questions about rights and confession estimations for different crimes, with different levels of seriousness. Relatedly, respondents in the current survey were asked about waiving their rights. However, these involved the right to remain silent and the right to have a lawyer present. So, it is not exactly clear what respondents had in mind when they said they would or would not waive their rights. Fourth, the seven countries that were surveyed all have different legal systems so it is not always possible to fully compare the results.

Although the present study revealed somewhat new information about layperson's beliefs about confession issues and related police interrogation, the knowledge about common sense of confessions of lay people is still incomplete. It is hoped that future studies will address the issue further and ideally examine beliefs in a combination of collecting thought and behavioral data. 



\section{CHAPTER 4}

\section{Police Practices and Beliefs:}

\section{A Survey of European Investigators}

Schell-Leugers, J. M., \& Kassin, S. M. (2014). Police practices and beliefs: A survey of European investigators. Manuscript in preparation. 


\begin{abstract}
In an effort to better understand how experienced investigators in different countries approach the processes of interviewing and interrogation, this study used a brief questionnaire concerning various police practices and beliefs to survey European police investigators. Seeking to replicate the self-report survey of North American police practices and beliefs by Kassin and colleagues (2007), we employed an adapted version of their instrument. Identical to the original study, the questionnaire covered investigators' beliefs and practices about 1) their ability to detect truth and deception, 2) Miranda waiver rates, 3) the use of various interrogation techniques, 4) the frequency and length of interviews and interrogations, 5) the rates of true and false confessions, and 6) their own practices and opinions with regard to the recording of interrogations and confessions.
\end{abstract}




\section{Introduction}

"I'm not sure how I did it. All I know is I did it" (Drizin \& Colgan, 2004, p. 141). This statement was made by Michael Crowe after he confessed to stabbing his two years younger sister Stephanie. Later it turned out that Michael had falsely confessed to the murder during a lengthy police interrogation and because of the misled belief by police that physical evidence existed that proved his guilt. After the real perpetrator was found, he was cleared of all charges (Kassin, 2008b).

One morning Marty Tankleff woke up to find his parents brutally slaughtered. His mother was already dead and his father was only barely alive. After police interrogated him and falsely informed him that his father had said that he was the perpetrator he (falsely) confessed and subsequently served 17 years in prison for allegedly murdering his parents. After a long fight for his innocence, all charges were dropped (Firstman \& Salpeter, 2008).

These are just two examples of American miscarriages of justice involving false confessions. Confessions are often seen as 'the queen of evidence'. A type of evidence that can even trump DNA in some cases (Appleby \& Kassin, 2011) and, when false, can corrupt other evidence (Kassin, 2012). In recent years, the detection of false confessions, often through the use of DNA testing, has highlighted the impact of confessions in the absence of other evidence. According to the US based innocent project, around $25 \%$ of their exonerated cases involved a false confession (http://innocenceproject.org). Many cases include horrific stories of harsh interrogations (Kassin et al., 2007) of suspects hindered by a range of dispositional and situational risk factors (for a review of such risk factors, see Kassin \& Gudjonsson, 2004). The two cases described above illustrate the danger of coercive and deceptive police interrogations. Even though an overall prevalence rate of false confessions is not known, these cases represent only the tip of an iceberg (Drizin \& Leo, 2004; Kassin \& Gudjonsson, 2004).

However, false confessions are not an American phenomenon; they have been reported all over the world (Huff \& Killias, 2008; "Symposium," 2012). For example, several cases have surfaced in Germany in the last decade. There was the case of Wolfgang Schwertz who was 'soft boiled' by police detectives until he confessed (Friedrichsen, 2010). Later it turned out that he was innocent. Then the infamous case of farmer Rudi Rupp, whose family had confessed to murdering him, cutting him into pieces and feeding him to the dogs. Four of his family members got convicted - despite missing physical evidence and recanted confessions. Apparently, they all had been interrogated repeatedly over many hours and mostly without a lawyer present. They claimed that they had confessed due to police pressure (Jüttner, 2009a; Peterhans, 2011). In 2011, the farmer's body was found and it emerged that he had died in a self-inflicted car accident ("Getöteter Landwirt" [“Murdered farmer"], 2011; Friedrichsen, 2011).

In Norway, a 20 year old man falsely confessed to killing his 17 year old cousin after being manipulated by the police. The detectives were sure of his guilt and 
interrogated him for several times in total over 100 hours. The officers made him believe that he had killed his cousin but that he could just not remember it. At some point the suspect wrote down that he killed his cousin but stated that he did not remember it: "No I don't remember it, but it must have been me because everyone says so" (Gudjonsson, 2003, p. 593). The young man was charged with the crime but fortunately acquitted by a jury.

Another European case of involving a supposedly false confession is that of the American Amanda Knox. She was an exchange student in Italy and when her British roommate was murdered, she became one of the prime suspects. She was interrogated by guilt presumptive officers several times over a period of four days. After she confessed, she recanted her involvement in the murder. She stated that "in regards to this 'confession' that I made last night, I want to make it clear that I am very doubtful of the verity of my statements because they were made under the pressures of stress, shock, and extreme exhaustion" (Kassin, 2012, p. 431).

It is interesting to note that harsh and lengthy interrogations are not only happening in the US, but seemed to be present in several European cases of false confessions as well. Just like in the US, no European prevalence rate is known for such untrue confessions. In Germany, Peters and colleagues (1970) examined over a 1000 appellate cases in Germany and found that 7\% involved false confessions. However, since this study was based on court files that are by now 50 years old, it is questionable in how far the rate of $7 \%$ can be applied to the situation today (Drews, 2013).

In the UK, Richardson (1991) surveyed juveniles in a residential forensic unit and his results indicate that $23 \%$ had falsely confessed to the police. Gudjonsson and Sigurdsson (1994) reported that 12\% of Icelandic prison inmates claimed to have made a false confession to police. Furthermore, Gudjonsson, Sigurdsson, and Sigfusdottir (2009) examined over 20.000 European high school students, of which $1.6 \%$ stated that they had made a false admittance statement to the police. Even though these study all share the limitation of being self-report studies and hence no corroboration of the false confessions, it is clear that false confessions do happen.

The documented false confession cases and the findings from the self-report studies lead to the question of why innocent suspects admit to something they have not done, especially in the light of severe consequences, such as spending time in prison. Since such a self-incriminating act is highly counterintuitive, confessions are a powerful type of evidence and are often taken for granted. As the above mentioned cases illustrate, this can lead to wrongful convictions of innocent (false) confessors.

While it is necessary to shed light on the problem of false confessions, it is also important to know the extent to which the cases that are discovered using coercive police interrogations reflect upon common or uncommon police practices. To examine this issue in the US and Canada, Kassin and colleagues (2007) surveyed 631 North American police investigators to examine their interrogation beliefs and practices. They constructed a questionnaire in which the participants, the police 
detectives, were asked to report on six topics: deception detection, Miranda warnings, interrogation techniques, interviews and interrogations, confession rates, and the recording of interrogations. Overall, their results showed that police detectives estimated themselves to be 77\% accurate at truth and deception detection. Regarding suspects' Miranda rights, it was reported that $81 \%$ waived their rights. On average detectives reported interrogations are 1.6 hours long, guilty suspects confess $68 \%$ of the time, and around $5 \%$ of innocent suspects wrongly make selfincriminating statements. Officers estimated that most common interrogation techniques were to isolate the suspect, to find inconsistencies in the suspects' story, to establish rapport, to face suspects with evidence that proves them guilty and to appeal to their moral standards.

The findings from this survey give insight into what happens in North American interrogation rooms. Furthermore, its results underpin outcomes of observational (e.g., Leo, 1996a; Thomas, 1996) and laboratory studies (e.g., Kassin \& Norwick, 2004). Most importantly, it was a positive step towards making police interrogations a less secretive process (Kassin et al., 2007).

Little is known about what happens in interrogations in Europe. No previous study has examined the beliefs and practices of European police investigators, yet insights are important, especially in light of documented false confession cases. Obtaining information from European investigators about the six examined issues (deception detection, Miranda rights, interrogation techniques, interrogations, confessions, and recording of interrogations) in the North American survey by Kassin and colleagues (2007) is significant to enhance our knowledge of interrogation processes and to identify possible risk factors for innocent suspects.

The first item - deception detection accuracy - is vital to innocent suspects in police custody. In order for police to correctly judge who is innocent and who is guilty, and hence to decide who will be interrogated and who will not be considered a suspect anymore, their deception detection skills need to be excellent. However, research has shown that law-enforcement personnel are rather poor at discriminating between truth and deception and that they are no better than the average person (Granhag \& Strömwall, 2004; Hartwig \& Bond, 2011; Vrij, 2008; Vrij, Granhag, \& Porter, 2010). Furthermore, a meta-analysis by Bond and DePaulo (2006) demonstrated that people in general are only $54 \%$ accurate in distinguishing between truth tellers and liars - a percentage that is barely better than flipping a coin. It is not only problematic that innocent suspects falsely believe that police detectives are better at detecting deception than lay people (Chojnacki, Cicchini, \& White, 2008; Costanzo, Shaked-Schroer, \& Vinson, 2010; Schell \& Kassin, 2009), it is worse that police are over confident in their judgment (Kassin, Meissner, \& Norwick, 2005; Meissner \& Kassin, 2002, Kassin et al., 2007). Field research even indicates that some detectives believe that they have a "sixth sense" (Leo, 1996b).

The Miranda rights, which guarantee suspects in police custody the right to remain silent and speak with a lawyer, have been established in the United States in the case Miranda v. Arizona, 1966. These rights were implemented to act as safe- 
guards for suspects. However, estimates based on observational and laboratories studies suggest that $80 \%$ of suspects in police custody waive these rights (Kassin \& Norwick, 2004; Moore \& Gagnier, 2008; Wrightsman \& Pitman, 2010). Miranda-like rights exist in many countries all over the world (Rogers, Drogin, Steadham, Clark, \& Cramer, 2013). In Europe, all members of the European Union have been advised to adopt the Letter of Rights by the European Parliament and the European Council (2012). Article 3, section 1 states that "Member States shall ensure that suspects or accused persons are provided promptly with information concerning at least the following procedural rights, as they apply under national law, in order to allow for those rights to be exercised effectively: (a) the right of access to a lawyer5; (b) any entitlement to free legal advice and the conditions for obtaining such advice; (c) the right to be informed of the accusation, in accordance with Article 6; (d) the right to interpretation and translation; (e) the right to remain silent."

In the United Kingdom, for example, the suspects' right to silence is embedded in the Criminal Justice and Public Order Act 1994. It states that "You do not have to say anything. But it may harm your defense if you do not mention when questioned something which you later rely on in court. Anything you do say may be given in evidence" (Home Office, 1995, p. 50). Likewise in Spain, the Law of Criminal Procedure (Ley de Enjuiciamiento Criminal, 1982) establishes in Article 520, Section 2, that suspects need to be informed about their right to remain silent.

Even though these legal rights have been established in the US and in many European countries, it is not known how many suspects actually make use of their rights. Results from a recent study suggest similar high waiver rates of such legal rights in Europe. Schell, Kassin, Merckelbach and Hospers (2014) used a mockcrime paradigm (based on Kassin \& Norwick's (2004) paradigm) to examine waiver rates in the Netherlands. Overall, $68 \%$ of the participants were willing to give up their right to remain silent. Innocent participants were more likely to waive their rights compared to guilty participants ( $86 \%$ vs. $50 \%)$. These findings suggest that high waiver rates are not an American phenomenon.

The third aspect concerns the usage of different interrogation techniques. In the US, the Reid Techniques is a commonly used interrogation method. In short, the Reid Technique can be divided in two processes: the interview and the interrogation. In the interview, it is established whether the suspect is lying or telling the truth. If the detectives believe that the suspect is telling the truth, he or she is no longer viewed as a suspect (Inbau, Reid, Buckley, \& Jayne, 2001). If however, the suspect is believed to be lying, the suspect will be interrogated (Gordon \& Fleisher, 2006; Inbau et al., 2001). Hence the goal of an interrogation is not to investigate

\footnotetext{
${ }^{5}$ In Salduz v. Turkey (2009), the European Court of Human Rights decided that suspects held at police stations have the right to have access to a lawyer. This decision has led to debates across Europe about when a detained person has the right to access a lawyer (for more information see van den Laar \& de Graaff, 2011). Particularly the Dutch situation has created upheaval (for more information see Brants, 2011).
} 
whether the suspect is guilty of the crime accused, but to get the suspect to confess (Leo, 2008).

In Europe, the situation is more complex since there is no universal interrogation technique. In the UK, the PEACE model has been routinely used since 1993. PEACE stands for preparation and planning, engage and explain, account and clarification, closure, and evaluation. It was developed after a series of wrongful convictions because of false confessions elicited during police interrogations (Gudjonsson, 1993). Several countries have adapted this model (e.g., New Zealand and Norway; Bull \& Soukara, 2010). It was established "to provide officers with an ethical foundation for police questioning" (Gudjonsson, 1993, p. 54) and furthermore to shift the focus "on information gathering rather than obtaining a confession per se (i.e., reliably establishing the facts), non-coercive interviewing and accurate recording of the interview" (Gudjonsson, 1993, p. 54).

A fourth issue concerns the length of interrogations but also how often suspects are interrogated. Referring back to the several cases - American and European briefly described at the beginning, it is obvious that the time spent in the interrogation room and the frequency of being interrogated played a major role in these false confession cases. American police investigators do not have to adhere to any limitations when it comes to the length and frequency of interrogations. While the North American investigators estimated an average of 1.6 hours per interrogation with an average of 4.21 hours for their longest one (Kassin et al., 2007), an archival study of 125 proven false confessions demonstrated a mean of 16.3 hours for interrogations resulting in false confessions (Drizin \& Leo, 2004). Regarding the frequency, the survey of Kassin and colleagues (2007) suggest that suspects are on average interrogated three times per investigation. Anecdotal evidence of case studies seems to paint a different picture in that many false confessors have been interrogated multiple times (Garrett, 2010). It remains to be seen what European investigators will estimate regarding their average interrogation length and frequency.

Another aspect - probably the most important one - concerns the rate of true and false confessions. As already described earlier, a prevalence rate is not known. Apart from experimental research results, self-report findings from prison inmates and DNA exoneration cases, police detectives' estimations are a valuable source for estimating confession rates of guilty and innocent suspects. In the original study by Kassin and colleagues (2007), detectives stated that $68 \%$ of suspects give selfincriminating statements during an interrogation $(69.5 \%$ for guilty suspects and $4.8 \%$ of guilty suspects). These estimated confession rates are in line with those suggested by others in the US (e.g., 64\% from Leo, 1996a; 46-69\% from Neubauer, 1974 and Witt, 1973). Based on several observational studies conducted in the UK, Gudjonsson (1993) cautiously concludes that confession rates range between 55 and $59 \%$ for British suspects.

Lastly, it is important to examine the opinion of police detectives about the recording of interrogations. In recent years, many have argued that videotaped recordings of interrogations and confessions should be mandated (for a review, see 
Kassin et al., 2010). On the one hand, such recordings could help the court to identify false confessions and to better understand how they happened. On the other hand, it would prevent police from using illegal interrogation techniques. Gudjonsson and Pearse (2011) argue that "the electronic recording of police interviews, which provides invaluable transparency and accountability, is the single best protection against police-induced false confessions" (p. 33). In the US, a new policy requiring the recording of interrogations will lead to a change and improvement in the criminal justice system (Schmidt, 2014). In the UK, mandatory recording of confessions has been in place for a while (see Gudjonsson, 2003 for a review of the "Confait Case"). It is uncertain how the situation is in other European countries since no previous study has investigated the legislation in other European countries regarding recording of interrogations and the opinions of detectives.

Following up on the survey conducted with North American Investigators (Kassin et al., 2007), the purpose of this study is to shed light on police practices and beliefs of European Investigators. Using an adapted, shorter version of their instrument, this study involved the administration of a 20 -item questionnaire covering investigators' beliefs and practices about 1 ) their ability to detect truth and deception, 2) Miranda warnings and waivers, 3) the use of various interrogation techniques, 4) the frequency and length of interviews and interrogations, 5) the rates of true and false confessions, and 6) their own practices and opinions with regard to the recording of interrogations and confessions. Our goal was to obtain descriptive data on European police practices and beliefs, to compare investigators from different countries, and to compare the data collected in this sample to those previously obtained in North America. Results are discussed for their consistency with prior research, policy implications, and methodological shortcomings.

\section{Method}

\section{Participants}

Sixty-three European ${ }^{6}$ police investigators participated in this study. The breakdown of participants by country is presented in Table 1 . Their mean age was 43.46 years $(S D=6.14$; Range $=27$ to 58); $67 \%$ were men, 33\% were women. Participants were recruited via email. The second author sent a link to our online questionnaire to a contact in Europe, who in turn forwarded the link to European police investigators.

\footnotetext{
${ }^{6}$ Not all participants turned out to be European investigators, because of the small sample size, all investigators are included. Non-European investigators came from Australia, New Zealand, Brazil, and Canada. One could argue that the jurisdictions in these countries have a European (primarily common law origin).
} 
Table 1. Distribution of countries represented in the sample

\begin{tabular}{lcc}
\hline Country & Sample sizes $(N=63)$ & \% of Total \\
\hline Spain & 2 & 3 \\
Portugal & 2 & 3 \\
The Netherlands & 1 & 2 \\
Poland & 2 & 3 \\
Lithuania & 1 & 2 \\
Slovakia & 1 & 2 \\
Latvia & 1 & 2 \\
Brazil & 1 & 2 \\
Denmark & 2 & 3 \\
Norway & 4 & 6 \\
Australia & 4 & 6 \\
New Zealand & 2 & 3 \\
Canada & 12 & 19 \\
UK & 28 & 44 \\
\hline
\end{tabular}

\section{The Questionnaire}

Using a slightly shorter version of the Kassin et al. (2007) survey, we designed and administered a 20-item online questionnaire. Four items related to demographic backgrounds (age, gender, country of residence and number of years employed in law enforcement) and 16 questions pertained to suspect interview and interrogation practices and beliefs about confessions.

Participants were asked several questions regarding their career in law enforcement. They were asked to estimate how many suspect interviews and interrogations they had been involved in. Furthermore, we asked them to consider all their interrogations and state how many suspects had given a partial or full confession and how many did not admit to anything. This question was asked for guilty and for innocent suspects, separately.

Furthermore, participants had to estimate, based on their own experience, the average number of times a suspect is interviewed and the average length of an interrogation session. Another question asked about the longest session they had ever been involved in. With regard to the length of the session, we wanted to know whether their country has a set time limit on how long a suspect can be interrogated.

Turning to deception detection, participants were asked to indicate how skilled they are at knowing if someone who denies guilt is telling the truth or lying. Also, 
we wanted to know if they had ever received special training on how to conduct interviews and interrogations. Regarding the matter of recording, participants had to indicate whether they usually record interviews and interrogation. Moreover, we asked them about their opinion regarding recording, specifically, whether they thought all sessions should be recorded.

Participants had to state whether they are required by law to inform suspects of the right to remain silent and the right to counsel when questioned by police. Another question required participants to estimate the percentage of suspects who waive their right to remain silent and counsel. They were asked to provide separate estimations for guilty and innocent suspects.

Lastly, participants were provided with a list of interviewing and interrogation techniques. We asked them to estimate how often they had used these techniques in trying to get suspects to confess. Participants had to use a five point scale $(1=$ never, $2=$ on rare occasion, $3=$ sometimes, $4=$ often, $5=$ always) to report their answers. Table 2 presents an overview of the techniques and their results. At last, we provided an open ended question for participants to report any other interrogation techniques that had not been mentioned.

\section{Results}

Since not all participants responded to all questions, each reported item includes the individual sample size. Due to the small sample size from each country, only descriptive results are presented since statistical power is lacking for most sample sizes per country. All results are descriptively compared to the results of the original North American survey (Kassin et al., 2007). Due to the small sample size of the current survey and the lack of access to the original data (other than described in the published paper), few statistical tests could be done for comparison.

On average, participants had 18.3 years of law enforcement experience $(S D=$ 7.79) and had conducted - by their own estimates - a mean of 517.6 suspect interviews and interrogations over the course of their careers $(S D=598.07)$. Overall, $89 \%$ said they had received special training on how to conduct interviews and interrogations. 
Table 2. Self- reported frequency of usage of 16 techniques. Scale: 1 (never) to 5 (always)

\begin{tabular}{|c|c|c|c|c|}
\hline Interrogation Techniques & $\mathrm{M}(\mathrm{SD})$ & Mdn & $\begin{array}{c}\text { Never } \\
(\%)\end{array}$ & $\begin{array}{c}\text { Always } \\
(\%)\end{array}$ \\
\hline Identifying contradictions in the suspect's story & $4.6(0.66)$ & 5 & 2 & 64 \\
\hline Establishing rapport and gaining the suspect's trust & $4.4(0.96)$ & 5 & 3 & 64 \\
\hline Confronting the suspect with actual evidence of his guilt & $4.2(0.90)$ & 4 & 3 & 44 \\
\hline Conducting the interrogation in a small, private room & $3.4(1.57)$ & 4 & 26 & 31 \\
\hline Isolating the suspect from family and friends & $3.1(1.57)$ & 3 & 29 & 26 \\
\hline Appealing to the suspect's self-interests & $3.1(1.51)$ & 3 & 15 & 10 \\
\hline Showing the suspect photographs of the crime scene and/or victim & $2.6(1.07)$ & 3 & 23 & 2 \\
\hline Interrupting the suspect's denials and objections & $2.4(1.22)$ & 2 & 27 & 10 \\
\hline Offering the suspect sympathy, moral justifications, and excuses & $2.2(1.21)$ & 2 & 39 & 3 \\
\hline Minimizing the moral seriousness of the offense & $2.1(1.19)$ & 2 & 44 & 3 \\
\hline Appealing to the suspect's religion or conscience & $2.0(1.11)$ & 2 & 44 & 3 \\
\hline Implying or pretending to have independent evidence of guilt & $1.7(0.99)$ & 1 & 57 & 2 \\
\hline Threatening the suspect with consequences for not cooperating & $1.6(1.00)$ & 1 & 68 & 2 \\
\hline Expressing impatience, frustration, or anger at the suspect & $1.5(0.71)$ & 1 & 58 & 0 \\
\hline $\begin{array}{l}\text { Having the suspect take a polygraph test - and telling } \\
\text { him that he failed it }\end{array}$ & $1.1(0.50)$ & 1 & 90 & 0 \\
\hline Physically intimidating the suspect & $1.1(0.38)$ & 1 & 94 & 0 \\
\hline
\end{tabular}

\section{Beliefs about Lie Detection}

Participants were asked to estimate the accuracy of their own truth vs. lie detection abilities. Results showed that participants estimated that they can distinguish truthful and deceptive suspects at a $70 \%$ accuracy level $(S D=16.68 ; N=59)$. This estimation is comparable - yet slightly lower - to the $77 \%$ reported in Kassin et al. (2007). The difference between the estimations obtained from North American and European investigators did attain significance, $t(664)=3.08, p<0.01, d=0.42$, indicating that North American investigators are somewhat more confident in their deception detection skills than their European counterparts.

\section{The Right to Remain Silent}

Regarding the legal right to remain silent and the right to counsel, all of the participants reported that their country's laws require that police informs suspects about such rights. Then they were asked to estimate how many suspects waive their right to silence and are willing to talk to the police. In line with research findings, investigators estimated that innocent suspects $(74 \% ; S D=24.01 ; N=60)$ were more likely 
to waive their rights than guilty suspects $(60 \% ; S D=29.64 ; N=61)$. In the original study, participants also reported such a difference in their estimation of waiver rates for innocent (84\%) and guilty (73\%) suspects. Even though investigators in both studies correctly perceived the difference between waiver rates of innocent and guilty suspects, significant differences were found between the two samples' estimations of waiver rates if innocent, $t(598)=3.27, p<0.01, d=0.43$, and if guilty, $t(648)=4.10, p<0.01, d=0.49$.

\section{Interrogation Techniques Used}

Participants rated on a 1-5 point scale ( 1 = never; 5 = always $)$ the extent to which they use different techniques. The results are presented in Table 2 starting with the most commonly used techniques. In order of estimated usage, the top three techniques were (1) "Identifying contradictions in the suspect's story" $(M=4.6 ; S D=$ 0.66), (2) "Establishing rapport and gaining the suspect's trust" $(M=4.4 ; S D=0.96)$, and (3) "Confronting the suspect with actual evidence of his guilt" $(M=4.2 ; S D=$ 0.90). Interestingly, the more confrontational approaches of the Reid technique (Inbau et al., 2001) - such as pretending to have evidence that does not exist and minimizing the moral seriousness of the offense - were endorsed at a much lower rate (Ms $=1.7 \& 2.1$, respectively). In Kassin and colleagues' (2007) survey, the top three of most often used techniques were different: (1) "Isolating suspect from family and friends" ( $M=4.5 ; S D=0.86)$, (2) "Conducting the interrogation in a small, private room" $(M=4.2 ; S D=0.82)$ and (3) "Identifying contradictions in the suspect's story" ( $M=4.2 ; S D=0.78)$. Significant differences were obtained when comparing the reported usage of the top three European investigators' tactics with how often North American Investigators rated the frequency of employing them, (1) $t(692)=3.54, p<0.01, d=0.49$; (2) $t(692)=3.05, p<0.01, d=0.38$; (3) $t(692)=$ 2.92, $p<0.01, d=0.37$. Examining the least used tactics, both samples rated "Having the suspect take a polygraph and telling him he failed it" (North America $M=$ 1.9; Europe $M=1.1$ ) and "Physically intimidating the suspect" (North America $M=$ 1.4; Europe $M=1.1$ ) as techniques practically never used.

\section{Length and Frequency of Interrogations}

Four questions were asked about the length and frequency of interrogations. First, participants were asked to indicate, based on their experience, the average number of times a suspect is interviewed. Then, they had to estimate the average length of a suspect interview session and recall the longest interview session they had ever been involved in. Lastly, they were questioned about whether the law in their country set a time limit on how long a suspect interview can last.

Regarding the first question, it was estimated that on average, suspects were interviewed 2.6 times $(S D=1.47 ; N=62)$. Their American counterparts reported an estimate of 3.1 times, which is not different from the current rate, $t(650)=1.73, p=$ 
$.09, d=0.26$. The average length of an interrogation was indicated as 2.6 hours ( $S D$ $=4.13 ; N=63)$. After omission of an outlier, the average length was 2.1 hours $(S D=$ 1.93; $N$ = 62). Relative to the average length of a North American session (1.6 hours), European interrogations (2.1 hours) are significantly longer, $t(661)=3.71$, $p<0.01, d=0.34$. The longest session they had ever been involved in was stated as being 7.3 hours long $(S D=3.43 ; N=60)$. In contrast, American investigators reported the longest interrogation had lasted on average 4.2 hours. Again, a significant difference was found between the two samples, $t(646)=8.81, p<0.01, d=$ 1.03. While North America does not have a set time on how long a session can last, we wanted to know how the situation in Europe is. We asked participants whether their country has a time limit on how long suspect interviews can last. While $68 \%$ of the respondents stated that there is no time limit, the remaining $32 \%$ stated an average of 3.8 hours as the limit.

\section{Estimated Confession Rates}

Participants were asked to estimate, based on all the interrogations they had been involved in, how many suspects make self-incriminating statements. They were required to separately report guilty and innocent suspect's confession rates.

They estimated that $45.9 \%(S D=24.6 ; N=62)$ of guilty suspects gave a partial or full confession. For innocent suspects, they estimated that $12.1 \%(S D=25.03 ; N$ = 62) gave a partial or full confession. A significant degree of Skewness (2.56; $S E$ $=.31)$ and Kurtosis (5.73; $S E=.61)$ was noted in the distribution of false confession estimates. After outliers were omitted, an average of $7.6 \%(S D=15.61 ; N=57)$ of innocent suspects falsely confessing was indicated. Comparing these confession estimates to the rates found in the original study, it emerges that North American investigators reported significantly higher confession rates for guilty suspects $(69.5 \%)$ and significantly lower rates for false confessors (4.8\%), $t(644)=7.36, p<$ $0.01, d=0.23$, and $t(435)=2.17, p=.03, d=0.97$, respectively.

\section{Recording Practices}

This section of the questionnaire required respondents to give information about the practices regarding the recording of interrogations and confessions. Additionally, the investigators were asked about their personal opinion when it comes to recording. The majority (84\%) stated that they usually do record interrogations. All respondents reported that according to their jurisdictions or law enforcement practices, all interrogations should be electronically recorded. In the Kassin et al. (2007) survey, an estimated $38 \%$ of sessions were recorded; $81 \%$ favored the practice. 


\section{Discussion}

The objective of the current survey was to examine police practices and beliefs of European investigators. Our goal was to shed light on various aspects related to interrogations and confessions. By replicating Kassin and colleagues (2007) survey of North American police investigators we aimed at comparing the practices and beliefs of North American and European investigators. Some consistencies with the original study and past research findings were found; other findings deviated from the pattern described by Kassin and colleagues (2007).

Regarding deception detection skills, the results showed that investigators overestimated their ability to distinguish between truthful and deceptive suspects. A comparison revealed that North American police (Kassin et al., 2007) believed even more in their skills than European police (70\% vs. 77\%). Not only do investigators rate their own accuracy at a high level, lay people rate the deception detection skills of police at a similar high rate (76\%; Schell \& Kassin, 2009). Such high accuracy rates contradict the vast research literature that suggests near-chance level performance (Hartwig \& Bond, 2011; Vrij, 2008; Vrij, Granhag, \& Porter, 2010). An overestimation of these skills can put innocent suspects in a dangerous position. Suspects mistakenly believe that police will be able to tell that they are innocent, while they are not. Additionally, research has shown that even though investigators are no more accurate than lay people, they are more confident in their judgments (Meissner \& Kassin, 2002). By being overconfident in their own deception detection skills, police investigators do not seem to be worried about innocent suspects' false confessions. The most common answer by police, when being asked about the risk of false confessions, was that they were not worried because they "do not interrogate innocent people" (Kassin, 2005, p. 26). This quote nicely illustrates their mistaken confidence in their own accuracy skills.

Concerning the legal rights of suspects, all respondents indicated their home countries have equivalents to the American Miranda rights. The outcome regarding these rights are consistent with previous research findings that innocent suspects are more likely to waive their rights to silence and to counsel compared to guilty suspects (Kassin \& Norwick, 2004; Moore \& Gagnier, 2008; Schell et al., 2014). As in Kassin et al. (2007), it appears that police understood that innocents are more likely than perpetrators to waive their rights rather than to "lawyer up." However, the findings revealed that European investigators rated the waiver rates of suspects lower than North American police. This suggests that police perceives these rights as being used more in Europe.

In contrast to these results are the findings from Schell and Kassin's (2009; see Chapter 3) survey of European lay people. In their study, participants were asked whether they would waive their right to remain silent - if innocent and if guilty. Only $16 \%$ of innocent suspects reported that they would waive their right to silence. Guilty suspects were even less likely to give up their right (5\%). These numbers suggest that suspects do use these legal rights as safeguards. However, it has 
to be taken into account that these results are based on participants who were asked to imagine being accused of a crime and asked to give up their rights. They were not suspects in a real life interrogation. Another study has recently shown that people are generally bad at predicting their behavior in police custody regarding their right to remain silent, especially if innocent (Schell et al., 2014; see Chapter 5). To the best of our knowledge, no comprehensive observational study has examined suspects' waiver rights during police interrogations; therefore a comparison is not possible.

Self-reported usage of different techniques suggests a strong preference for techniques that are consistent with an investigative interviewing approach to suspect interviews (e.g., rapport, use of actual evidence, identification of contradictions) and a rejection of techniques associated with the more confrontational approach of the Reid technique (e.g., the false evidence ploy, minimization). These findings indicate that the European interrogation room is less dangerous for innocent suspects to falsely confess compared to North American interrogations.

Reasons for different interrogation approaches in Europe and North America are - at least partly - due to the laws regarding the usage of certain techniques. For example, it is not only permitted in North America to lie about evidence and/or imply during an interrogation that independent evidence of guilt exists (Frazier $v$. Cupp, 1969; R. v. Oickle, 2000) (e.g., DNA, fingerprints or an eyewitness), but these techniques are also taught during interrogation trainings (e.g., Inbau et al., 2001). Yet, cases of false confessions (e.g., Marty Tankleff, Jeff Deskovich) and laborartory studies (e.g., Kassin \& Kiechel, 1996) have demonstrated that the presentation of false evidence is a risk factor for false confessions. Moreover, studies have shown that only implying to have evidence - the so-called bluff tactic - can have the same effect on innocent suspects (e.g., Perillo \& Kassin, 2011). In the UK, deceiving suspects about the existence of false evidence is not legally allowed (Kassin et al., 2010). Thus, by not permitting false evidence ploys in interrogations, one risk factor for false confessions is already eliminated.

Regarding the frequency of how often a suspect is questioned, both - European and American - investigators estimated an average of three times. These reported numbers seem rather low when looking at documented false confession cases. Often false confessors, as for example those in the cases described at the beginning of this article, had been interrogated by the police multiple times over several days or even weeks. Results from both surveys suggest that extensive interrogations do not display common police practices.

Turning now to the length of the average interrogation, our findings suggest that the common American interrogation is shorter (1.6 hours) than the common European one (2.1 hours). Also, regarding the longest session our participants had been involved in, European investigators reported longer sessions. Taking into account that lengthy interrogations are a risk factor for false confessions (Kassin et al., 2010), these findings seem to suggest that the American interrogation lengths are safer for innocent suspects. However, when looking at the average of 16.3 hours 
(of American false confession cases) that was reported by Drizin and Leo (2004), the reported lengths in both samples seem to be not alarming. Furthermore, these outcomes indicate that lengthy interrogations are not the norm (Kassin et al., 2007).

Turning to confession rates, police reasonably estimated that roughly half of all guilty suspects make incriminating admissions or confessions. When asked about suspects who turned out to be innocent, they estimated that roughly $12 \%$ would make an admission or confession - which is higher than the 5\% obtained in Kassin et al. (2007) and suggests that experienced police are well aware of the risk that innocent people sometimes confess to crimes they did not commit.

Questionable is whether such an awareness can prevent the occurrence of false confessions. The assumption: "I'd know a false confession if I saw one" has been proven to be a myth (Kassin, 2008a). Problematic is here that police investigators do not possess high accuracy deception detection skills that would enable them to identify an untrue confession. Kassin, Meissner, and Norwick (2005) demonstrated that police investigators were not better than the average person at detecting true and false confessions. They were, however, "biased toward perceiving true confessions and overconfident despite a lack of accuracy." (Kassin et al., 2005, p. 221). Such a guilt-presumptive attitude poses a risk for innocent suspects in interrogation.

On the subject of recording of interrogations and confessions, all of our respondents stated that they are in favor of electronically documenting sessions. A majority (84\%) reported that such procedures are already in use. These statistics are slightly higher than the ones obtained in the original study. They suggest that European investigators are already in line with research recommendations of various scholars to make it mandatory to record interrogations and confessions. As previously mentioned, the PEACE model already includes such a policy (Gudjonsson, 2003). The FBI has recently released a policy about mandatory recording as well (Schmidt, 2014). Making electronic recordings mandatory for police interrogations is a positive step towards reducing coercive police interrogations and avoiding false confessions (Gudjonsson \& Pearse, 2011; Kassin et al., 2010).

The current results provide a first and preliminary glimpse into the European interrogation room. Even though our results have been mostly consistent with those gained in the North American police survey (Kassin et al., 2007), several differences stand out as well. Overall, we can report that European interrogations are - at least to a certain extent - safer than American ones. This is due to time limits of interrogations, compulsory recording of interrogations, and a more investigative interviewing approach (especially the fact that the false evidence ploy is illegal) all of which are adequate ways to avoid false confession or at least reduce the risk of innocent suspects confessing to crimes they have not committed.

Several limitations of the present survey have to be acknowledged. A major shortcoming is the small sample size overall. The small sample sizes (specifically per country) make it impossible to generalize these findings to all European police prac- 
tices. Another problem of our study is the fact that Europe does not follow 'one police practice'. Methods of police procedure and interrogations differ per country. Furthermore, law systems are variable across Europe. Even if the sample size overall would have been bigger, specific results can only be generalized per country (if a bigger sample size would be available). The current sample also included nonEuropean nationals, which would have to be excluded. A third concern, which has also been pointed out in the North American sample, is that of memory accuracy. We asked our participants about several instances that happened in their past, in their daily life at work, but research has shown that memory often relies on inference strategies, which can have a biasing effect on the correctness of the answers given, especially regarding frequency estimations (Schwarz, Groves, \& Schuman, 1998; Tourangeau, Rips, \& Rasinski, 2000).

As numerous miscarriages of justice have shown, false confessions do occur and most of the times have detrimental consequences for the innocent confessor. Once the 'queen of evidence' is on the table, police deem the case closed. The power of a confession is stronger than inconsistencies in the suspect's story or disproving evidence (such as an alibi, an eyewitness or DNA evidence; Drizin \& Leo, 2004; Leo \& Ofshe, 1998). Even exonerations cannot always trump a confession as the case of American Bruce Godschalk illustrates. After he was proven innocent based on DNA testing, the prosecutor still believed in his guilt: "I have no scientific basis. I know because I trust my detective and my tape-recorded confession. Therefore the results must be flawed until someone proves to me otherwise (Rimer, 2002, p. A14). Similar attitudes have surfaced in Europe as well. After it was proven that the German farmer Rupp had not been hacked into pieces and fed to the dogs, prosecutors and police still believed that his family was guilty of murdering him (Friedrichsen, 2011).

Even though we were only able to gain preliminary information about European police investigators' beliefs and practices, it was a first step in the right direction. It showed that some of the recommendations to prohibit false confessions are in place (e.g., time limits, electronic recording, and 'safer' interrogation techniques). However, since false confessions do exist in Europe as well, more research is needed. Our findings will hopefully work as an incentive for other researchers to replicate our survey and gain comprehensive sample sizes from various European countries. Furthermore, since electronic recording of interrogations has been established in some European countries, we appeal to the police to make such tapes available for research. One crucial step in future research is a comparative approach in which self-reports of police personnel about interrogation characteristics are compared to actual statistics. It is not only in the interest of the public, and especially innocent suspects, but also in the interest of police and government to avoid wrongful convictions because of false confessions produced in coercive police interrogations by all means. By making police procedures a less secretive approach, we are making it safer for innocent suspects. 



\section{CHAPTER 5}

\section{Not Acting According to Our Beliefs: The Dangers of Waiving the Right to Remain Silent}

Schell-Leugers, J . M., Kassin, S. M., Merckelbach, H., \& Hospers, H. J. (2014). Not acting according to our beliefes: The dangers of waiving the right to remain silent. Manuscript under review. 


\begin{abstract}
The privilege to remain silent and to have a lawyer present is a fundamental right that defendants in many countries may invoke. Across two experiments, we examined the association between people's behaviors and beliefs about this type of situation. Study 1 employed a mock theft paradigm that was previously used by Kassin \& Norwick (2004). Students $(N=48)$ were assigned to either a guilty or innocent condition. After they stole money from the experimenter (or not), they were approached by a detective and were read their rights to silence and to counsel. Overall, 68\% waived these rights - 50\% in the guilty condition and $86 \%$ in the innocent condition. In study 2 , students $(N=62)$ were presented with a description of the experiment and asked to imagine being a participant in the guilty or innocent condition. Then they were asked to imagine being approached for questioning by a detective and to predict whether or not they would waive their rights to remain silent and to counsel. Whereas waiver rates were the same in the guilty conditions of study 1 and 2 , predicted waiver rates in the innocent condition were significantly lower than those obtained in Study 1 (i.e., 58\% vs. 86\%). Results indicate that people are not aware of the innocence effect on waiver rates as a matter of common sense, and are discussed in the light risk factors for false confession.
\end{abstract}




\section{Introduction}

An old and famous adage says that speech is silver and silence is golden. In light of the numerous miscarriages of justice that have been reported around the world (Huff \& Killias, 2008; "Symposium," 2012), in which false confessions were an alltoo-common contributing factor (Saks \& Koehler, 2005; http://innocenceproject.org/), this adage offers sage advice. Personal risk factors (e.g., youth, mental illnesses, low IQ), and situational risk factors (e.g., custody, long periods of isolation, highly deceptive interrogation tactics) have been identified as possible causes leading to false confessions and wrongful convictions (for reviews, see Kassin, 2005; Kassin \& Gudjonsson, 2004). However, before suspects can be interrogated by police and hence exposed to these risks, they must be informed about and waive their rights to silence and to counsel. These rights have been codified in many of the world's legal systems (Rogers et al., 2013).

In North America, the landmark case Miranda v. Arizona (1966) established that all suspects in the US must be informed by the police about their right to remain silent and to have a lawyer present - and they must waive these rights before police can take a statement that would be admissible in court. In Canada, the Charter of Rights and Freedoms (1982) ensures these same rights. The situation in Europe is similar. All member states of the European Union have been recommended the Letter of Rights by the European Parliament and the European Council (2012). For example, in Germany Article 136 of the Code of Criminal Procedures stipulates these rights (STPO, 2008). Likewise, in the Netherlands, Article 29 of the Dutch Code of Criminal Procedure (CCP) gives suspects the so-called zwijgrecht (the right to keep silent) while in police custody (Hirsch Ballin, 2012). The objective of these legal cautions "is to prevent suspects from incriminating themselves unless they truly want to" (Wrightsman \& Pitman, 2010, p. 4). Hence, these warnings are intended to serve as safeguards, especially for innocent suspects.

Although the purpose of these rights is clear, their effectiveness in safeguarding the accused individual is an empirical question. Observational studies, surveys, and experiments suggest that a large majority of suspects in police custody waive such rights, especially those who are innocent (e.g., Kassin, 2005; Kassin et al., 2010; Leo, 1996b; Leo \& White, 1999; Wrightsman \& Pitman, 2010). One reason for high waiver rates is that many suspects, especially those who are young and mentally retarded, do not fully understand their rights (Cloud, Shepherd, Barkoff, \& Shur, 2002; Oberlander \& Goldstein, 2001; Rogers, 2011). Wrong beliefs and misconceptions about legal rights can be found even among competent suspects (Rogers, 2011). Rogers and colleagues (2010) investigated Miranda rights misconceptions held by pre-trial defendants compared to college students. Their findings showed that $31 \%$ of pre-trial defendants and $36 \%$ of the students failed to understand what it means to have the right to remain silent. They were not aware of the fact that their right to silence is protected by the constitution and that invoking that right cannot be used against them. Furthermore, results showed that "many misconceptions appeared 
unrelated to intelligence, education, or prior contacts with the criminal justice system" (p. 300). These findings indicate that suspects feel they run no risk by waiving their rights.

Theorizing that innocent people in particular are prone to waive their Miranda rights because the phenomenology of innocence provides false comfort, Kassin and Norwick (2004) examined Miranda waiver rates in a laboratory setting. They used a mock theft paradigm in which participants were randomly assigned to steal (guilty) or not steal (innocent) money from the experimenter. Overall, 58\% of the participants signed a waiver. Furthermore, as predicted, innocent participants were more than twice as likely as guilty participants to sign a waiver of their rights (81\% vs. $36 \%$ ). When asked why they did so, most innocent participants cited their innocence as an explanation, indicating that they had nothing to fear or hide and expressing the belief "in the power of [this] truth to prevail" (p. 216). Thus, especially innocent suspects are at risk of giving up their rights and hence getting exposed to an interrogation. This result was more recently replicated in Canada (Moore \& Gagnier, 2008).

In 2007, Kassin and colleagues surveyed 631 North American police investigators about their interrogation beliefs and practices. As part of the survey, investigators were asked to estimate Miranda waiver rates. Overall, they estimated that $81 \%$ of suspects give up their right to remain silent, a finding consistent with research derived from actual criminal justice statistics (e.g., Leo, 1996b). Furthermore, participants were questioned separately about guilty and innocent suspects. Police estimates indicated their belief that innocent suspects are more likely to waive their rights (84\%) compared to guilty suspects (73\%). These estimates are consistent with the hypothesis that innocent suspects are more likely to waive their rights because of a naïve belief in the power of their own innocence (Kassin, 2005; Kassin \& Norwick, 2004).

Taken together, estimates suggest that approximately four out of every five suspects give up their legal rights to remain silent and do not make use of these safeguards (Wrightsman \& Pitman, 2010). However, a multinational survey conducted by Schell and Kassin (2009; see Chapter 3) investigating lay people's beliefs about various confession issues (e.g., confession estimates of guilty and innocent suspects, interrogation techniques) including the right to remain silent, indicated that people anticipate lower waiver rates. Across seven countries, 573 participants were asked to imagine being brought to a police station to be questioned about a crime that they did or did not commit and being informed about their rights to silence and counsel. Participants were then asked to (1) predict whether they would waive these rights and agree to talk to the police, and (2) rate how innocent and guilty other suspects would react in the same situation. Overall, only $10.1 \%$ of the participants said that they would waive their rights, with $15.9 \%$ when innocent and $4.5 \%$ when guilty. For others, however, they estimated that $39.2 \%$ would waive their rights - $48.3 \%$ of innocent suspects and $29.3 \%$ of guilty suspects (Schell \& Kassin, 2009). These predictions stand in sharp contrast to the actual waiver rates 
and police estimates noted earlier. Once again, however, support was obtained for the innocence effect - namely, that anticipated waiver rates for innocent suspects were significantly higher than for guilty suspects.

To determine if laypeople can use their common sense to predict the extent to which people would waive their rights to silence and to counsel, and that innocents in particular are likely to do so, two experiments were conducted. In experiment 1 , we used the Kassin and Norwick (2004) mock crime paradigm in an effort to replicate their results, notably the "innocence effect," ten years after the original study and in a European context. In experiment 2, we described this paradigm to an independent group of participants in order to examine how accurately people can predict the actual waiver results, and to test for their awareness of the behavioral differences observed between guilty and innocent suspects.

\section{Experiment 1}

\section{Method}

Participants and Design. Forty-eight undergraduate students (32 female, 16 male; mean age $=20.5$ years; $S D=2.7$ ) from a large Dutch research university were recruited to take part in an experiment ostensibly to test their memory. Participants took part in this study in exchange for research credits or a voucher worth $7,50 €$. The study was approved by the standing ethics committee of this university. All participants were randomly assigned to one of two conditions: guilty $(n=24)$ or innocent $(n=24)$. Four participants had to be excluded from data analyses. One decided to withdraw from the experiment after reading the informed consent disclosure that he or she might be asked to commit a mock crime; one knew the student assistant who was acting as an interrogator; and two misunderstood the instructions. This final sample consisted of 44 participants with equal numbers in each condition.

Procedure. Seeking to replicate Kassin and Norwick (2004), we used an identical procedure. Participants were greeted by a female experimenter and received the informed consent form which included the statement: "For the purpose of this study, I may be asked to commit a mock crime or a related innocent act and undergo an interrogation about the experience ${ }^{7 "}$. After participants consented to the study, the experimenter instructed them that "they should do whatever they see as necessary to protect themselves (e.g., "You can choose to talk to the police or not, you can be friendly or you can be hostile, whatever you think will help your cause")". In order to enhance ecological validity, a long-term consequence was add-

\footnotetext{
${ }^{7}$ All phrases in quotation marks were taken verbatim from the Kassin and Norwick (2004) protocol.
} 
ed that there may be a second part to the study - a trial to be held at a later point in time. Participants were told "whether there is a trial phase will depend on whether there is sufficient evidence that you are guilty. So do what it takes in your long-term best interest to either avoid going to trial or to be acquitted at trial".

After the directions were given, all participants received an envelope with specific instructions. Participants in the guilty condition were told to go to a room alone and steal 100 Euros out of a drawer; participants in the innocent condition were told to go to the same room alone and open the drawer without taking anything. The instructions stated that they should then return to the experimenter who took them to a small, windowless room that was furnished with a desk, a drawer and two chairs. After five minutes a 22 year old student assistant wearing a suit came in and introduced himself as Detective McCarthy. Since there were no significant differences found in the original study between the three interrogation styles (neutral, sympathetic, and hostile), we used only the neutral interrogation style. The "detective" was blind to the participant's condition - guilty or innocent. In each session, he accused the participants of stealing money and said that he wanted to question them about it but first he would have to read them their rights.

After reading the rights, he gave the participants the waiver form and a pen. $\mathrm{He}$ asked them to read their rights again and then sign one of the two statements: "I am willing to make a statement and answer questions at this time" or "I am not willing to make a statement or answer questions at this time". The order of the statements was counterbalanced from one session to the next. Once the participants signed they were asked whether they were sure of their decision. At that point, the detective left the room and the experimenter returned.

The experimenter informed the participants that they would not be questioned and asked them to fill out a post-session questionnaire. This questionnaire included three demographic questions (age, gender, nationality) and then asked participants for an explanation of their waiver decision. Participants were also asked to rate the stressfulness of the experiment and how believable it was on a 10-point scale that ranged from 1 (= not stressful at all; not plausible) to 10 (= extremely stressful; very plausible). After answering the questions participants were debriefed by the experimenter about the real purpose of the study and thanked for their participation.

\section{Results}

The post-session questionnaire ratings indicated that the experiment was moderately stressful $(M=5.3$ on a 1-10 point scale; $S D=2.11)$ and moderately believable $(M=5.5 ; S D=1.65)$. The original study was similarly rated for stressfulness $(M=$ $5.9)$ and believability $(M=6.08)$.

Altogether, $68 \%$ of participants signed the statement that they are willing to talk and answer questions. Comparing this waiver rate to the original study finding 
of 58\%, no significant emerged, $\chi^{2}(d f=1, N=116)=1.125, p=.29$. As in Kassin and Norwick (2004), innocent participants were more likely to waive their rights (86\%) than those who were guilty of committing the mock crime (50\%), $\chi^{2}(\mathrm{df}=1, N=44$ ) $=6.71, p<0.01$. Comparing the waiver rates of innocent suspects (86\%) to those in the original study $(81 \%)$, no significant differences were found, $\chi^{2}(\mathrm{df}=1, N=58)=$ $.32, p=.57$. Similarly, no differences were revealed between the waiver rates of guilty participants in the original study $(36 \%)$ and this experiment $(50 \%), \chi^{2}(\mathrm{df}=1$, $N=58)=1.09, p=.30$.

Through a post-hoc examination of the participants' explanations for waiving and non-waiving, different categories were established for coding the reasons given. Two independent coders rated all answers according to these categories and the agreement rate between them was $100 \%$. As in Kassin and Norwick (2004), innocent participants offered various reasons for waiving their rights, but the majority (13 out of 19) stated that they believed in the power of their innocence (e.g., "I did not steal any money so I've got nothing to hide," "I didn't do anything, so they won't have any evidence against me"). Concerned about self-presentation, four stated that they were afraid to look suspicious if they would not talk (e.g., "I didn't steel anything so I thought it would be safe to answer immediately to not look guilty"); and two said that they wanted to explain what happened (e.g., that they did not steal anything).

The majority of the guilty suspects who gave up their rights (seven out of eleven) used the same self-presentation reasoning as four of the innocent participants ("I think that not answering questions will make you look suspicious," "Not saying anything might look suspicious"). Three stated that they would make a statement to try to get out of the situation and convince the detective of their innocence (e.g., "I would say that I wouldn't have any reason to steal the money and how would I know that it was in that room in the drawer?"), and one said that there was no evidence so it was alright to talk. Again, these explanations were comparable to those given by the participants in the original study. ${ }^{8}$

\section{Experiment 2}

Despite the passage of time and our variation in place, study 1 closely replicated the results originally obtained by Kassin and Norwick (2004). Using these new results as a baseline, we conducted a second study to assess the extent to which participants drawn at approximately the same time and from the same population would be able to predict the results on the basis of their common sense. In particular, we sought to determine if lay people would accurately predict both the magnitude of the overall waiver rate and the "innocence effect."

\footnotetext{
${ }^{8}$ No gender differences were predicted or obtained on any dependent measures, so the data for female and male participants were combined for analyses.
} 


\section{Method}

Participants and Design. Sixty-two liberal arts undergraduate students (42 female, 20 male; mean age $=20$ years; $S D=2.84$ ) from the same university sampled in experiment 1 volunteered to participate in a study about decision making. All participants were randomly assigned to one of the two groups: guilty $(n=31)$ or innocent $(n=31)$.

Procedure. After being greeted by a female experimenter and signing an informed consent form, all participants were asked to read the description of the procedures used in experiment 1 . While reading the description, participants were asked to imagine that they were in the guilty or innocent condition. Then they were asked to predict whether or not they would sign a waiver in this situation ("Imagine that you were participant in this study. Which statement would you sign?"). They were also asked to estimate in general how many people out of 100 in this experiment waived their rights and were willing to talk to the detective. After answering these questions, participants were fully debriefed about the purpose of the experiment and thanked for their participation.

\section{Results}

Experiment 1 replicated Kassin and Norwick's (2004) "innocence effect" of actual waiver rates ( $86 \%$ for innocence vs. $50 \%$ for guilt). In experiment 2 , we sought to determine if people can accurately predict these results. Our key dependent measures were participants' projections as to whether they would waive their rights (self-predictions) and their estimates of how many participants in the actual experiment actually did waive their rights (others prediction).

Overall, $52 \%$ of participants predicted that they would sign a waiver of their rights; similarly, on average, they estimated that $53 \%$ of others who were in the study actually did so. These overall waiver percentages are slightly lower but consistent with the 58\% waiver rate reported by Kassin and Norwick (2004) and lower than the $68 \%$ obtained in experiment 1 . No significant differences were found comparing the self-predicted waiver rates of experiment 2 (52\%) to Kassin and Norwick's results $(58 \%), \chi^{2}(d f=1, N=116)=.61, p=.44$ and to experiment $1(68 \%)$, $\chi^{2}(d f=1, N=106)=2.91, p=.09$. Table 1 displays the waiver rates in all three studies.

As Table 1 shows, $58 \%$ of participants in experiment 2 predicted that they would waive their rights if innocent and $45 \%$ if guilty. A $2 \times 2$ Chi-square on these self-predictions indicated that the difference between these groups was not significant, $\chi^{2}(d f=1, N=62)=1.03, p=.31$. Hence, people did not exhibit the innocence effect in their commonsense predictions of their own behavior. To statistically compare waiver rates between experiment 1 and the self-predictions of experiment 
2, two 2 x 2 Chi-square analyses were conducted. In the guilty condition, the difference in waiver rates across the two studies was not statistically significant, $\chi^{2}(d f=$ $1, N=53)=0.12, p=.73$. This lack of difference indicates that participants in experiment 2 were able to predict the actual waiver rates of guilty participants in experiment 1 . Yet, when we compared the waiver rates of experiment 1 and 2 in the innocence condition, we found a significant difference between actual behavior and predicted behavior, $\chi^{2}(d f=1, N=53)=4.89, p=.03$. This difference indicates that the innocence effect obtained in experiment 1 was not predicted in experiment 2.

With regard to predictions about the behavior of others, Table 1 shows that our participants estimated that $58 \%$ of innocent suspects in experiment 1 would waive their rights compared to $48 \%$ of those in the guilty condition. To assess whether there were differences in the waiver rate predictions made by those in the guilty and innocent conditions, a t-test was conducted. The results revealed no difference. That is, participants did not predict the innocence effect for others, $t(60)=1.42, p=$ $.16, d=0.36$.

Table 1. The Right to Remain Silent - Actual and Estimated Waiver Rates ( $=178$ )

\begin{tabular}{|c|c|c|c|c|c|c|c|c|}
\hline & \multicolumn{4}{|l|}{ GUILT } & \multicolumn{4}{|c|}{ INNOCENCE } \\
\hline & Waived & (\%) & Not Waived & $(\%)$ & Waived & (\%) & Not Waived & $(\%)$ \\
\hline Original (2004) & 13 & 36 & 23 & 64 & 29 & 81 & 7 & 19 \\
\hline Exp. 1 & 11 & 50 & 11 & 50 & 19 & 86 & 3 & 14 \\
\hline Exp. 2 Self & 14 & 45 & 17 & 55 & 18 & 58 & 13 & 42 \\
\hline Exp. 2 Others & - & 48 & - & 52 & - & 58 & - & 42 \\
\hline
\end{tabular}

\section{General Discussion}

Nemo tenetur se ipsum accusare. No one is bound to accuse himself. This legal principle is embedded in legal systems around the world (Rogers et al., 2013). It is meant to be a safeguard for innocent suspects against possibly coercive police interrogations that could lead to false confessions. However, observational studies of police interrogations (e.g., Leo, 1996a) and results of laboratory studies (e.g., Kassin \& Norwick, 2004; Moore \& Gagnier, 2008) have shown that about $80 \%$ of innocent suspects in police custody give up their right to remain silent. Hence, they do not use such rights to protect themselves and risk getting exposed to a coercive police interrogation. In light of these high waiver rates of suspects in custody, the objective of this study was twofold: (1) to determine if the tendency of people to waive their rights persist and whether it can be replicated today, in Europe; and (2) to determine if people know as a matter of common sense that they and others will likely waive their rights to police and that innocent people in particular are at risk 
of doing so. In other words, do people understand the phenomenology of innocence (Kassin, 2005), for themselves and for others?

Our results can be summarized as follows. The first experiment investigated waiver rates of innocent and guilty suspects in a mock crime paradigm. The overall waiver percentage $(68 \%)$ was consistent with the original study $(58 \%)$ that had been conducted ten years ago in the United States (Kassin \& Norwick, 2004). Thus, a decade after the original study, a non-trivial percentage of men and women still waive their right to remain silent, even in a European setting (i.e., at a Dutch university).

The second experiment addressed the relationship between predicted and actual performed behavior regarding the right to remain silent. In particular, we sought to examine whether or not participants would know about the innocence effect when predicting their own behavior in this decision-making situation and estimating the normative behavior of others. Results of this second experiment indicate that there is a discrepancy between predicted and actual behavior. When it comes to people who are innocent, our data indicate that whereas $86 \%$ actually waived their rights, replicating Kassin and Norwick (2004), only 58\% of participants assigned to imagine themselves in the innocent condition predicted that they would waive their rights - a significant decrease from the actual waiver rate in the imaginative condition. No such discrepancy was obtained for participants who imagined that they were guilty. Interestingly, predictions about the behavior of others were highly similar. This suggests that the discrepancies revealed in the current study do not just reflect lack of self-insight or sloppiness of responders. It is specifically in the innocent condition that the discrepancy between the ease with which people actually waive their right to remain silent (86\%) and their predicted insistence on this right occurs (42\%). Apparently, it is difficult for people to forecast how they would behave as innocent suspects in a police interrogation, a finding that underlines Kassin's (2005) argument that innocent defendants in particular are at risk.

These findings should be placed in the context of the numerous wrongful conviction cases involving false confessions in the United States (e.g., Jeffrey Deskovic, Doug Warney, Byron Halsey, the Central Park Five), European cases (e.g., Rudi Rupp, Herman DuBois, Wilco Viets, Thomas Quick), and laboratory experiments (e.g., Horselenberg, Merckelbach, \& Josephs, 2003; Kassin \& Kiechel, 1996; Russano, Meissner, Narchet, \& Kassin, 2005). By waiving their rights to silence and to counsel - the only protection the accused are afforded from a potentially stressful interrogation - innocent suspects expose themselves to the police and risk falsely confessing to a crime they did not commit.

Two questions are of interest and should be raised with regard to the current results: First, why do innocent suspects waive their rights to silence? Answers to this question are manifold. Kassin (2005) theorized that innocent people "have a naïve faith in the power of their own innocence to set them free" (p. 218). Research has thus shown that innocence is a mental state that leads people to waive their 
rights (Kassin \& Norwick, 2004; Moore \& Gagnier, 2008), to behave in ways that are open and forthcoming with police (Hartwig, Granhag, \& Strömwall, 2007), to disclose their alibis, without fear that police would view minor inaccuracies with suspicion (Olson \& Charman, 2012), to exhibit less physiological arousal in response to the stress of interrogation (Guyll et al., 2013), and even to confess as an act of compliance out of a belief that they will be exonerated by subsequent evidence (Perillo \& Kassin, 2011). Consistent with this body of research, innocent participants in experiment 1 both waived their rights at a high rate and cited their own innocence as an explanation of that decision (e.g., "I did not steal any money so I've got nothing to hide").

The more fundamental psychological mechanisms that operate behind the high waiver rates of our innocent participants are the "illusion of transparency" and "belief in a just world" (see Kassin, 2005). Research on the illusion of transparency shows that people believe that their internal thoughts, feelings, and attitudes are transparent to others (Gilovich, Savitsky, \& Medvec, 1998). Similarly, such statements as "I am not guilty, so I don't have to fear anything" may reflect the belief in a just world according to which people believe that the world is a just place in which everyone gets what they deserve (Lerner, 1980). Unfortunately, these widespread assumptions and the accompanying implication that others, including police, can detect one's innocence are unfounded. This can be seen in the vast number of false confession cases that have resulted in wrongful convictions all over the world (e.g., Egan, 2006; Gudjonsson, 2003; Inglis, 2004; Kahn, 2005; Kassin et al., 2010; Meissner, Horgan, \& Albrechtsen, 2009; Onishi, 2007; Otto, 2006; Santtila, Alkiora, Ekholm, \& Niemi, 1999; Sherrer, 2005; Rahn, 2008; Rastam, 2012; Wagenaar, 2002).

The second question raised by the present research is which implications flow from the fact that participants in experiment 2 did not through common sense correctly predict the innocence effect. Comparing our two studies, it is clear that there is a large discrepancy between actual waiver rates (86\%) and the prediction of waiver rates $(58 \%)$ in the innocent condition. How can such a mismatch between the waiver rates of innocent suspects be explained? It is likely that people who have themselves never been accused of a crime cannot imagine what it is like to be interrogated (Sangero \& Halpert, 2011). Hence, people not only underestimate their waiver rates but also misjudge the hostile feeling that can arise during the isolation, confrontation, and minimization phases of a typical interrogation (Kassin, 2005). When participants in experiment 1 were asked why they gave up their rights, several answered that they were afraid to look guilty (e.g., "I think that not answering questions will make you look suspicious," and "Not saying anything might look suspicious"). If one has never been exposed to a pre-interrogation situation, it might be hard to imagine that not talking (i.e., not explaining that one is innocent) is better than talking to the police and risk being exposed to an interrogation.

Our findings support the argument that a "false confession is not a phenomenon that is known to the average layperson as a matter of common sense" (Kassin, 
2012, p. 433). Several studies have shown that false confessions are seen as counter-intuitive by laypersons (Leo \& Liu, 2009) and are not generally known (Chojnacki, Cicchini, \& White, 2008; Schell \& Kassin, 2009). Hence, expert testimony is a possibly helpful aid for judges and juries in cases involving disputed confessions (Chojnacki et al., 2008, Costanzo, Shaked-Schroer, \& Vinson, 2010). Yet despite our findings, and those of others, suggesting that the psychology of confessions is not known as a matter of common sense, many US courts in recent years have disallowed testimony from confession experts on the ground that what they have to say is not beyond the ken of the jury (Cutler, Findley, Loney, 2014; Fulero, 2010; Quintieri \& Weiss, 2005). In State v. Free (2002), for example, the state Supreme Court rejected an expert's testimony on false confessions arguing that jurors are aware of the fact that not all confessions are true and that jurors can identify risk factors for false confessions (e.g., vulnerable suspect characteristics - including innocence; the use of such interrogation tactics as isolation, repeated questioning, the false evidence ploy, and minimization). At least with regard to people's understanding of how innocence can lead innocent people to waive their rights, the present research indicates that the reasoning US courts have used in this context overestimates people's knowledge.

Several limitations of the current study deserve some comment. First, our experiments relied on undergraduates - all young and intelligent people. Therefore, the results might not be generalized to suspects who are older or less educated. Drizin and Leo (2004) examined 125 proven false confession cases and their sample alone included 28 intellectually impaired suspects, a rather disproportionally high number. One could argue that the high percentage of waiver rates that we found for innocents is an underestimation of actual rates in suspects with low IQ and low self-esteem. However, our results are consistent with findings from observational studies conducted in the US (Cassell \& Hayman, 1996; Leo, 1996a) and UK (Softley, 1980), which have indicated similar high waiver rates (80\%) with suspects from various backgrounds, ages, characteristics etc.

Second, our results are based on a mock crime procedure. Of course, participants will have realized that they were not really involved in a criminal proceeding. But again, it might be much easier to insist on one's right to remain silent in a simulated mock crime than in a real police station setting. Third, our experiments were not based on a test-retest approach and so we cannot claim that we documented an inconsistency between individuals' actual waiving and their beliefs. The reason for not using a test-retest approach is that employing such design may create its own problems. Thus, after people have been inquired about their opinions about Miran$d a$ rights, people may want to stick to these opinions in a mock crime procedure, producing overestimation of insistence on Miranda rights. Thus, it is difficult to design belief-behavior experiments in this domain that do not have these artificial side-effects. It is a challenge for future studies to come up with better paradigms.

The present research has shown that at the group level, innocent participants have difficulties in predicting how they and others will behave in a pre- 
interrogation situation. Such a discrepancy poses a potential risk for innocent suspects to falsely confess. Cases of wrongful convictions due to false confessions demonstrate the importance of these rights as safeguards. More research is needed in this area to examine closely the reasoning behind high waiver rates and what can be done to teach people - especially those without a criminal record - about the significance of the right to remain silent. As already argued above, more research regarding the prediction-behavior relationship in police custody is needed to explain how expert testimonies may educate judges and juries. Resurrecting an old adage, our findings suggest that while silence is golden, innocent people who stand accused do not avail themselves of that right - an empirical fact not known to those who may later judge them. 



\section{CHAPTER 6}

\section{"I Would Never Do That!" Exploring the Inconsistencies between Predicted and Actual Behavior in Interrogations}

Schell-Leugers, J. M., Merckelbach, H., \& Kassin, S. M. (2014). "I would never do that"! Exploring inconsistencies between predicted and actual behavior in interrogations. Manuscript in preparation. 


\begin{abstract}
False confessions have caused miscarriages of justice around the world. Even though the occurrence of false confessions has been established, individuals usually believe that it could never happen to them. Results from surveys compared to cases and research has shown that there is a discrepancy between people's predicted and actual behavior during interrogations. The current study examines whether participants are able to correctly predict their behavior and that of others in a typical false confession paradigm. Our results demonstrate that individuals are poor at foreseeing how they react during interrogations and neglect the powerful influence of certain interrogation techniques. Based on these findings, an explanation for why common sense is not so common during interrogations is provided. Potential risks for innocent suspects will be discussed.
\end{abstract}




\section{Introduction}

Common sense tells us that beliefs will guide our behavior (Maoi \& Haddock, 2009). Confessing to a crime one has not committed is counterintuitive; it goes against any common sense. Therefore, people are generally sceptical about the possibility of false confessions because they cannot imagine that they would ever admit to a crime they did not commit. Yet, in the last decades, several cases involving false confessions have been overturned and innocent people have been freed from prison (http://innocenceproject.org). To make the matter more complicated, there is no simple explanation as to why people falsely confess. Findings have shown that, even though some people are more vulnerable than others (see Kassin \& Gudjonsson, 2004), it can happen to anyone (Kassin et al., 2010), anywhere (Huff \& Killias, 2008; "Symposium", 2012).

Research has demonstrated that false confessions can be elicited in laboratory studies. The by now well-known ALT key paradigm was the first study to investigate the occurrence of false confessions in a lab setting (Kassin \& Kiechel, 1996). Participants had to type out letters on a computer, which were read by another participant (who was in reality a confederate). The letters were either read out in a slow pace or a fast pace. Clear instructions were given as to not touch the ALT key because this would result in the computer crashing and all data being lost. As a manipulation of the experiment, the computer would crash after one minute (even though none of the participants actually touched the forbidden key). Then the participant was accused of hitting the ALT key and causing the computer to crash. In half of the conditions, the confederate acted as a false witness, claiming that he/she had seen the participant touch the key. The results of this experiment were stunning - overall, $69 \%$ of the participants (who were all innocent) admitted to having touched the forbidden key and causing the computer to crash. When the letters were read out in the fast pace and the confederate acted as a false witness, false confession rates went up to $100 \%$ (Kassin \& Kiechel, 1996). Their results support the hypothesis that the presentation of false evidence (in this case a false witness) and high vulnerability (in this case the fast pace reading of the letters) led to higher false confession rates of innocent individuals. The ALT key paradigm and its findings have been repeatedly replicated in the US (e.g., Redlich \& Goodman, 2003), as well as in Europe (Horselenberg, Merckelbach \& Josephs, 2003). But due to some shortcomings of the experiment (e.g., only innocent 'suspects', no severe consequences, no intention), this classic false confession paradigm has also received considerable critical attention.

To address some of the problems in the ALT key paradigm, Russano and colleagues (2005) designed a novel paradigm - a cheating paradigm - to test the influence of psychologically based interrogation tactics on confession rates in a lab setting. In their paradigm, participants were paired up with a confederate (who they believed to be a normal participant) and were instructed to solve tasks either individually or as a pair. In the individual condition, they were not allowed to talk to 
each other. Half of the times however, the confederate asked the participant for help in the individual condition and hence tricked the other person into cheating. This way the researchers successfully created a paradigm with guilty ('cheaters') and innocent suspects. Furthermore, they employed different interrogation techniques (minimization and the offer of leniency) to produce confessions. If participants in this study helped the confederate, they intentionally cheated and broke the rules of the experiment, which added a more severe consequence compared to the ALT key paradigm. Their results displayed that the higher true confession (43\%) and false confession (87\%) rates were obtained when both interrogation techniques were used. This suggests that even though these two tactics increase the likelihood that guilty suspects will confess, they also substantially increase the risk for innocent suspects to admit to a crime they have not comitted. Overall, empirical studies have shown that false confessions can be elicited.

Even though the existence of false confessions has been acknowledged because of many high profile cases appearing in the media, DNA exonarations, and a vast amount of research studies, people still find it hard to understand why they occur. As Davis and Leo (2012) stated it might be because of "our inability to walk in the skin and shoes of the accused: to truly understand the forces facing them, the personal context in which those forces operate on them, and the mechanisms through which these forces exert their effects" (p. 737). If we assume that people display such an inability to understand why false confessions occur then this poses a risk factors for innocent suspects. Research has shown that a confession, even after it has been recanted and proven to be false, often still has severe consequences for the false confessor (Drizin \& Leo, 2004; Leo \& Ofshe, 1998). In order to find out why confessions have such a strong impact on a trial outcome and such a heavy influence on jurors, it is necessary to examine the beliefs of lay people - potential jurors. Not only to find out whether they can make informed decisions in cases of possible false confessions, but also to see what lay people's beliefs are and whether such beliefs - possible misconceptions - can pose a risk to innocent suspects. Furthermore, shedding light on lay people's beliefs can help judges with the decision whether expert testimonies about false confession issues should be accepted in court.

Judges are often reluctant to allow expert testimony on the issue of false confessions, because they believe that the fact that they occur is common sense knowledge (Cutler, Findley, \& Loney, 2014). For example, in the case Commonwealth of Pennsylvania v. Harrell (2013), the expert testimony on the issue of false confessions was excluded. The court argued:

[I]f the expert is only testifying generally about the fact that false confessions happen, that is well within the grasp of the average layperson and expert testimony would not be required under Rule 702. The components of a false confession, according to Dr. Davis, include factors such as the interrogation tactics employed, the training of the law enforcement personnel involved, and the stress tolerance of the 
suspect. This [c]ourt found that testimony concerning these factors can be elicited (and attacked) through the testimony of other witnesses and is capable of being understood by the average juror. The jury can then make its own determination as to the weight afforded to the defendant's confession. Therefore, Dr. Davis' testimony was not proper because expert testimony is inadmissible when the matter can be described to the jury and the conditions evaluated by them without the assistance of one claiming to possess special knowledge upon the subject.

However, several studies (e.g., Blandon-Gitlin, Sperry \& Leo, 2011; Chojnacki, Cicchini, \& White, 2008; Costanzo, Shaked-Schroer, \& Vinson, 2010; Henkel, Coffman, \& Dailey, 2008; Leo \& Liu, 2009) have studied the beliefs of potential jurors and findings suggest that false confessions are perceived as counter-intuitive (Leo \& Liu, 2009) and that expert testimony is seen as a possible helpful aid in cases involving false confessions (Chojnacki et al., 2008; Costanzo, Shaked-Schroer, \& Vinson, 2010). Several scholars have argued that the phenomenon of false confession is not common sense knowledge of the average person (Chojnacki et al., 2008; Kassin, 2012).

Moreover, Schell and Kassin (2009; see Chapter 3) have demonstrated that knowledge about various confession issues is not so common after all. In their study, over 500 participants from seven different countries were surveyed about their beliefs about police procedures, interrogations and confessions. Overall, the results displayed misconceptions about various factors regarding confession issues. For example, participants overestimated deception detection skills for themselves (66\%) and believed police detectives to be even more accurate (76\%) at distinguishing between truth and lies. As well, compared to actual cases and laboratory findings (e.g., Kassin \& Kiechel, 1996, Perillo \& Kassin, 2011; Russano et al., 2005), the results of this survey showed that lay people are poor at estimating confession rates of innocent suspects and confession rates of guilty suspects. Furthermore, the findings indicate that over $95 \%$ think that they would keep their right to remain silent (which is an important safeguard for innocent suspects), whereas in reality only about $20 \%$ do (Wrightsman \& Pitman, 2010).

Looking more closely at the results of Schell and Kassin's (2014) survey, it becomes clear that certain misperceptions are dangerous for innocent suspects in custody. For example, the right to remain silent should supposedly act as a safeguard for innocent suspects to not be exposed to a stressful interrogation. Yet it has been shown that around $80 \%$ of suspects give up their legal right to silence (Wrightsman \& Pitman, 2010) and hence do not make use of this possible safety net. Comparing the survey results with observed behavior in studies and cases, a discrepancy between people's beliefs (what they think they would do) and actual behavior emerged. To test the assumption that people think they would keep their right to remain silent in an interrogation situation but in reality would waive it, Schell, Kassin, Merckelbach, and Hospers (2014; see Chapter 5) tested undergraduate students' beliefs and behavior regarding such rights. Their first experiment 
used a mock-crime paradigm (a replication of Kassin \& Norwick, 2005), which involved guilty and innocent participants, to examine how many would give up their right in a mock-interrogation. In the second experiment, participants were asked to read a detailed description of the first experiment and required to predict whether they would waive their right to silence, if innocent and if guilty. Results showed that guilty participants' behavior did not differ significantly in experiment 1 (50\%; behavior) and experiment 2 (48\%; waiver prediction). However, if innocent, participants predict significantly lower waiver rates (58\%) than in the actual behavioral experiment (86\%).

This research suggests that at the group level, there is a discrepancy between actual waiver rates (i.e., behavior) and waiver rates reported when people imagine themselves to be in an interrogation situation (i.e., attitude). Such a discrepancy can be dangerous for innocent suspects in custody. To the best of our knowledge, the above study was the first to investigate attitude-behavior relationship for suspects in police custody.

To further investigate the attitude-behavior relationship in police custody, the current study seeked to investigate how well people predict their own behavior regarding confessions during a police interrogation and that of others. To test the assumption that there is a discrepancy between predicted confession rates and actual behavior, we conducted a self-report study based on the results the Kassin and Kiechel's (1996) ALT key paradigm. Participants were asked to read a description of this paradigm and predict confession rates for themselves and others. We hypothesised that participants fail to predict the 'false evidence' effect and 'state of vulnerability' as participants did demonstrated in the original study.

\section{Experiment}

\section{Method}

Participants and Design. One hundred eleven undergraduate students participated in this study. Their mean age was 19.8 years $(S D=2.03) ; 34 \%$ were males and $66 \%$ were females. Participants were invited to take part in an experiment about decision making; all participants volunteered to join the experiment. Once participants had consented, they were randomly assigned to one of the four conditions: 1 . slow pace - no witness $(n=30), 2$. slow pace - false witness $(n=29), 3$. fast pace no witness $(n=29)$, 4 . fast pace - false witness $(n=23)$.

Procedure. All participants were asked to read the description of the ALT key paradigm (based on Kassin \& Kiechel, 1996). In the original experiment, participants were recruited to participate in a reaction time task. There were two subjects per session: the participant and a female confederate. The confederate was to read 
letters and the participant was to type them. Participants were instructed not to press the ALT key because it would cause a crash and data loss. Depending on the condition, the letters were read slow or fast. After one minute, the computer crashed and the experimenter accused the participant of hitting the forbidden ALT key. The confederate was asked whether she saw something and based on the condition she either said yes or no (no witness vs. false witness). The experimenter then asked the participant to sign a confession, admitting that he or she had hit the ALT key and caused the computer crash. Our participants read a detailed description of one of the four conditions. We asked them to predict how many of the subjects in the original study signed the confession. Additionally, they were asked to imagine being a participant in the ALT key paradigm and had to state whether they would sign a confession or not. One person did not provide a prediction for himself/herself because the answer would 'depend on the impact the social environment would have on me'. Therefore, the final sample size for self-predictions is $N=$ 110. Afterwards, participants were fully debriefed about the real purpose of our experiment and thanked for their participation.

\section{Results}

Kassin and Kiechel's (1996) results demonstrate that innocent individuals are at risk of falsely confessing if false evidence is presented and if they are in a heightened state of uncertainty (i.e., fast pace). We sought to test whether participants neglect these two influences when predicting confession rates for others and themselves. The key dependent measure was the prediction of how participants in the original experiment signed the confession and whether they themselves would confess.

Overall, participants predicted that $53 \%$ of the individuals in the original study admitted to signing the confession. Regarding themselves, $20 \%$ stated that they would confess. A statistically significant difference was found between the original study's results (69\%) and the current self-predicted confessions $(20 \%):, \chi^{2}(\mathrm{df}=1$, $N=185)=45.22, p<0.01$. This demonstrates that participants were not able to predict the likelihood of false confessions in a laboratory experiment.

Table 1 displays the confession rates across the four different conditions in the original experiment and our prediction study. Our participants clearly failed to predict the 'false evidence effect' obtained by the original study. Compared to the original percentages, where the false confession rates increased from 35\% in the slow pace - not witness baseline condition (condition 1) to $100 \%$ in the fast pace witness false evidence condition (condition 4), subjects predicted only a small increase for others. From $44 \%$ in condition 1 to only $56 \%$ in condition 4 ; while $100 \%$ vs. $35 \%\left(\mathrm{p}<.001^{9}\right)$ is highly significant, $44 \%(S D=32.01)$ vs. $56 \%(S D=30.22)$ is

\footnotetext{
${ }^{9}$ As reported in the original study (Kassin \& Kiechel, 1996, p. 127).
} 
not, $t(51)=1.39, p=.17$. A one-way ANOVA determined that there were no statistically significant differences between conditions for predicted confession rates for others, $F(3,107)=1.16, p=.33$. This shows that participants substantially underestimated false confession rates across the board - especially in condition 4: $56 \%$ (others prediction) vs. 100\% (original study).

Comparing the self-predicted confession rates of the current study to the original results, statistically significant discrepancies were found in all conditions: condition $1(10 \%$ vs. $35 \%)-\chi^{2}(\mathrm{df}=1, N=53)=4.86, p=.03$; condition 2 (21\% vs. $65 \%)-\chi^{2}(\mathrm{df}=1, N=46)=8.91, p<0.01$; condition $3(28 \%$ vs. $89 \%)-\chi^{2}(\mathrm{df}=1, N=$ $47)=16.71, p<0.01$ and condition $4(23 \%$ vs. $100 \%)-\chi^{2}(\mathrm{df}=1, N=39)=23.29, p$ $<0.01$. Across all conditions, participations underestimated the likelihood that they would confess and failed to predict the false evidence effect and the vulnerability state. Interestingly, participants believed others to be more likely to admit to touching the ALT key than themselves (condition 1: $44 \%$ vs. $10 \%$; condition 2: $53 \%$ vs. $21 \%$ ); condition 3: $58 \%$ vs. $28 \%$; condition $4: 56 \%$ vs. $23 \%$ ). ${ }^{10}$

Table 1. (Estimated) Confession Rates (reported in \%)

\begin{tabular}{lccccc}
\hline & \multicolumn{2}{c}{ No Witness } & & \multicolumn{2}{l}{ Witness } \\
\cline { 2 - 3 } \cline { 5 - 6 } \cline { 5 - 6 } & Slow Pace & Fast Pace & & Slow Pace & Fast Pace \\
\hline Original (1996) & 35 & 65 & & 89 & 100 \\
Self & 10 & 21 & & 28 & 23 \\
Others & 44 & 53 & & 58 & 56 \\
\hline
\end{tabular}

\section{Discussion}

Acting against one's own self-interest is counter-intuitive, such as confessing to a crime one has not committed. Yet, documented miscarriages of justice around the world involving false confessions demonstrate that people sometimes act against their own interest. In the last two decades various risk factors have been identified for false confessions - ranging from personal vulnerabilities to coercive police interrogations (Gudjonsson, 2003; Kassin \& Gudjonsson, 2004; Kassin et al., 2010). Even though lay people show an awareness of the occurrence of false confessions, people generally believe that it could not happen to them (Henkel, Coffman, \& Dailey, 2008; Horgan, Russano, Meissner, \& Evans, 2012). The current study sought to determine whether individuals can accurately predict how they and how others behave in a police interrogation and whether the presentation of false evidence affects the behavior (i.e., confession rates). We used the classic ALT key paradigm

\footnotetext{
${ }^{10}$ No significant gender differences were found for self-predictions and others predictions regarding predicted confession rates.
} 
as a basis for our study. Participants were asked to read a description of the experiment and predict how many individuals confessed and whether they themselves would. Within the context of interrogation, we explored whether lay people understand the powerful effect police interrogations can have on innocent suspects as a matter of common sense. Are people able to correctly foresee their behavior and that of innocent suspects in police custody?

Our findings confirmed our hypothesis that a discrepancy exists between predicted behavior and actual behavior. First, our results indicate that people overall are poor at predicting confession rates for themselves (20\% vs. $69 \%$ in the original study). These low confession rates are inconsistent with research findings (e.g., Kassin \& Kiechel, 1996; Horselenberg, Merckelbach, \& Josephs, 2003). Second, in line with previous research (Henkel, Coffman, \& Dailey, 2008; Horgan, Russano, Meissner, \& Evans, 2012), our participants believed that it was more likely that other people would confess (53\%) compared to themselves (20\%). Third, our results demonstrate that individuals clearly neglect the influences of vulnerability and false evidence presentation for others and for themselves, and that the power of such influences is not a matter of common sense. This poses a risk for innocent suspects in police interrogation, supporting Kassin's (2005) phenomenology of innocence claim.

Neglecting the false evidence ploy is especially troubling because police routinely use this tactic to make suspects believe that there is solid proof of their guilt. Not only is deceiving suspects with false evidence (e.g., DNA, fingerprint, eyewitness) legally permissible in the US (Frazier v. Cupp, 1969), it is also recommended by interrogation training manuals (e.g., Inbau, Buckley, Reid, \& Jane, 2001). Documented false confession cases illustrate the danger of the false evidence presentation. Marty Tankleff, for example, was told by police that his dying father had woken up and told them that Marty was the perpetrator. Marty started to distrust his own memory and confessed to murdering his parents. He was wrongly convicted and spent 17 years in prison (Firstman \& Salpeter, 2001).

On the one hand, presenting false evidence to innocent suspects is dangerous because they might start believing in their own guilt, distrusting their own memory (Kassin, 2007; Van Bergen, Horselenberg, Merckelbach, Jelicic, \& Beckers, 2010). On the other hand, research has shown that even if suspects know that they are innocent, they feel trapped by the strength of the evidence and use the confession as a means to get out of the interrogation (Gudjonsson \& Sigurdsson, 1999; Moston, Stephenson \& Williamson, 1992). Our results demonstrate the danger of not being aware of such powerful influences during interrogations. Laypeople underestimate the effect and therefore do not think it could happen to them. The failure to predict the power of the false evidence ploy for others (i.e,. innocent suspects in custody) suggests that jurors are not able to identify false confessions in court easily.

The present findings, along with those of Schell et al. (2014; see Chapter 5), converge on the notion that individuals are bad at predicting their behavior (and that of others) in police custody, making interrogations an even more dangerous 
place for innocent suspects than previously thought. Such naivety leads to innocent suspects feeling 'safe' in police custody. Schell et al. (2014; see Chapter 5) have shown that the right to remain silent - the meant-to-be safeguards - are believed to be used by innocent suspects, while they are not. The current results show that innocent suspects think that they would not confess, while they do. In order to reduce the risk of false confessions, various recommendations have been made as to how improve police procedures, such as better policies regarding suspects' Miran$d a$ rights instructions (e.g., Rogers et al., 2013), avoiding the false evidence ploy technique (e.g., Kassin et al., 2010), and electronically recording all interrogations and confessions (e.g., Gudjonsson \& Pearse, 2011).

However, once a suspect has confessed the consequences are often detrimental since judges and jurors are not able to distinguish accurately between true and false confessions, even if the confession has been recanted (Kassin \& Sukel, 1997; Kassin \& Wrightsman, 1980; Redlich, Ghetti, \& Quas, 2008). To make matters even worse, potential jurors are also poor at discounting false confessions when psychological problems or stressful interrogations played a role (Henkel, 2008). This suggests that judges and juries cannot comprehend the risks and influences on false confessions without assistance of experts. Problematic is that, at least in the US, not all courts agree with this (Perez, 2010). It is up to the trial judge to decide whether expert testimony is necessary (Soree, 2005). The judge is in charge of ensuring the admissibility of the testimony and its helpfulness about the issue at hand. To figure out if the aid of expert testimonies is needed, a judge must decide whether laypersons (i.e., the jury) can understand the subject matter without assistance (Perez, 2010). The US Supreme Court has not ruled about the admissibility of false confession experts (Agar, 1999; Perez, 2012) and therefore courts differ on their opinion about its admissibility (Soree, 2005). Many judges have excluded expert testimonies about false confessions because of the belief that juries had the necessary common knowledge (State v. Davis, 2000), that allowing such experts opinion in court "invades the province of the jury" (State v. Cobb, 2002), and that jurors are able to comprehend whether a police interrogations lead to a false confession (State v. Ritt, 1999). However, we argue for the admissibility of false confession experts as our results, and those of others (Chojnacki et al., 2008; Schell et al., 2014; see Chapter 5) have shown that false confession issues are beyond the knowledge of the average citizen.

Our study has certain limitations. First, we used a behavioral paradigm (Kassin \& Kiechel, 1996) that was conducted 18 years ago in the United States, while we collected the data recently (2011) at a large Dutch research university. However, this paradigm has been replicated many times over the last decade in various countries (e.g., Horselenberg, Merckelbach, \& Josephs, 2003; Horselenberg et al., 2006; Klaver, 2008; Perillo \& Kassin, 2011) proving its robust effect. Therefore, we believe that it was acceptable to use the description of this paradigm and compare our predicted results to the findings of the original study. Second, our shortcomings go hand in hand with the ones of the original study - we did not present a description 
of an actual crime to participants and asked them about their confession rates, but we presented a paradigm that only includes factually innocent participants and is not based on an intentional act (which would be closer to a 'real' crime). One could argue that a close comparison makes only sense with a thought experiment versus an actual crime and interrogation situations, since actual crimes involve various aspects and their influences cannot be controlled. Third, we used young and intelligent undergraduate students, so our results might not be able to be generalized to the population of suspects. However, it could be claimed that lesser educated people will be even worse at predicting confession rates and the influences of false evidence.

The current study represents a necessary step toward empirically supporting the argument that false confession issues are not a matter of common sense knowledge and judges and juries can benefit greatly from expert testimony on false confessions. Although actual behavior in police interrogations may differ and further research is warranted, we believe that our findings help to understand innocent suspects' beliefs better. We encourage other researchers to further examine common sense knowledge of the average citizen to shed light on the 'forces' that lead people to act against their own self-interest in police custody. 



\section{CHAPTER 7}

\section{"Yes, I Have Sometimes Stolen Bikes": Blindness for Norm-Violating Behaviors and Implications for Suspect Interrogations}

This chapter is an adapted version of the following article:

Sauerland, M., Schell, J. M., Collaris, J., Reimer, N. K., Schneider, M., \& Merckelbach, H. (2013). "Yes, I have sometimes stolen bikes": Blindness for norm-violating behaviors and implications for suspect interrogations. Behavioral Sciences and the Law, 31, 239-255. 


\begin{abstract}
Across two experiments, we studied a phenomenon akin to choice blindness in the context of participants' accounts of their own history of norm-violating behaviors. In experiment $1, N=67$ participants filled in an 18-item Questionnaire about their History of Norm-Violating Behaviors (QHNVB). Subsequently, they were questioned about four of their answers, two of which had covertly been manipulated by the experimenter. Of the 134 manipulations, 20 (14.9\%) remained undetected concurrently and 13 were accepted in retrospect (9.7\%). In experiment $2(N=37)$, we inserted a 1-week interval between questionnaire and interview. Twenty-seven $(36.5 \%)$ of the 74 manipulations remained undetected concurrently and 3 were accepted in retrospect (8.1\%). Data obtained in a 4-week follow-up indicated that our manipulations may have long-term effects on participants' perception of their own history of norm-violating behaviors. Implications for the occurrence of false confessions during the course of an interrogation are discussed.
\end{abstract}




\section{Introduction}

Our lives are full of decisions and most of the time we feel that we are aware of our preferences, choices, and intentions. Recent experimental research on a phenomenon called choice blindness (Hall, Johansson, Tärning, Sikström, \& Deutgen, 2010; Johansson, Hall, \& Sikström, 2008; Johansson, Hall, Sikström, \& Olsson, 2005) challenges this view. For example, in one typical choice blindness experiment (Johansson et al., 2005), participants were presented with two stimuli (e.g., female faces) and had to decide which one they found more attractive. After making a decision, participants were handed the chosen face and indicated why they had made this decision. In some trials, however, the participant's choice was manipulated with the help of a card trick. As a consequence, participants ended up with the face they did not choose. Surprisingly, only $13 \%$ of the manipulated trials were detected at the time of the manipulation (concurrent detection), while $87 \%$ of the participants were choice blind (i.e., accepted the manipulated item as their own choice).

Interestingly, some participants based their motivation statement on facial features that were absent from the (manipulated) face they held in their hand (e.g., "she had a nice smile" while the person on the photo was not smiling). Likewise, some participants gave reasons that could only refer to the non-chosen face (e.g., refer to a smile when only the non-chosen photo displayed a smile). What is more, the majority of participants who failed to detect the manipulations (84\%) expressed the belief that they would be able to do so during a post-test interview. This metacognition phenomenon was dubbed choice blindness blindness (Johansson et al., 2005).

Merckelbach, Jelicic, and Pieters (2011b, experiment 2) used a paradigm akin to the choice blindness paradigm to test participants' blindness for their own psychological symptoms. Specifically, participants were asked to fill in the Symptom Checklist-90 (SCL-90; Derogatis, Lipman, \& Covi, 1973), which measures a wide range of psychological symptoms on a five-point Likert scale. During a short break, the experimenter discreetly increased two of the answers given by two full scale points. Next participants were asked to explain their answers to the two manipulated target items as well as to the eight control items. The results showed that $57 \%$ of the participants were blind to both manipulations (75\% for target item 1, 68\% for target item 2). Contrary to baseline testing, blind participants showed a tendency to score higher on the target items, compared to control items, when filling in a short 30-item version of the SCL-90 at a later time. This suggests long-term effects of the conducted manipulations.

Merckelbach, Jelicic, and Pieters (2011a) replicated these findings with 74\% of the participants being blind to both manipulations. In this study, follow-up scores were obtained twice, once about 10 minutes after baseline testing and then again after a week. Parallel to the earlier study, the target item scores were higher in blind participants than control item scores at follow-up testing while there was no such difference at baseline testing. There were no such differences for non-blind 
participants at any of the three testing times. Both studies (Merckelbach et al., $2011 \mathrm{a}, 2011 \mathrm{~b}$ ) lend support to the hypothesis that symptom manipulations can have long-term effects on participants' symptom strength perception. Interestingly, blind participants scored higher on target and control items from the very beginning, indicating that a non-zero symptom level introduces a degree of ambiguity that increases the likelihood of being blind for manipulations.

Indeed, recent research transferring the choice blindness paradigm to eyewitness identifications supports the idea that ambiguity plays an important role for blindness phenomena. Specifically, Sagana, Sauerland, and Merckelbach's (2013) participants watched four mock crime videos and then identified the actors (four per video) from individual target present lineups. Following their forced-choice identification decision, participants were presented with their selection and gave reasons for their decision. Two of the 16 identifications were manipulated, with participants ending up with a non-chosen lineup member. As expected and in line with the ambiguity notion, retrospective detection was high (94-100\%) when no time interval was inserted between making the identification decision and being confronted with the manipulated outcome (experiments 1a, 1b, 2). However, retrospective detection deflated to $61 \%$ when a 48 hrs interval was introduced (experiment 4). So it seems that when memory becomes fuzzier and therefore the situation more ambiguous, participants are more likely to be blind to manipulations. Importantly, this study also provided additional evidence for the long-term effects of the manipulations: specifically, identification accuracy was decreased for manipulated but not non-manipulated lineups three to five months after the initial test.

Taken together these studies (Merckelbach et al., 2011a, 2011b; Sagana et al., 2013) help to understand the scope of choice blindness phenomena. First, they demonstrate that choice blindness is not limited to preferences (Hall et al., 2010; Johansson et al. 2005), but can also occur for intensity and frequency ratings as well as objective decisions. Accordingly, these studies provide evidence that (choice) blindness is a phenomenon that also applies to evaluations that rely on long-term episodic memory. Second, the results of the follow-ups (Merckelbach et al., 2011a; Sagana et al., 2013) suggest that manipulations may not only go unnoticed during an interview, but may actually have long-term effects on participants: some participants seem to internalize the new answer, as indicated by their symptom escalation and wrongful identification decisions on a later test.

Internalization of false statements induced by misinformation is not only typical for choice blindness in the context of symptom or lineup evaluations. It is also a key feature of interrogation situations (Kassin \& Gudjonsson, 2004). With this in mind, we wanted to link the choice blindness phenomenon to the false confessions literature. Confessions are one of the most potent forms of evidence in criminal law (Kassin \& Neumann, 1997). False confessions have often been found to be a result of coercive and deceptive interrogation methods (e.g., Kassin, 2005). While presenting false evidence to a suspect is unlawful in most European countries, a 1969 ruling of the US Supreme Court (Frazier v. Cupp, 1969) explicitly allowed the presenta- 
tion of misleading evidence in police interrogations. Deceptive tactics have since then been an important part of the widely-taught, controversial Reid technique for criminal interrogations (Inbau, Reid, Buckley, \& Jayne, 2001). However, misleading suspects by confronting them with false evidence during an interrogation has been proven to be one of the causes of false confessions (Kassin, Drizin, Grisso, Gudjonsson, Lea, \& Redlich, 2010).

To test the effect of false incriminating evidence experimentally, Kassin and Kiechel (1996) introduced the so-called computer-crash paradigm. Allegedly as a test of reaction time, participants were instructed to type letters on a computer keyboard that were read aloud by a confederate. Participants were warned not to press the ALT key, because this would cause a computer crash and data loss. One minute into the task, the computer automatically crashed. In the ensuing interrogation, the experimenter falsely accused the participant of having caused the crash by pressing the ALT key. Overall, 69\% of the 75 participants signed a confessions form. When introducing the confederate's false witness statement as evidence, the rate of confessions was significantly higher than when no false evidence was presented (range $89-100 \%$ vs. $35-65 \%$ in the no witness conditions). Judging from participants' private statements towards another confederate, $55 \%$ of the participants who were confronted with false evidence actually internalized their confessions, compared to $6 \%$ in the group without false witness evidence. The memory corrupting effect of false evidence has also been observed in other studies (e.g., Horselenberg, Merckelbach, \& Josephs, 2003; van Bergen, Jelicic \& Merckelbach, 2008) and some authors have argued that it is primarily carried by false evidence promoting a state of memory distrust in which people become more willing to confess to things that they did not do (Van Bergen, Horselenberg, Merckelbach, Jelicic, \& Beckers, 2010).

Obviously, false confessions are by no means always caused by internalization and memory corruption. Research suggests that another mechanism that can lead innocent suspects to confess because of false evidence is the feeling of being trapped by the weight of the (false) evidence provided during the interrogation. In such cases suspects may perceive a confession as the only way out of the situation (Gudjonsson \& Sigurdsson, 1999; Moston, Stephenson, \& Williamson, 1992; Perillo \& Kassin, 2011). Both mechanisms can play a role in choice blindness phenomena. Consider an interrogation situation in which an interrogator - intentionally or unintentionally - keeps record of answers different from those given by the suspect. Confronted with those changes in a later interrogation, the suspect might accept these (false) answers, either as a result of internalization and memory corruption or due to a feeling of being trapped.

In the current studies, we wanted to apply the choice blindness paradigm to an interviewing situation. Specifically we explored whether people would admit to norm-violating behaviors as a result of misinformation given about their own previous accounts. To this end, we adopted a research paradigm akin to the choice blindness paradigm and to the symptom misinformation procedure employed by 
Merckelbach et al. (2011a, 2011b). Specifically, we questioned participants about their own accounts of the frequency of certain norm-violating behaviors in their personal history after we had covertly inflated or deflated their previous answers. Given the evidence on choice blindness (Hall et al., 2010, Johansson et al., 2005), blindness concerning one's own psychological symptoms (Merckelbach et al., 2011a, 2011b), and one's eyewitness identification decisions (Sagana et al., 2013), we expected to find a significant proportion of our participants to be blind to our manipulations. Analogous to Sagana et al. (2013), we tested the effect of ambiguity by varying the retention interval between filling in the questionnaire and being interviewed about them. In experiment 1, participants were questioned within minutes after giving their answers; in experiment 2, a 1-week interval was inserted. Accordingly, we expected higher rates of choice blindness with the longer retention interval. Additionally, experiment 2 included a four weeks follow-up to test for long-term effects of the manipulations. We expected that blind participants would tend to adopt the misinformation during follow-up sessions.

\section{Experiment 1}

\section{Methods}

\section{Participants}

A total of $N=67$ participants ( 12 men, 55 women; $M_{\text {age }}=20.7$ years, $S D_{\text {age }}=2.8$, age range: 18 -38 years) took part in the experiment. All participants were undergraduates at Maastricht University, most of them (96\%) at the Faculty of Psychology and Neuroscience. Participants received course credits or a small financial reimbursement for their participation.

\section{Design}

Severity of norm-violating behaviors (low vs. moderate vs. high) was manipulated as a between-subjects variable, while the status of the items (manipulated target items vs. non-manipulated control items) was a within-subjects variable.

The detection rate of the manipulated items was the dependent variable. Two different measures of detection were used, namely concurrent and retrospective. The concurrent detection rate includes all participants who noticed the manipulation immediately after it had taken place. Retrospective detection additionally includes all those participants who reported that they had noticed the change of the item ratings in the post-test questionnaire. 
Materials

Questionnaire about History of Norm-Violating Behaviors (QHNVB). This Dutch questionnaire consisted of 18 items concerning norm-violating behaviors. Nine items were taken from Jelicic, Merckelbach, Timmermans, and Candel (2004) to which we added nine more. In a pilot study, $N=15$ psychology students ( 8 women, age 18-25) rated the severity of the 18 behaviors on a five-point Likert scale (range 1 to 5). Based on the results, we created three conditions in which (1) two less severe (items 6 and 12), (2) two moderately severe (items 7 and 13), or (3) two highly severe (items 8 and 14) behaviors were manipulated. The severity scores of these behaviors can be found in Table 1. The means of each severity level differed significantly from the means of the two other severity levels, all $F_{S}(1,14) \geq$ 10.42 , $p s \leq .006$.

Table 1. Severity scores of the manipulated items on the Questionnaire about History of Norm-Violating Behaviors

\begin{tabular}{llll}
\hline Item & & $M$ & $S D$ \\
\hline 6 & Cheat in high-school exam & 2.2 & 1.15 \\
12 & Keep silent about too much change & 2.4 & 1.30 \\
7 & Use public transport without ticket & 3.3 & 1.16 \\
13 & Park on disabled parking & 3.5 & 0.99 \\
8 & Shop lifting & 4.5 & 0.52 \\
14 & Bike theft & 4.4 & 0.64 \\
\hline
\end{tabular}

Note: Items 6 and 12, 7 and 13, or 8 and 14 were manipulated together

We used two different versions of the QHNVB. In version 1, participants $(n=24)$ had to answer whether or not they had ever engaged in the behavior described by the item (yes-no format). The answers to the manipulated items were hence changed from yes to no or from no to yes, depending on the answers given by the participant. In version 2 , participants $(n=43)$ indicated whether they had displayed the behavior never, seldom, sometimes, or often (4-point format, coded 0-3). Here, the target items were increased by 2 scale points (i.e., from never to sometimes and from seldom to often). In those instances in which participants had scored the critical items with sometimes or often, the manipulation consisted of decreasing the items by 2 full scale points (i.e., they were recoded as never or seldom, respectively).

The answer format had no impact on either concurrent or retrospective detection for both manipulated items, $\chi^{2}(1, N=67) \leq 3.68, p s \geq .081$, $\mid$ phi|s $\leq .23$ (Fisher's exact test due to expected counts $<5$ ). We will therefore not discuss this responseformat manipulation any further. 
Marlowe-Crowne Social Desirability Scale (MCSDS). The MCSDS (Crowne \& Marlowe, 1960) is a 33-item true/false self-report inventory that aims at assessing an individual's need for approval. Examples of items are: "I like to gossip at times" or "I never resent being asked a favor". In the current study, we administered the MCSDS to examine whether blindness to manipulations is associated with the tendency to act according to social demands, meaning that people might fail to report that they did notice the change in manipulated items due to their need for approval from the experimenter.

Gudjonsson Compliance Scale (GCS). The GCS (Gudjonsson, 1989) is a selfreport inventory consisting of 20 true/false statements such as: "People with a lot of authority make me feel uncomfortable" or "I try to please others". It is used to measure the tendency of people to conform to other people's requests. The instrument was included to control for the possibility that participants were not blind to the manipulations, but rather complied with the presumed expectations of the experimenters. The same holds for the GSS.

Gudjonsson Suggestibility Scale (GSS). We used the Dutch research version (Merckelbach, Muris, Wessel, \& van Koppen, 1998) of the GSS (Gudjonsson, 1984, 1997). It consists of 20 questions concerning a short story that was previously read to the participants, of which 15 are suggestive. After answering all questions, participants are given negative feedback on their performance and all questions are repeated once again. Yield1 and yield2 scores indicate the number of suggestive items to which a participant agreed during the first and second round of questions, respectively. The shift score indicates how many answers were changed between the two questioning rounds. Finally, the total score consists of the sum of the yield1 and shift score.

Abbreviated Big Five Questionnaire. This questionnaire consists of 15-items (Furnham, McManus, \& Scott, 2003) that were drawn from the original sixty-item version (NEO-FFI; McCrae \& Costa, 1997). It provides measures of Neuroticism, Extraversion, Openness, Agreeableness, and Conscientiousness that are measured by three items each. We included this test to explore how personality traits relate to blindness for our manipulations.

Post-test questionnaire. The post-test questionnaire was adjusted from Johansson et al. (2008). Specifically, participants were first asked whether they had noticed anything strange during the experiment, then whether they had noticed anything odd with the answers to the QHNVB. If participants had noticed something strange, they were asked to explain. Explanations indicating that the manipulations had been detected were counted as retrospective detection. If, however, no signs of detection were revealed, participants were told that we planned a follow-up study in which the answers would sometimes be manipulated and were asked if they would notice such a change. The answer to this question is referred to as the degree of blindness for one's blindness in the results section. Finally, participants were explicitly asked if they had noticed such a manipulation in the current experiment. If this question was answered with yes, this was also coded as retrospective detection. 


\section{Procedure}

Participants signed the informed consent form and were then asked to fill in the QHNVB. Next, they were given two Sudoku puzzles to solve. In the meantime, the experimenter manipulated 2 of the given answers as described in the QHNVB section above. When the experimenter came back to the lab after about $10 \mathrm{~min}$, he asked the participant questions about the two manipulated items and about two non-manipulated control items. Here is an example of questions asked: "You answered that you have often cheated on a high school test. Could you elaborate on that? Why did you do that?" Subsequently the experimenter would ask: "Why do you think other people would cheat on a high school test?" Depending on the participant's answer, follow-up questions were asked to be certain about whether or not the manipulation had been discovered. All in all, participants were asked about 3-4 questions per item. The non-manipulated items were items 1 and 10. The order of questioning was always control item 1, first manipulated item (item 6, 7 or 8), control item 10, and second manipulated item (item 12, 13, or 14).

Hereafter, participants worked on part 1 of the GSS $(n=48)$ or filled in the abbreviated Big Five questionnaire $(n=19)$. The MCSDS and the GCS followed for all participants. Those participants who had the GSS administered then worked on the second part of the GSS. Finally, participants filled in the post-experimental questionnaire.

\section{Results and Discussion}

An alpha level of .05 was used for all inferential analyses. For comparisons of means, we report $d$ as a measure of effect size. For nonparametric analyses of $2 \times 2$ contingency tables we report phi; for $3 \times 2$ contingency tables we report Cramer's $V$.

\section{Blindness for Manipulations}

The first manipulation was concurrently detected by $82.1 \%(n=55)$ of the participants, the second manipulation by $88.1 \%(n=59)$ of the participants. Three participants did not detect any of the two manipulations concurrently. In total, of the 2 * $67=134$ manipulations, $114(85.1 \%)$ were detected. Note that $92(68.7 \%)$ of the manipulations involved inflations (i.e., upscaling) of the initial answers given and $42(31.3 \%)$ involved deflations (downscaling). This did not have an impact on concurrent or retrospective detection rates, $p \mathrm{~s} \geq .43$, phis $\leq .12$.

One may argue that the reported detection rates are inflated since participants become suspicious after the first detection is made (Johansson et al., 2005). To avoid such cascading detection effects, we discarded all second manipulation items when the first one had been detected. With this method, 64 out of 79 manipulations were detected (81.1\%). This distribution differed significantly from the expected, 
Cochran's $Q$ (1) $=23.05, p<.001$. Accordingly, we ran all analyses for these 79 trials as well as with the full 134 trials. The results for the 79 trials generally paralleled the results of the 134 trials. We will therefore report the results for the full 134 trials.

Retrospective detection for the first manipulated item was $89.6 \%(n=60)$ and 91.0\% $(n=61)$ for the second manipulated item. Only one participant detected neither manipulation retrospectively, 12 detected one and 54 detected both manipulations.

To explore whether severity of the manipulated items had any effect on detection rates, we computed four Chi-square tests with severity (low, moderate, high) as independent variable and concurrent and retrospective detection as dependent variables. Due to some expected cell counts being less than 5, we computed Fisher's exact tests. No significant effects were found, all $p s \geq .24$, Cramer's Vs $\leq .14$.

Following Merckelbach et al. (2011a, 2011b), we established whether blind participants had higher initial scores on the QHNVB for the 4-point version of the QHNVB. (No such analyses were run for the yes-no version due to the small number of detections within that sample and the resulting lack of power.) No significant effects were found for concurrent or retrospective detection of the first manipulated item, $|t| s(41) \leq 0.52, p s \geq .61,|d| s \leq 0.21$. Contrary to our expectations, the mean baseline items rating for detectors was (non-significantly) higher $(M=1.1, S D=$ $0.94)$ than that of non-detectors $(M=0.9, S D=0.64)$. For retrospective detection, the mean baseline items rating for detectors was (non-significantly) smaller ( $M=$ $1.0, S D=0.93)$ than that of non-detectors $(M=1.2, S D=0.45)$, as expected. Participants who were concurrently or retrospectively blind to the second manipulation, however, did score significantly higher $(M s=1.0, S D s=0.71)$ than non-blind persons on the QHNVB $(M s=0.3, S D s=0.61), t s(41)=2.40, p s=.021, d s=0.90$. These results lend some support to Merckelbach et al.'s (2011a, 2011b) hypothesis that a non-zero answer level introduces a degree of ambiguity that increases the likelihood of being blind. This finding is particularly worrying when translating it to the context of interrogations and the risk of false confessions. It suggests that suspects who already have a criminal record are ultimately more likely to falsely confess than those who do not. An interesting topic for future research would be whether partial acceptance makes people more prone to accept other false information offered during the course of an interrogation.

\section{Blindness for One's Blindness}

Of the participants who did not concurrently detect the first manipulation $(n=12)$, 91.7\% thought they would be able to do so (retrospective detection: $85.7 \%, n=7$ ). Of the participants who did not concurrently detect the second manipulation (n = 8), $62.5 \%$ thought they would be able to do so (retrospective detection: $50 \%, n=6$ ). 
Compliance, Suggestibility and Social Desirability Measures, and Abbreviated Big Five Questionnaire

Although $t$ tests are most suited to test for individual differences, we reverted to correlational analyses due to the small number of blind participants. Concurrent and retrospective blindness (scored as 0 , 1, or 2 detections) were not significantly associated with social desirability, compliance, or the GSS yield, GSS shift, and GSS total score, $|r| \mathrm{s} \leq .17, p \mathrm{~s} \geq .247$. These results contradict the idea that blindness for manipulations of one's own responses can be attributed to social demands, compliance, or suggestibility. This is in agreement with earlier studies that did not find an association between blindness and social desirability (Merckelbach et al., 2011a) as well as compliance (Sauerland, Sagana, \& Otgaar, 2013). To our knowledge, this is the first study to show that blindness is not associated with suggestibility.

To explore the possible link between blindness and personality traits, some participants $(n=19)$ filled in the Abbreviated Big Five Questionnaire. No significant correlations between blindness and four of the five factors were found, $|r| \mathrm{s} \leq .25, p s$ $\geq .31$. There was a significant correlation of Openness for concurrent and retrospective detection, though, $|r| s(17) \geq-.59, p s \leq .01$, indicating that more detection occurred when participants had lower openness scores. This result is somewhat counterintuitive as one would expect that Openness should be associated with higher detection rates, not lower ones. On the other hand, Openness to Experience is a higher order trait involving the lower order trait of fantasy proneness. Previous work has shown that those with elevated fantasy proneness levels also have heightened false confession rates (Horselenberg, Merckelbach, Smeets, Franssens, Peters, \& Zeles, 2006), probably because it is easier for these people to see the plausibility of misinformation.

To summarize, blindness for one's own history of norm-violating behaviors seems to be much weaker than choice blindness for facial attractiveness or other preferential choices (Hall et al., 2010; Johansson et al., 2005, 2008). The base rate of blindness found here was also smaller than reported for psychological symptoms (Merckelbach et al., 2011a, 2011b). One reason for the differences found in blindness between the current and the psychological symptom study could be that perhaps different levels of ambiguity were achieved. For example, in the latter study, participants answered 90 questions, using a five-point scale and were interviewed about ten items, two of which were manipulated. In the current study, participants answered 18 questions, using a two- or four-point scale and were interviewed about four items, again, two of which were manipulated. Thus the difference between the given and the manipulated answer were slightly less extreme in the psychological symptom study. Further, the proportion of manipulated items, in proportion to the total number questions and also in proportion to the number of items that were discussed during the interview was much larger in the current study.

Be that as it may, it cannot be sugarcoated that about $20 \%$ of the manipulations remained undetected concurrently and about $10 \%$ retrospectively. A rate of 10 - 
$20 \%$ of suspects who go along with investigator-introduced manipulations constitutes a serious challenge to the probative value of confessions and raises issues regarding interrogation practice-related policy.

One limitation of experiment 1 is that there were only minutes between filling in the QHNVB and being confronted with one's (manipulated) answers. Therefore, we inserted a one-week interval in experiment 2. This situation has more ecological validity, as a suspect is commonly interrogated repeatedly on different days (Johnson \& Drucker, 2009; Kassin et al., 2007; Wagenaar, 2002). This should also increase ambiguity and thus lead to increased blindness rates in Experiment 2, compared to experiment 1.

Furthermore, we included a follow-up session after four weeks in experiment 2. Specifically, we contacted participants via email four weeks after the experiment had taken place and asked them to fill in the QHNVB once again. This allowed us to draw conclusions about the long term effects of the manipulations. Drawing from Merckelbach et al. (2011a, 2011b) and Sagana et al. (2013), we expected that answers to manipulated items should shift more often between baseline testing and follow-up testing, compared to answers to non-manipulated items.

\section{Experiment 2}

\section{Methods}

\section{Participants}

A total of $N=40$ participants were tested. Three had to be excluded from the analysis, because the experimenter had accidentally manipulated the wrong item $(n=2)$, and because one participant turned out to be underage. The sample thus included $N$ = 37 participants ( 14 men, 23 women; $M_{\text {age }}=21.8$ years, $S D_{\text {age }}=2.1$, age range: 18 26). All participants were undergraduates of University College Maastricht $(n=32)$ or Maastricht University $(n=5)$ and received a candy bar for their participation. Participants were randomly assigned to one of the three conditions (low severity: $n$ =14, moderate severity: $n=11$, high severity: $n=12$ ), with gender being counterbalanced. The study was approved by the standing ethical board of the Faculty of Psychology and Neuroscience, Maastricht University.

\section{Procedure}

The procedure was similar to experiment 1 with the exception that there were two sessions as well as a follow-up session about 4 weeks after the second session. In session 1, participants filled in version 2 (4-point scale) of the QHNVB and the ab- 
breviated Big Five questionnaire. Since the default language at the University College is English and many students at this College do not speak Dutch, we used the English version of the QHNVB. Session 2 was scheduled one week $( \pm 2$ days, $M=$ 167.4 hours) later. Here, participants were interviewed about their answers given to the QHNVB. They also filled in the GCS, the MCSDS, and the post-test questionnaire. Five to six weeks after the experiment had taken place, participants were contacted via email and asked to fill in the QHNVB again.

\section{Results and Discussion}

\section{Blindness for Manipulations}

Of the $2 * 37=74$ manipulations, 47 (63.5\%) were detected. The first manipulation was concurrently detected by $64.9 \%(n=24)$ of the participants, the second manipulation by $62.2 \%(n=23)$ of the participants. As previously reported (Johansson et al., 2005), blind participants could often provide a rationale for their alleged answer (confabulation). Seven participants did not detect any of the two manipulations, of which 3 also failed to detect the mismatch retrospectively. Note that we did not ask participants separately about their retrospective detection of the two manipulated items. Rather, retrospective blindness was scored dichotomously (i.e., blind or non-blind rather than detected 0,1 , or 2 items). Thus, as expected, the concurrent detection rates in experiment 2 (63.5\%) were smaller than those observed in experiment $1(85.1 \%), \chi^{2}(1, N=208)=11.45, p<.001$, Cramer's $V=0.25$. The retrospective blindness rates were almost identical, however (9.7\% vs. 8.1\%). Across all 74 manipulations, 61 (82.4\%) involved upscaling of the initial answer given and 13 (17.6\%) involved downscaling. This did not have an impact on concurrent detection rates, $p \mathrm{~s} \geq .14$, phis $\leq .25$.

As in experiment 1, we tested for possible inflated detection rates due to cascading effects. When discarding second manipulated items when the first one was detected, 30 out of 50 manipulations were detected (60\%). This distribution did not differ significantly from the expected, Cochran's $Q(1)=0.16, p=.69$. It is therefore unproblematic to continue our analyses with the full 74 trials.

It is interesting to look deeper into some of the reactions that came from detectors when they were confronted with the manipulated answers. There were 35 trials $(74.5 \%)$ during which participants did not continue until they had been given the chance to change "their" answer on the questionnaire. In another 7 trials (14.9\%), participants accepted the answer only after they had been shown "their" answer on the questionnaire. Finally, in 5 trials (10.6\%), participants expressed some doubts, but continued. The last two categories are a cause of concern when translated to the context of interrogations. While these participants actually detected the manipulation (and were accordingly coded as detectors), they nevertheless 
accepted it. This behavior can be seen as analogous to a compliant confession in the context of an interrogation. We will return to this point in the general discussion.

To explore whether the severity of the manipulated items plays a role in blindness, we computed two $2 \times 3$ Chi-square tests with severity (low, moderate, high) as independent variable and concurrent detection as dependent variable. No analyses were run for retrospective detection because of the small number of participants who failed to detect the change retrospectively. Due to some expected cell counts being less than 5, we computed Fisher's exact test. No significant effect was found for the first manipulated item, $\chi^{2}(2, N=37)=2.65 p=.27$, Cramer's $V=0.27$. There was, however, a significant effect for the second manipulated item, $\chi^{2}(2, N=37)=$ $6.58 p=.03$, Cramer's $V=0.43$. Post-hoc $2 \times 2$ Chi-square tests showed that there was a significant difference in the number of detections when comparing the most severe and the least severe norm-violations, $\chi^{2}(1, N=26)=6.0 p=.02$, phi $=0.48$. For more severe norm-violations there were only 2 out of 12 blind participants (16.8\%), for the least severe norm-violations it were 9 out of 14 participants $(64.3 \%)$. None of the other comparisons reached significance, $p s \geq .11$.

The difference in detections as a function of severity for the second, but not the first manipulated item could have to do with the very items we used. For example, there might have been less ambiguity for the second manipulated item, compared to the first one. Inspection of the data shows that the baseline scores of manipulated item 2 were smaller on average $(M=1.5, S D=0.73)$ than those of manipulated item $1(M=2.1, S D=0.78), t(36)=3.07, p<0.01, d=0.50$. As mentioned before, it seems straightforward that potential for misleading information is greater with behavior that has a relatively high prevalence rate, compared with a relatively low prevalence rate (Merckelbach et al., 2011a, 2011b). It speaks in favor of this interpretation that participants who were blind to the second manipulation had initially scored higher $(M=1.9, S D=0.66)$ than non-blind persons $(M=1.4, S D=0.71), t(35)$ $=2.16, p=.04, d=0.61$ ). No such difference was found for the first manipulated item, $t(35)=-1.68, p=.10, d=-0.51$. This is consistent with experiment 1 and provides further support to Merckelbach et al.'s (2011a, 2011b) hypothesis that a nonzero level increases the likelihood of being blind. Furthermore, this reinforces our concern raised above regarding the use of deceptive information by investigators in the course of an interrogation.

\section{Blindness for One's Blindness}

Of the participants who did not concurrently detect the first manipulation $(n=13)$, $38.5 \%$ thought they would be able to do so. For the second manipulation $(n=14)$, $50.0 \%$ gave this answer. For retrospective detection, 1 out of the 3 blind participants $(33.3 \%)$ thought $\mathrm{s} /$ he would be able to detect the manipulation. As in experiment 1, blindness for one's own blindness was found. The effect was, however, smaller. This could be expected, since participants were probably more aware of 
their own proneness to be blind to changes due to the inserted interval of one week.

\section{Follow-up Testing}

One could argue that non-detection does not reflect blindness, but simply poor memory. That is, participants can simply not remember what answers they gave. While it is unlikely that participants would forget whether or not they have, for example, stolen a bike, some participants may have decided to embellish their answers on the QHNVB. Those participants may later have had problems with remembering to which level of embellishment they had decided. If this was the case, one would expect shifts in the given answers from the initial testing to the followup testing for both, manipulated and non-manipulated items.

Fourteen (37.8\%) participants responded to our follow-up email. We inspected their responses to the two non-manipulated (control) items participants had been interviewed about (items 1 and 10) as well as to the two manipulated items. The results are displayed in Figure 1. We found no shifts, that is, deviations from the initial score, in the responses to items 1 and 10 . Five shifts out of 28 possible ones (17.9\%) did, however, take place for the two manipulated items ( 1 referring to the first manipulation, 4 to the second one). These shifts referred to two upwards as well as two downwards manipulations and, surprisingly, one of the shifts did not concur with the direction of the manipulation. Note that none of these five shifting participants were retrospectively blind for the manipulation. Three had been blind concurrently, whereas two had detected the manipulation on the item that they had now shifted on.

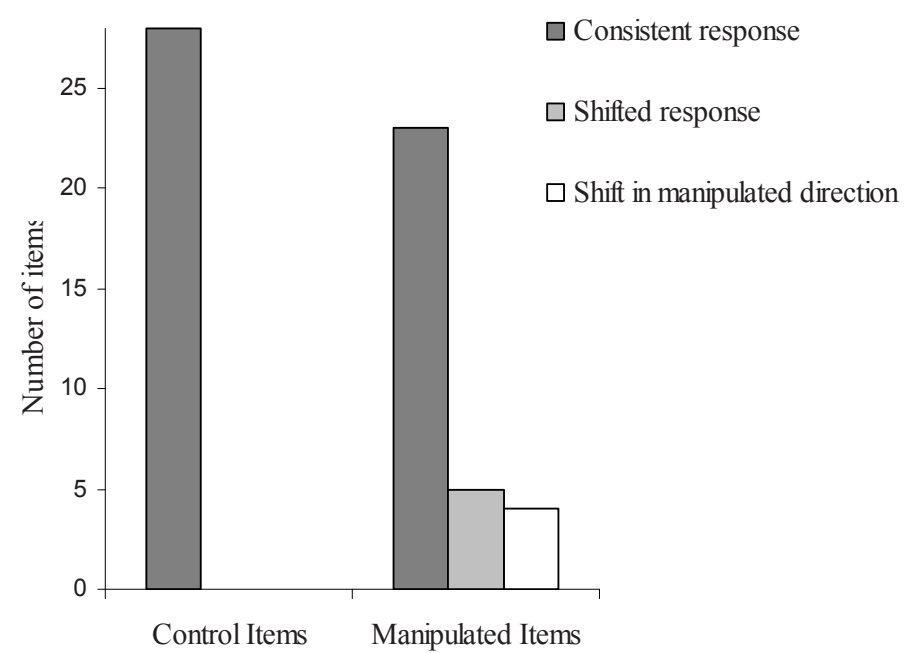

Figure 1. Number of answer shifts occurring for two manipulated and two control items after a four week follow-up $(\mathrm{N}=14)$. 
These results speak against the interpretation that the blindness for manipulations that we observed is merely a memory problem. Rather, participants seem to be quite reliable in their statement regarding their history of norm-violating behaviors, as long as their answers are not manipulated. If their responses are manipulated, however, these manipulations can have long-term effects on participants' statements regarding the frequency of them having been involved in certain normviolating behaviors. Importantly, this is regardless of whether or not participants retrospectively detected the manipulations. We are aware of the fact that we are looking at a small sample here. Nevertheless, we believe that the results give some interesting insights.

\section{Compliance, Social Desirability and Abbreviated Big Five Questionnaire}

Parallel to experiment 1 , concurrent blindness (scored as 0,1 , or 2 detections) neither correlated significantly with social desirability, nor with compliance, $r s \leq|.30|$, $p s \geq .071$. When treating participants who detected only one manipulation as nondetectors, $t$ test revealed a marginally significant effect for compliance, $t(35)=-$ $1.85, p=.05, d=-0.67$. The effect was contrary to the expectations, though, with blind participants being less compliant $(M=8.2, S D=3.08)$ than non-blind participants $(M=10.0, S D=2.37)$. Furthermore, there was a significant effect for social desirability, $t(34)=2.35, p=.03, d=0.79$. As one would expect, social desirability scores were higher for blind participants $(M=17.4, S D=4.79)$, compared to nonblind ones $(M=13.6, S D=4.66)$.

We found, no correlations between concurrent blindness and the five personality factors, $r s \leq|.20|, p s \geq .225$. Analogously, no significant effects revealed when analyzing the data with $t$ tests. Thus, personality traits as measured by the Abbreviated Big Five Questionnaire do not seem to be a relevant factor when it comes to blindness. With regards to Openness, this result contradicts experiment 1.

\section{General Discussion}

In two experiments, we tested the hypothesis that a phenomenon akin to choice blindness can occur in the context of people's accounts of their own history of norm-violating behaviors. To that end, participants indicated how frequently they had been involved in certain norm-violating behaviors in the past. As expected, a substantial proportion of participants was blind for manipulated increases or decreases of their own statements. The current studies thus demonstrate that choice blindness phenomena are relevant not only with regards to medical practitioners or lineup administrators, but also for interrogators. The degree of concurrent blindness varied as a function of the time interval inserted between filling in the questionnaire and being interviewed about it. As expected, a longer time interval resulted in reduced concurrent detection, whereas the degree of retrospective de- 
tection did not. Essentially, participants should still remember how often they involved in certain norm-violating behaviors, regardless of how long ago they made statements about this. The longer time interval, however, seems to have introduced a level of ambiguity about the answers, leading to a higher threshold to query about answers presented by the experimenter. Once participants were apprised of the fact that some answers had been manipulated, however, they felt free to express their doubts. This is, to some extent, good news: while concurrent detection referring to norm-violating behaviors seems to be prone to factors that introduce ambiguity, retrospective detection seems to be relatively constant, at least across our two experiments.

The results of our follow-up test invalidate the hypothesis that participants can simply not remember their answers. Rather, retest-consistency was found to be $100 \%$ for non-manipulated items, whereas some participants shifted their answers for manipulated items in a follow-up about a month after the initial testing. This speaks for long-term effects of misinformation manipulations on statements as obtained in the current study and should be of concern for legislations in which deception during interrogations is common practice.

Our results have important implications for the treatment of official statement records. These documents play a crucial role in legal proceedings. The implicit assumption is that these records reflect the account of the suspect, eyewitness, or victim in a correct way. In many jurisdictions, the persons concerned are given the opportunity to re-read their accounts after making a statement and authors have argued that this is beneficial as it increases statement consistency (e.g., Magner, Markham, \& Barnett, 1996). However, the upshot from the current findings is that suspects or eyewitnesses may be blind at a low, but non-trivial rate when confronted with legal documents that contain elements that they did not introduce themselves.

Two of our findings could raise doubts about the relevance of our findings for the field of false confessions: the relatively small proportion of retrospective blindness and the finding that blindness can vary as a function of the severity of the manipulated behavior. Both can be rebutted, we believe. First, although blindness in the interrogation room may be a rare phenomenon, it might concern a large number of cases in absolute numbers since thousands of suspects and eyewitnesses are interviewed each year. Furthermore, inspection of a mock jury study (Kassin \& Sukel, 1997, experiment 2) leads to the conclusion that after-the-fact corrections (i.e., detecting in retrospect, but no concurrently) matter little in criminal proceedings. In Kassin and Sukel's study, mock jurors' verdict was more often in favor of the prosecution (i.e., "guilty") when a confession was presented, compared to a control condition where no confession was presented. This was the case even though mock jurors accepted the confession as involuntary and explicitly denied any influence on their verdict. Hence, even if defendants' incriminating statements are retracted and dismissed on the basis that they were caused by police misinformation, the influence of such dismissal on the jury might be negligible. This holds 
especially in legal systems in which the presentation of false evidence is considered legitimate (e.g., the United States).

Turning to the second point, one may assume that more severe (rather than less severe) behaviors are frequently the subject of confession-related false convictions. However, interrogations are a process in which law enforcement agents try to either obtain an explicit confession or extract incriminating statements. Statements of the latter kind, for example about the defendant having been at the crime scene, do not directly refer to the crime itself but can, nevertheless, serve as potent evidence against an innocent defendant in court. These, presumably less severe statements can be conceived as similar to less severe norm-violations. Confabulations or lack of explicit reaction (as found in experiment 2) following deliberate misinformation by the police might be interpreted as silent admission of guilt or as contradictive, increasing law enforcement agents' suspicion. Hence, the effect of the severity of allegations on detection does not necessarily negate the importance of the phenomenon for false convictions. Also note that the effect of severity was found for experiment 2 only. Further research will have to find ways to test whether indirectly incriminating statements such as the one described above are subject to choice blindness.

We believe that the current results have research and policy related implications. Future studies should particularly focus on three aspects of false confession related blindness: the first revolves around the question at which level of severity manipulated statements fall short of being noticed, while they still have the potential to serve as incriminating evidence. Second, it would be interesting to investigate whether participants show blindness not only with regard to norm-violating behaviors, but also to alibi-related statements. Research could thus not only investigate prevalence statements, but also statements related to the details of certain locations and times. Third, case studies that illustrate blindness phenomena during real-life interrogations could inform the field.

Looking at the practice of law enforcement, our findings corroborate several warnings that have been issued by other scholars in the field of law and psychology (Kassin, 2008b; Kassin \& Kiechel, 1996). Investigators should beware of deceiving the suspect and confronting him or her with misinformed statements. As demonstrated, innocent suspects can easily fail to detect the misinformation, and stay blind to the mismatch between their original and their new, induced testimony. Investigators should especially refrain from this practice in overly long interrogations (Kassin et al., 2010). As demonstrated, participants are especially prone to deceptions if time introduces ambiguity about what has been said. This issue becomes even more relevant when taking into account that persons with a criminal record are more likely to become suspects, given that their photos more frequently appear in mug shots. The current results have demonstrated that the presence of non-zero level is among the factors that increase people's proneness to blindness. Likewise, our findings reemphasize the need of camera recording during the interrogation, making it possible to discern original testimony from investigator-induced statements (Kassin et al., 2010). We would therefore like to reinforce the call for abolishing the use of willful manipulations in police interrogations to reduce the occurrence of false confessions (Horselenberg et al., 2003; Kassin, 2008b; Kassin \& Kiechel, 1996). 
CHAPTER 8

General Discussion 
CHAPTER 8 


\section{Aims of the Present Dissertation}

An alarming number of false confession cases have appeared around the world. This dissertation aimed at enhancing our knowledge about why innocent suspects in police custody would falsely admit to crimes. Research findings from the last two decades suggest that innocence itself puts innocent suspects at risk of wrongly making self-incriminating statements. The studies described in this dissertation were focused on three issues: 1) to explore common sense beliefs and common police practices about confession related issues; 2) to study whether possible common misbeliefs put innocent suspects at risk; and 3) to examine the relationship between people's beliefs and their behavior in police custody. Furthermore, we investigated the link between choice blindness and false confessions as an avenue for future research directions.

The overall structure of this thesis took the form of eight chapters. The first chapter introduced the case of Ulvi Kulac. Chapter 2 provided a theoretical background and review about the current state of literature about false confession related issues - such as research findings, risk factors, implications, and recommendations. While analyzing false confession literature a general lack of research regarding lay people's common sense beliefs of confession issues was revealed. To reduce the gap, Chapter 3 was concerned with a survey across seven countries about lay people's beliefs, attitudes, and perceptions about police interviews, interrogations, and confessions. Our results demonstrated that participants across countries exhibited a relative lack of knowledge about confessions and the factors that put innocent suspects at risk. In an effort to better understand how experienced investigators in different European countries approach the processes of interviewing and interrogating, Chapter 4 provided an overview concerning various police practices and beliefs. We examined investigators' beliefs and practices about their ability to detect truth and deception, legal rights waiver rates, the use of various interrogation techniques, the frequency and length of interviews and interrogations, confession rates and practices and opinions with regard to the (video) recording of interrogations and confessions. The findings suggest that several recommendations to avoid false confessions are in place and that police interrogations are 'safer' for innocent suspects in Europe than in North America. However, due to a small sample size this statement has to be made cautiously.

The results of Chapter 3 have shown that lay people actually are - to some extent - aware of the risks and causes of false confessions. But when comparing the results to actual cases and outcomes, it is clear that reality seems to paint a different picture. Judging from previous research findings, it seems that people think they would behave in a certain way, but actually behave differently. Therefore, the goal of Chapter 5 and Chapter 6 was to examine whether there is a discrepancy between what people think they know and how they would react - their predicted future behavior - and their actual reactions to certain situations in the legal context. In Chapter 5, we investigated the relationship between people's behaviors and be- 
liefs regarding the fundamental right to remain silent. First, we replicated Kassin and Norwick's (2004) mock crime paradigm and demonstrated that innocent individuals are more likely to waive their rights than guilty individuals. Second, we used the same paradigm as a basis for a prediction study and our results indicate that people are poor at predicting the high waiver rates if innocent. Such an inconsistency poses a risk for innocent suspects in police custody. Chapter 6 used a wellresearched paradigm - the ALT key Computer Crash - to further explore the discrepancy between peoples' predicted future behavior and their actual behavior. Our findings suggest that people believe that others might falsely confess, but that it would never happen to them. We argued that the displayed discrepancies in Chapter 5 and Chapter 6 present another risk for false confessions of innocent people, because they think they are 'safe' while they are not. Our results show that the mechanisms involved in false confessions are not part of people's everyday knowledge.

Chapter 7 deals with another investigation of suspects' behavior during police interrogations. As a new direction for further research we examined choice blindness for norm-violating behaviors and discussed the implications for suspect interrogations. Finally, the current chapter draws upon the entire thesis, tying up the various theoretical and empirical strands in order to explain its importance for the field of false confession research and the forensic field in general. Possible improvements are proposed to reduce the risk of false confessions from a future predicting perspective. It also includes an analysis of Ulvi's case and a discussion of the implications of the findings to future research into this area.

\section{Summary and General Discussion}

The case of Ulvi - A reversal of a miscarriage of justice

"On the day with the blood, I was done with my nerves. And when Schwemmer [the lawyer] was gone and Henik Walter [one of the detectives] said that I should admit that I murdered Peggy, because otherwise he would not be my friend anymore, I admitted that I did it."

Ulvi Kulac, 2002

Lichtenberg, 2014: thirteen years later Peggy is still missing, her grave is still empty and Ulvi is still locked up in a forensic hospital. However, one thing changed - in May 2014 Ulvi was acquitted of all charges (Friedrichsen, 2014c). Journalists and supporters of Ulvi - all of whom were convinced of his innocence - fought for years to prove that he was not involved in Peggy's disappearance. Ulvi's current lawyer successfully applied for a retrial based on two main reasons. First, the main witness 
in the case, the criminal informant Peter H., came forward and admitted that he falsely testified to Ulvi's disadvantage. Peter $\mathrm{H}$. had told the police that Ulvi had confided in him and admitted to the murder of Peggy. In 2010, Peter H. claimed that he had lied and that police had pressured him to make these false statements. Second, it was proven that the so-called Tathergangshypothese from the police had been written three months before Ulvi confessed. Yet, his confession was very similar to the hypothesis of the police, too similar. The court decided that these reasons heavily changed the perception of the confession, especially regarding the expert testimony, which had stated that there was no reason to believe that the confession could be not true (Friedrichsen, 2014b; "Mordfall Peggy", 2013). By now, the expert's opinion changed. The expert took back his previous evaluation and admitted that he could not rule out that the confession was false (Friedrichsen, 2014a). The case reopened and the new trial started in April 2014. It was a short retrial - within one month the court decided to overthrow the conviction and acquitted Ulvi (Friedrichsen, 2014c).

An acquittal - a happy ending? Yes, a happy ending, indeed, but the long way there was everything but happy. How could the police, the expert and the court believe in Ulvi's confession, even though there was no factual evidence and many inconsistencies? More importantly, why did Ulvi confess to a crime he did not commit? Reviewing the details of his case presented in Chapter 1, it becomes obvious that everything reads like a blueprint for a false confession. Situational and personal risk factors played a huge role. Even though a combination of all of these risk factors cannot be used as a justification or excuse for the occurrence of a false confession and the non-detection by the involved law enforcement personnel, it does help to understand why Ulvi falsely confessed and why the German justice system failed him.

Overall, this thesis has shown that any innocent suspect can be at risk of falsely confessing anywhere in the world. However, Chapter 2 has provided evidence for the fact that some suspects are more vulnerable than others. Personal risk factors include age, mental retardation, mental illness, and certain personality traits that make individuals more compliant and suggestible (e.g., Drizin \& Leo, 2004; Kassin, 2012). For example, Drizin and Leo (2004) have shown that $63 \%$ of a sample of proven false confessors were under the age of 25 and $22 \%$ suffered from intellectual impairments. Ulvi was 24 when he confessed to murdering Peggy and disposing her body, although he had the mental state of a 10 year old. He was diagnosed with mental retardation (a low IQ); he cannot read time and can barely write and calculate. Furthermore, the quote at the beginning of this chapter illustrates that he complied with the suggestion of the detective to admit to the murder, because otherwise the detective would not have been his friend anymore. Even though no documents are accessible to prove that he has certain personality traits that put him in danger, from his overall behavior it is obvious that he wanted to please people and told them what they wanted to hear. Ulvi meets all the criteria for personal risk factors for false confessions. 
Apart from personal risk factors, situational risk factors play a role as well. Several have been identified and analyzed throughout the various chapters. For example, repeated and lengthy interrogations, and the use of certain interrogation techniques, such as the presentation of false evidence. Chapter 2 has cited the average interrogation length of proven false confessions in the United States as 16.3 hours (Drizin \& Leo, 2004). Kassin and colleagues (2007) surveyed North American police and reported an average length of 1.6 hours for an interrogation and an average of 4.2 hours for their longest interrogation. The results of the European investigators survey presented in Chapter 4 demonstrated an average length of 2.1 hours per interrogation and an average of 7.3 hours for the longest. Both samples of investigators stated that suspects are on average interrogated three times. While the results of these surveys indicate that long and repeated interrogations are not common practice, case studies show that false confessions were often elicited in lengthy and frequent interrogations. Over the course of several months, Ulvi was interrogated 42 times, often longer than four hours at a time.

In the United States many police detectives are trained in the Reid Technique (Inbau et al., 2001) that has been described in Chapter 2. One tactic that is suggested to be used by the Reid Technique is the so-called false evidence ploy, in which investigators pretend to have strong evidence of the suspect's guilt. For example, in the case of Jeffrey Deskovic (Chapter 2) police told him that he had failed the polygraph, while Marty Tankleff was told that his dying father had identified him as the perpetrator. As has been mentioned in Chapter 6 the presentation of false evidence is dangerous for innocent suspects because they might start believing in their own guilt (Kassin, 2007; Van Bergen et al., 2010) or they confess because they feel trapped in the interrogation and want to get out (Gudjonsson \& Sigurdsson, 1999; Moston, Stephenson, \& Williamson, 1992). In the United States, the presentation of false evidence is permitted by law (Frazier v. Cupp, 1969), while it is not in most European countries (Kassin et al., 2010). In Germany, deceiving the suspect with false evidence is illegal (Bradley, 2007; Jung \& Lemmer, 2013). Yet, Ulvi was confronted with the lie that Peggy's blood had been found on the clothes he wore the day the girl disappeared. The truth was that the stains were not Peggy's blood, or anyone's blood. The forensic tests were not able to identify the source of these stains, but the tests did confirm that it was not Peggy's blood (Jung \& Lemmer, 2013). The presentation of this false evidence could have led Ulvi to feel that police had evidence against him and that the only way out was to confess as he stated "on the day with the blood, I was done with my nerves". Or maybe he even started believing that he had something to do with Peggy's disappearance. False evidence influences suspects' behavior in interrogations, as documented false confession cases (e.g., Marty Tankleff; Jeffrey Deskovic) and research findings (e.g., Kassin \& Kiechel, 1996) demonstrate. The findings of Chapter 6 additionally showed that individuals seem to be ignorant of the powerful effect false evidence can have on innocent suspects in interrogations. Participants in our studies did poorly at pre- 
dicting how confession rates of innocent suspects would be affected by false evidence. And they did even worse with predicting their own confession rates.

Apart from frequent and long interrogations and the false evidence ploy, it also turned out that some of the detectives who interrogated Ulvi had been trained in the Reid Technique (Jung \& Lemmer, 2013), even though most of their accusative maneuvers are not allowed by German law. Jung and Lemmer (2013) analyzed what is accessible from Ulvi's files and compared it to tactics of the Reid Technique. Their analysis proved that several steps were used in Ulvi's interrogations, such as lying about evidence that did not exist (Peggy's blood on his clothes). Another troubling aspect of Ulvi's confession is that it was not electronically documented. The police wrote a Gedächtnisprotokoll after his confessions because the tape recorder had allegedly malfunctioned at the time of his confession. Since his lawyer was also not present, no one really knows what happened. Ulvi claims that the detectives pressured him and threatened to not be friends with him anymore, while the detectives deny this. In line with the recommendations stated in Chapters 2, 4, and 7 to electronically videotape all interrogations and confessions, Ulvi's case proves that recordings are important to be able to reconstruct what happens in an interrogation. Additionally, we have demonstrated in Chapter 7 that choice blindness may be a problem for suspects in interrogation, especially if only memory minutes of the interrogation exist, as was the case with Ulvi. The police detectives might have written incorrect information in the protocol - intentionally or accidental. Ulvi might have been confused later on whether he said certain things or even felt trapped after his first confession was written down. Since it was not electronically documented, it is impossible to find out what exactly Ulvi said compared to what has been written in the protocol of his interrogation.

As mentioned above, Ulvi had been interrogated in total over 40 times. To make things worse - during 18 interrogations his lawyer was not present. The fact that Ulvi had been questioned several times without his lawyer present showed that he had given up his right to remain silent. As in most Western countries, by German law suspects have the right to silence and to counsel a lawyer (Bradley, 2007; STPO, 2008). It is questionable whether Ulvi even understood what that meant. As research presented in Chapter 5 has shown, even competent suspects have problems understanding these legal rights (Rogers, 2011). With Ulvi's low IQ and inability to read and write, it is highly plausible that he had no idea what it meant to waive these rights. Chapter 3 and Chapter 5 have displayed that individuals think that they would keep their rights and hence be safe from a coercive interrogation while they are not. Prediction results showed that participants neglected the innocence effect and believed in their own innocence to set them free (e.g., "I had nothing to hide"). Our results indicated that people do not - as a matter of common sense understand the danger of being exposed to an interrogation. It is plausible that Ulvi relied on a similar reasoning. He probably wanted to help the police and did not understand the risk he took by talking to the police, even without his lawyer. 
To further complicate matters, interrogations are guilt-presumptive processes as stated in Chapter 2 and Chapter 4 . The goal is to get the suspects to confess (Inbau et al. 2001; Meissner \& Kassin, 2002; 2004) and some detectives even believe that they do not interrogate innocent suspects (Kassin, 2005). In Ulvi's case a detailed description of the crime including a motive had been written already three months before he confessed. The so-called Tathergangshypothese was basically identical to Ulvi's confession. This means that police were convinced of his guilt long before he admitted to being responsible for Peggy's disappearance, which makes his interrogations guilt presumptive. An investigators guilt bias is usually detrimental for the suspect because of confirmation bias. Confirmation bias is "the seeking or interpreting of evidence in ways that are partial to existing beliefs, expectations, or a hypothesis in hand" (Nickerson, 1998, p. 175). Applying this bias to the interrogation room it may mean that investigators start looking for information that confirms their opinion, but not for disproving information.

Additionally, research has shown that police are often confident in their judgment whether somebody is lying or telling the truth while their confidence has nothing to do with their accuracy. Chapter 3 has shown that lay people overestimate their own ability to distinguish between truth tellers and liars, while attributing even higher accuracy skills for police detectives. Chapter 4 illustrated that police detectives share this belief as they reported rather high accuracy levels for themselves. However, research has shown that usually deception detection skills are barely better than flipping a coin, no matter if you are an average citizen or a trained police detectives. Applying these findings to Ulvi's situation, one could argue that Ulvi believed in the police investigators' ability to see that he was telling the truth when he denied the murder and that he was lying when he confessed. Arguably, the police detectives trusted their own judgment that Ulvi was lying when he denied his involvement and that he was the perpetrator.

Many of the risk factors that are known through proven false confession cases and vast amounts of research can be applied to Ulvi's case. Based on what is known about Ulvi's case one can argue that his confession fits into the category of coercedcompliant false confessions. It seemed that he was pressured by police to confess and just wanted to get out of the uncomfortable situation. Later he recanted his confession and maintained his innocence. However, it is not known whether he actually started believing in his own guilt as well. He did re-enact the murder of Peggy in front of a camera for the police, which would suggest that he started believing in his own guilt. If true, his confession would have to be categorized as a coerced-internalized false confession. Of course, it could also be possible that he just complied with the demands of the investigators when he was willing to demonstrate how he killed Peggy. No matter which category his confession fits in, this analysis has shown that it is likely that he is, indeed, innocent and that he had nothing to do with the disappearance of Peggy. Even though it is unclear what exactly happened to Peggy - and the case might never be solved - one could claim that there is no hard evidence for Ulvi's innocence either. However, if he really is the 
perpetrator he would have committed the perfect crime - no body, no evidence, no witness. Arguably, it is unlikely for a person who suffers from mental retardation to commit such a perfect crime. Many experts believe in Ulvi's innocence. And fortunately the German justice system does so too, just over a decade too late.

\section{Beliefs, Attitudes, and Behavior}

This dissertation has demonstrated that common sense beliefs of confessions issues are not so accurate after all. A relative lack of knowledge about interrogations and police procedures shows that lay peoples' idea about what happens in police custody is limited. Even though European police practices seem to be on the right track in reducing the risk for innocent suspects to falsely confess, the small sample sizes we obtained for the survey in Chapter 4 suggest that not all police investigators are willing to work together with researchers. Interrogations are mostly still a secretive procedure in Europe and it is doubtful whether that will change any time soon. We were not able to get a single respondent from Germany. When we asked at the German ministry for internal affairs whether we could survey Germany police our request was rejected because it was "too costly and time consuming". The same held for our online questionnaire for European police investigators.

Chapter 5 and Chapter 6 examined whether misconceptions, misbelief, and relative lack of knowledge about police practices pose a danger for innocent suspects. Our prediction studies showed that people were poor at predicting their behavior and hence they did not act according to their beliefs. It can be argued that our research shows that there is a discrepancy between people's attitude about police practices and their actual behavior in police custody. To the best of our knowledge, no previous study has investigated this relationship in the legal context. However, in general, social psychologists have been investigating the relationship between attitudes and behavior for decades. Early studies of LaPierre (1934) and Kutner, Wilkins, and Yarrow (1952) brought inconsistencies between attitude and behavior to the fore. LaPierre travelled to over 200 hotels and restaurants with a Chinese couple in the 1930s and only one establishment declined service. Yet, when he wrote a letter to all of these places six months later asking whether they would serve a Chinese couple, 92\% said that they would refuse service. In a similar study, Kutner et al. (1952) investigated whether restaurants would take table reservations for a group including a person of color. Their study had almost identical results: when they asked in advance whether the establishment would accept such a reservation, they were either denied or received no response. But when the researchers went to a restaurant with a group that included a person of color, they were served without incident. Findings from both studies suggest that the relationship between attitude and behavior is a fragile one and moderated by a number of variables (Fazio \& Roskos-Ewoldsen, 2005). 
While these classic studies of the attitude-behavior relationship challenge the presumption that people behave according to their attitudes (Fazio \& RoskosEwoldsen, 2005), many researchers have criticized the methodology of these studies. For example, since LaPierre (1934) wrote the letters six months after their visit, there is no way of knowing who responded to the letter and whether it was the same person who served them. The same applies to the Kutner et al. (1952) experiment. There is unfortunately no way of telling whether the person who waited on them was the same person who answered their questions (Fazio \& RoskosEwoldsen, 2005; Maoi \& Haddock, 2009). Furthermore, other findings have suggested that under some conditions, attitudes and behavior correlate (e.g., Goodmonson \& Glaudin, 1971; Kelly \& Mirer, 1974). Overall, various studies have been examined attitude-behavior relationship, some finding perfect relations and others none. The basic conclusion that can be drawn is that people under certain circumstances act according to their attitudes and beliefs, while other times they do not (Fazio \& Roskos-Ewoldsen, 2005). Hence, the question is not whether attitudes predict behavior, but when they predict behavior.

One line of research has examined the correspondence (i.e., the similiarty) between the measured attitude and the behavior. For example, Ajzen and Fishbein (1977) demonstrated that attitudes do predict behavior when the attitudes measured correspond closely to the behavior predicted. The more specific an attitude is examined, the better the correlation between the measured attitude and behavior is (Davidson \& Jaccard, 1979). Furthermore, the theory of planned behavior by Ajzen (1991) has been used successfully to predict behavior, for example in the health sector (e.g., dieting behavior (Armitage \& Conner, 1999)). This theory states that "our attitudes influence our behavior through a process of deliberate decision making" (Kassin, Fein, \& Markus, 2008, p. 188-89). Apart from our attitude toward the behavior, we are also affected by what others think about our behavior (i.e., subjective norms). Additional, it is important that we believe that the behavior is in our control in order to follow through with it. Most importantly, the theory of planned behavior argues that our intentions are relevant to act upon our attitudes. Overall, this theory has been underlined by various research findings (Madden, Ellen, \& Ajzen, 1992; Ajzen \& Fishbein, 2005), but obviously can only predict a certain proportion of our future behavior.

Furthermore, research has shown that the strength (i.e., the importance) of the attitude plays an important role. Boning and colleagues (1995) have suggested that attitudes were usually stronger when they influenced the person's self-interest, were related to their values, and affected their family and close social groups. In general, then, it can be concluded that attitudes are good predictors of behavior if they correspond to the behavior and if it is a strong attitude (Kassin, Fein, \& Markus, 2008).

We tested how well individuals predict their behavior in police custody regarding the right to remain silent (Chapter 5) and the likelihood of confessing (Chapter 6). The above presented research in mind, we should have expected that partici- 
pants would do well in predicting their own actions. First, we examined their attitude closely. They received a specific description of the experiment that was used as a basis. Therefore, we can argue that the correspondence between the attitude and behavior was high. In contrast, the survey presented in Chapter 3 only asked participants in more general terms (e.g., "Would you ever confess to a crime you did not commit?"). General questions can be criticized for not measuring an attitude closely related to the behavior predicted. However, our results demonstrate that people did equally poor at predicting their behavior - no matter if we asked specific or general questions.

Furthermore, we can apply Ajzen's (1991) theory of planned behavior to our prediction results. This theory sees the individuals' intention to act in a certain way as the best predictor of the actual behavior. As described earlier, several factors play a role as well (attitude toward a behavior, subjective norm, perceived behavior control), all of which can be beneficial for the intention or have the opposite effect. Taking the study presented in Chapter 6 as an example, one could argue that all aspects should facilitate the intention. We asked participants whether they would confess to a 'crime' (in this case hitting the ALT key) when innocent. A certain attitude to this behavior was given, for example we can speculate that individuals belief that they should help the police solve a crime and therefore cooperate with the police (i.e., explain to them that they are innocent). Additionally, this would be expected of them as well. If a crime has been committed and someone is innocent, others could argue that this person should talk to police to explain that he is innocent so that police can focus on a different suspect because otherwise the guilty suspect could get away. Also, confessing to a crime or not should be perceived as within the individual's control since third degree tactics such as torture are no longer permitted nowadays. Based on these assumptions, we could claim that according to the theory of planned behavior, our actions in police custody can be expected to be guided by our attitude. Participants should have acted according to their predictions that they would not confess to a crime when innocent. Moreover, the attitude to not confess can be seen as an important one because confessing to a crime one has not committed goes against the person's self-interest. And it could have a negative effect on family and close friends, since the consequence may be to go to prison and be away from loved ones.

Our prediction results have demonstrated that attitudes about behavior in police custody are not good predictors of behavior, even if they closely correspond to it. Probably, this has to do with interrogation situations being highly unfamiliar to most people. Several questions remain unanswered at present; therefore further research should be done to investigate the attitude-behavior relationship in police custody and in the legal context in general. Such findings would extend our knowledge about risk factors of innocent suspects in police custody and based on such research, recommendations can be establish how to minimize the risk. Of course, critics could disagree that people's predictions about how they would behave represents an 'attitude'. It could be argued that our participants merely made 
a prediction, indicating a belief; a belief that had no positive or negative evaluative component attached to it. However, it is reasonable to assume the sum of our beliefs is the basis for our attitudes. There is a close connection between beliefs and attitudes; beliefs are important in shaping our attitudes (Maoi \& Haddock, 2009). In the legal context, it is almost impossible to distinguish between attitudes and beliefs because they are intertwined. For example, people's attitude toward police practices can be - and most likely is - influenced by their beliefs about police integrity and fairness. We could speculate that individuals in general have a positive attitude toward police based on their beliefs that they serve justice in a fair way. Based on this positive attitude they make the prediction that they would not admit to a crime not committed. When individuals are now asked to predict their behavior in police custody, it is reasonable to assume that this is based on their attitudes and beliefs.

\section{Common Sense Beliefs and Dangers}

Moving the discussion from attitudes and beliefs to lay people's common sense, this thesis has established that common sense knowledge of false confessions is not so accurate. We have investigated whether individuals know, first, that they and most other people would (a) give up their rights, (b) confess, and second, that innocent suspects in particular are likely to do so. These findings are important in light of false confession cases. The results described throughout this thesis have shown that individuals are not able to use their common sense to correctly predict their behavior and that of others in police custody. This can be added to the long list of risk factors of false confessions. This risk factor can also be applied to Ulvi's case as the expert for example state that there was no reason to believe that the confession was not true.

In contrast to our findings and the argumentation above, others have argued to trust in our common sense. Lilienfeld, Lynn, Ruscio, and Beyerstein (2010) in their book 50 Great Myths of Popular Psychology: Shattering Widespread Misconceptions about Human Behavior have presented the view of a popular radio talk show host who defends common sense: "Use your common sense. Whenever you hear the words "studies show"- outside of the natural sciences - and you find that these studies show the opposite of what common sense suggests, be very sceptical. I do not recall ever coming across a valid study that contravened common sense (Prager, 2002, p. 1 as quoted in Lilienfeld et al., 2010). One could could even go step further and cite the famous philosopher Thomas Reid who believed that everyone is born with an innate common sense and that we should rely on such intuitions to find the fundamental truth about the world (as stated in Lilienfeld et al., 2010). However, a philosophical discussion about common sense would go well beyond the scope of this thesis. 
Given that confessions are still powerful even after they have been recanted (e.g., Drizin \& Leo, 2004; Ofshe \& Leo, 1998), the relevant discussion needs to go further than police custody - it needs to extend to the court room. After all, juries and judges are the ones who decide upon the fate of the defendant. Do juries and judges know intuitively - based on their common sense - about the psychology of confessions? Research has shown that they cannot accurately distinguish between true and false confessions even after the confessor retracts his or her statement (Kassin \& Sukel, 1997; Kassin \& Wrightsman, 1980; Redlich, Ghetti, \& Quas, 2008). Furthermore, the false confession cases that went to court support this as the juries and judges were not able to identify the confession as a false one (e.g., the cases of Rudi Rupp and Micheal Crowe). Thus, we argue that false confession expert testimonies should be admissible in court and routinely used to educate the jury and judges about this topic. Yet, in the past US courts courts have often excluded expert testimony on the topic of false confession arguing that jurors do not need the assistance of experts because their testimony is not beyond the ken of the jury (Cutler, Findley, \& Loney, 2014; Fulero, 2010; Quintieri \& Weiss, 2005). The discussion in Chapter 6 illustrated this reasoning with several examples. We argue that false confession issues are not known to the average citizen as a matter of common sense, especially the effect of powerful influences (such as the false evidence ploy) on innocent suspects are neglected by lay people. Our findings present a first step toward providing an empirical basis for the danger of common sense in police custody and court rooms, especially for innocent suspects and defendants. Thus, we argue for the admissibility of expert testimony on false confessions in court. Taken together, the extant literature on false confessions also drives home the point how important it is to have a Criminal Cases Review Commissions, as is currently the case in the UK and the Netherlands. It is the task of these commissions to critically evaluate suspicious evidence and often such evidence consists of confessions along with eyewitness evidence (e.g., provided by police informants). ${ }^{11}$

One might object here that this argument of admitting expert testimony to educate juries is only valid in adversarial law systems, such as the American legal system (Costanzo, 2004) in which judges and juries are in charge of decision making in the court room. Nevertheless, even though there is no typical common law jury in, for example, Germany and Belgium, laypersons do participate in criminal matters as co-equal judges (Bradley, 2007). Additionally, it is unclear how much judges know about the psychology of confession. Arguably, judges would need assistance from experts as much as laypersons do. However, not always is the testimony of the expert beneficial for the defendant. For example, in Ulvi's case two experts were asked to provide assistance. They were not asked to educate the court about con-

\footnotetext{
11 The Criminal Case Review Commission for England, Wales and North Ireland receives around 1000 cases per year for review. Out of those, around 30 are referred to a Court of Appeals, out of which around ten are upheld by a Court of Appeals (https://www.justice.gov.uk/about/criminal-cases-reviewcommission).
} 
fession issues, but one of them was asked to evaluate the truthfulness of Ulvi's confession. It was however problematic that the psychiatrist had no prior knowledge of confession research or false confession cases (Friedrichsen, 2014c). It should have been a legal psychologist, familiar with the psychology of confession. Ulvi's case illustrates that just having an expert in court is not enough; it has to be a qualified expert.

\section{Methodological Shortcomings and Future Directions}

While the studies presented in this dissertation have shown interesting and relevant findings, there are methodological shortcomings that limit the generalizability of the results. First, the samples in Chapter 3 and Chapter 6 per country were rather small. Small sample sizes restrict the generalizability of the outcomes. We have, however, established instruments for both surveys - the common sense survey of confessions and the survey about police beliefs of European investigators. Ultimately, surveys including a larger number of participants should be conducted. Another suggestion would be to include even more countries in both samples. Second, the word 'crime' has been used in the common sense survey, which is however a general term. Future surveys should include different types of crimes to make the question more specific. Especially when participants are asked to provide a prediction it would be of essential value to make sure the type of crime is specified. One limitation of the study described in Chapter 3, that the relationship between the predictions (i.e., attitudes) of respondents and their behavior was not clear, was picked up in Chapter 5. There we did collect behavioral data with matching prediction data. A third limitation is that for the studies presented in Chapter 5 and Chapter 6, only undergraduate students were used as participants. Collecting data from a community sample would strengthen the results of these studies. Fourth, our studies used mock-crime procedures, not real crimes. Therefore, they lack ecological validity to a certain extent. However, in order to stay within ethical limitations, it is difficult to employ any other paradigms; it is a challenge for future research to come up with more ecologically valid studies that stay within the realm of ethics. Not only do we want to encourage other researchers to collect similar data as we did in Chapter 3 and Chapter 4, we also hope that our prediction studies stimulate similar lines of research. Furthermore, we hope to see more data collection and research conducted across Europe, but especially in Germany, to analyze the problem of false confession.

Apart from these future research hopes of extension and replication of our studies, we would also like to promote a different research area: the occurrence of choice blindness in interrogations. As Chapter 7 displayed, it is possible that participants experience choice blindness in interrogations if detectives provide them with misinformation about their earlier statements. It can be speculated that police might provide false information on purpose (i.e., to intentionally deceive the suspect) as is legal in North America. Or it could also be that police detectives just mis- 
remember what a suspect said. When an interrogation is not recorded, some information might get lost or is misremembered. Our memory is not perfect; it is not a tape recorder that can be replayed so chances are that detectives make genuine mistakes when later summarizing interrogation findings in their protocol. The results of Chapter 7 have supported the notion that a small but trivial amount of suspects displayed choice blindness for norm-violating behavior. Further research is required to establish the link between choice blindness and false confessions.

As a last note, not only is research about false confessions currently important as it is not part of our common sense knowledge, but what happens once lay people's beliefs begin to align with false confession literature? It might well be the case that from that point onwards, suspects and their counsels will invoke a false confession defense on a regular basis. It would make research on false versus genuine confessions even more urgent. A genuine confession that is later presented as false is, in fact, a form of false denial. Interestingly enough, there is almost no literature on false denials. Is it possible that not only false confessors can start believing in their guilt, but that genuine confessors can start believing in their innocence? As the research and knowledge about false confessions extends, an important avenue for research should be perpetrators' memories and possible genuinely believed false denials.

\section{Final Remarks}

Even though false confessions remain a problem and we still have a long way to go to implement changes that will make police custody a safe(r) place for innocent suspects, it is relieving to see that the German justice system does accept its mistakes at times and reverses them. As the case of Ulvi has shown, justice was served in the end. However, currently the German government is not taking any measures to systematically examine the (possible) problem of false confessions. Therefore, I have to agree with criminal justice reporter Gisela Friedrichsen's (2014c) when she states that it seems that in the eyes of the German justice system, a convicted innocent man is still better than no convicted man.

Finally, in the last decade a number of false confession cases have surfaced, indicating that such numbers are only the 'tip of the iceberg'. The main objective of the research presented in this dissertation was to further investigate risk factors of false confessions by researching prevalence rates of false confessions, examining lay people's beliefs about confession issues, exploring common police practices and investigating the attitudebehavior relationship of suspects in police custody. Despite several limitations, the results have enhanced our knowledge regarding confessions. We have demonstrated that false confessions are not a rare phenomenon, that misbeliefs about confessions exists and are dangerous for innocent suspects, and finally that people are poor at predicting their behavior during police custody which puts them at risk of falsely confessing. Concluding, it can be stated that Voltaire was right when he said that 'common sense is not so common'. 



\section{References}

Agar II, J. R. (1999). The admissibility of false confession expert testimony. Army Lawyer, 321, 26-42.

Ajzen, I. (1991). The theory of planned behavior. Organizational Behavior and Human Decision Processes, 5, 179-211.

Ajzen, I., \& Fishbein, M. (1977). Attitude-Behavior relations: A theoretical analysis and review of empirical research. Psychological Bulletin, 84, 888-918.

Ajzen, I., \& Fishbein, M. (2005). The influence of attitudes on behavior. In D. Albarracin, B. T. Johnson, \& M. P. Zanna (Eds.), The handbook of attitudes (pp. 173-221). Hillsdale, NJ: Erlbaum.

Appleby, S., \& Kassin, S. M. (2011). When confessions trump DNA: Relative impacts of self-report and DNA evidence on juror decisions. Paper presented at the meeting of the American Psychology-Law Society, Miami, FL.

Armitage, C. J., \& Connor, M. (1999). Distinguishing perceptions of control from self-efficacy: Predicting consumption of low-fat diet using the theory of planned behavior. Journal of Applied Social Psychology, 29, 72-90.

Blandon-Gitlin, I., Sperry, K., \& Leo, R. A. (2010). Jurors believe interrogation tactics are not likely to elicit false confessions: Will expert witness testimony inform them otherwise? Psychology, Crime \& Law, 17, 239-260. doi:10.1080/10683160903113699

Bond, C. F., \& DePaulo, B. M. (2006). Accuracy of deception judgments. Personality \& Social Psychology Review, 10, 214-234. doi: 10.1207/s15327957pspr1003_2

Boninger, D. S., Krosnick, J. A., \& Berent, M. K. (1995). Origins of attitude importance: Self-interest, social identifications, and value relevance. Journal of Personality and Social Psychology, 68, 61-80.

Bradley, C. M. (Ed.). (2007). Criminal procedure. A worldwide study. Durham, North Carolina: Carolina Academic Press.

Brants, C. (2011). The reluctant Dutch response to Salduz. The Edinburg Law Review, 15, 298-305. Brown v. Mississippi, 297 U.S. 278 (1936).

Bull, R., \& Soukara, S. (2010). Four studies of what really happens in police interviews. In G. D. Lassiter, \& C. A. Meissner (Eds.). Police interrogations and false confessions (pp. 81-95). New York, NY: American Psychological Association.

Canadian Charter of Rights and Freedoms, s 2, Part I of the Constitution Act, 1982, being Schedule B to the Canada Act 1982 (UK), 1982, c 11.

Cassell, P. G., \& Hayman, B. S. (1996). Police interrogation in the 1990s: An empirical study of the effects of Miranda. UCLA Law Review, 43, 839-931.

Chojnacki, D. E., Cicchini, M. D., \& White, L. T. (2008). An empirical basis for the admission of expert testimony on false confessions. Arizona State Law Journal, 40, 1-45.

Cloud, M., Shepherd, G.B, Barkoff, A. N., \& Shur, J. V. (2002). Words without meaning: The constitution, confessions and mentally retarded suspects. University of Chicago Law Review, 69, 495-624.

Common sense. (2013). In Oxford Dictionaries. Retrieved November 9, 2013 from http://www.oxforddictionaries.com/Commonwealth of Pennsylvania v. Harrell, No. 450 MDA 2011 (2013).

Conti, R. (1999). The psychology of false confessions. Journal of Credibility Assessment and Witness Psychology, 2, 14- 36.

Costanzo, M. (2004). Psychology applied to law. Belmont: Wadsworth/Thomson Learning.

Costanzo, M., Shaked-Schroer, N., \& Vinson, K. (2010). Juror beliefs about police interrogations, false confessions, and expert testimony. Journal of Empiricial Legal Studies, 7, 231-247. doi: 10.1111/j.1740-1461.2010.01177.x 


\section{REFERENCES}

Crowne, D. P., \& Marlowe, D. (1960). A new scale of social desirability independent of psychopathology. Journal of Consulting Psychology, 24, 349-354. doi:10.1037/h0047358

Davidson, A. R., \& Jaccard, J. J. (1979). Variables that moderate the attitude-behavior relationship: Results of a longitudinal survey. Journal of Personality and Social Psychology, 49, 1184-1198.

Davis, D., \& Leo, R. A. (2012). To walk in their shoes: The problem of missing, misunderstood, and misrepresented context in judging criminal confessions. New England Law Review, 46, 737-767.

Derogatis, L. R., Lipman, R. S., \& Covi, L. (1973). SCL-90: An outpatient psychiatric rating scale-preliminary report. Psychopharmacology Bulletin, 9, 13-28.

Drews, F. (2013). Die Königin unter den Beweismitteln? Eine interdisziplinäre Untersuchung des (falschen) Geständnisses [The queen of evidence? An interdisciplinary investigation of (false) confessions]. Berlin: LIT Verlag.

Drizin, S. A., \& Colgan, B. A. (2004). Tales from the juvenile confessions front. In G. D. Lassiter (Ed.). Interrogations, confessions and entrapment (pp. 127 - 162). New York: Kluwer Academic/Plenum.

Drizin, S. A., \& Leo, R. A. (2004). The problem of false confessions in post-DNA world. North Carolina Law Review, 82, 891-1007.

Egan, C. (2006, February 22). A murderer no more. The Australian Newspaper, p. 13.

European Parliament and the Council of the European Union. (2012, May 22). Directives on the right to information in criminal proceedings. Retrieved from http://eur-lex.europa.eu/LexUriServ/LexUriServ.do?uri=0J:L:2012:142:0001:0010:en:PDF

Fazio, R. H., \& Roskos-Ewoldsen, D. R. (2005). Acting as we feel: When and how attitudes guide behavior. In T. C. Brock and M. C. Green (Eds.), The psychology of persuasion (2nd ed., pp. 41-62). New York: Allyn \& Bacon.

Firstman, R., \& Salpeter, J. (2008). A criminal injustice. A true crime, a false confession, and the fight to the free Marty Tankleff. New York, NY: Ballantine Books.

Frazier v. Cupp, 394 U.S. 731 (1969).

Friedrichsen, G. (2010, February 8). "Lange genug weichgekocht" [Soft-boiled long enough]. Spiegel Online. Retrieved from http://www.spiegel.de/spiegel/print/d-69003629.html

Friedrichsen, G. (2011, February 24). Getöteter Bauer: "Man brauchte Geständnisse" [Killed farmer: "Confessions were needed"]. Spiegel Online. Retrieved from http://www.spiegel.de

Friedrichsen, G. (2011, February 28). Schämt sich keiner? [Is no one embarrased?] Der Spiegel. Retrieved from http://www.spiegel.de/

Friedrichsen, G. (2014a, May 6). Gutachter macht Rückzieher vor Gericht [Expert draws back his testimony in court]. Spiegel Online. Retrieved from http://www.spiegel.de

Friedrichsen, G. (2014b, May 7). Schwere Umkehr [Heavy reverse]. Spiegel Online. Retrieved from http://www.spiegel.de

Friedrichsen, G. (2014c, May). Spektakuläre Irrtümer [Dramatic mistake]. Der Spiegel, 21, 52-53.

Fulero, S. (2004). Expert psychological testimony on the psychology of interrogations and confessions. In G. D. Lassiter (Ed.), Interrogations, Confessions, and Entrapment. Kluwer Publishers.

Fulero, S. M. (2010). Tales from the front: Expert testimony on the psychology of interrogations and confessions revisited. In G. D. Lassiter \& C. A. Meissner (Eds.), Police interrogations and false confessions. Current research, practice, and policy recommendations (pp. 211-223). Washington, DC: American Psychological Association.

Furnham, A., McManus, C., \& Scott, D. (2003). Personality, empathy and attitudes to animal welfare. Antrozoös, 16, 135-146. doi:10.2752/089279303786992260

Garrett, B. (2010). The substance of false confessions. Stanford Law Review, 62, 1051-1119.

Gilovich, T., Savitsky, K., \& Medvec, V. H. (1998). The illusion of transparency: Biased assessments of others' ability to read one's emotional states. Journal of Personality and Social Psychology, 75, 332346.

Getöteter Landwirt: Gericht spricht im Fall Rupp Familie frei [Murdered farmer: Court acquits family members in the Rupp case].(2011, February 25). Spiegel Online. Retrieved from http://www.spiegel.de/panorama/justiz/0,1518,747654,00.html

Gordon, N. J., \& Fleisher, W. L. (2006). Effective interviewing and interrogation techniques (2nd ed.). San Diego, CA: Academic Press. 
Granhag, P. A., \& Strömwall, L. A. (Eds) (2004). The detection of deception in forensic contexts. Cambridge, England: Cambridge University Press.

Gudjonsson, G. H. (1984). A new scale of interrogative suggestibility. Personality and Individual Differences, 5, 303-314. doi:10.1016/0191-8869(84)90069-2

Gudjonsson, G. H. (1989). Compliance in an interrogative situation: A new scale. Personality and Individual Differences, 10, 535-540. doi:10.1016/0191-8869(89)90035-4

Gudjonsson, G. H. (1997). The Gudjonsson suggestibility scales manual. Hove, East Sussex: Psychology Press.

Gudjonsson, G. H. (2003). The psychology of interrogations and confessions: A handbook. Chichester, England: John Wiley \& Sons.

Gudjonsson, G. H., \& Sigurdsson, J. F. (1999). The Gudjonsson Confession Questionnaire-Revised (GCQR). Factor structure and its relationship with personality. Personality and Individual Differences, 27, 953-968. doi:10.1016/S0191-8869(98)00278-5.

Gudjonsson, G. H., \& Sigurdsson, J. F. (1994). How frequently do false confession occur? An empirical study among prison inmates. Psychology, Crime and Law, 1, 21-26.

Gudjonsson, G. H., Sigurdsson, J. F., \& Sigfusdottir, I. D. (2009). Interrogation and false confessions among adolescents in seven European countries. What background and psychological variables best discriminate between false confessors and non-false confessors? Psychology, Crime \& Law, 15, 711-728.

Gudjonsson, G. H., \& Pearse, J. (2011). Suspect interviews and false confessions. Current Directions in Psychological Science, 20, 33-37. doi: 10.1177/0963721410396824

Guyll, M., Madon, S., Yang, Y., Lannin, D. G., Scherr, K., \& Greathouse, S. (2013).

Innocence and resisting confession during interrogation: Effects on physiologic activity. Law and Human Behavior, 37, 366-375. doi: 10.1037/lhb0000044

Hall, L., Johansson, P., Tärning, B., Sikström, S., \& Deutgen, T. (2010). Magic at the marketplace: Choice blindness for the taste of jam and the smell of tea. Cognition, 117, 54-61. doi:10.1016/j.cognition.2010.06.010

Handel, S. (2003, March 9). Die Last des eigenen Lügengebirges [The burden of one's own mountains of lies]. Süddeutsche Zeitung. Retrieved January 20th, 2010, from http://www.sueddeutsche.de/muenchen/12/366829/text/

Hartwig, M., \& Bond, C. F. (2011). Why do lie-catchers fail? A lens model meta-analysis of human lie judgments. Psychological Bulletin, 137, 643-659. doi:10.1037/a0023589

Henkel, L. A., Coffman, K. A. J., \& Dailey, E. M. (2008). A survey of people's attitudes and beliefs about false confessions. Behavioral Sciences and the Law, 26, 555-584. doi:10.1002/bsl

Hirsch Ballin, M. F. H. (2012). Anticipative criminal investigation. Theory and counterterrorism practice in the Netherlands and the United States. The Hague, the Netherlands: T.M.C. ASSER PRESS.

Home Office. (2003). Police and Criminal Evidence Act 1984. Codes of Practice A-E Revised Edition. London: HMSO.

Horgan, A. J., Russano, M .B., Meissner, C. A., \& Evans, J. R. (2012). Minimization and maximization techniques: Assessing the perceived consequences of confessing and confession diagnosticity. Psychology, Crime \& Law, 18, 65-78. doi: 10.1080/1068316X.2011.561801

Horselenberg, R., Merckelbach, H., Smeets, T., Franssens, D., Peters, G. J. Y., \& Zeles, G. (2006). False confessions in the lab: Do plausibility and consequences matter? Psychology, Crime \& Law, 12, 61-75. doi:http://dx.doi.org/10.1080/1068310042000303076

Horselenberg, R., Merckelbach, H., \& Josephs, S. (2003). Individual differences and false confessions: A conceptual replication of Kassin and Kiechel (1996). Psychology, Crime and Law, 9, 1-8. doi:10.1080/10683160308141

Huff, C. R., \& Killias, M. (Eds.). (2008). Wrongful conviction. International perspectives on miscarriages of justice. Philadelphia: Temple University Press.

Inbau, F. E., Reid, J. E., Buckley, J. P. \& Jayne, B. C. (2001). Criminal interrogation and Confessions (4th ed.). Gaithersburg, MD: Aspen.

Inglis, T. (2004). Truth, power and lies: Irish society and the case of the Kerry babies. Dublin: University College Dublin Press.

Innocence Project. (2010). Retrieved January 18th, 2010, from http://www.innocenceproject.org. 


\section{REFERENCES}

Jelicic, M., Merckelbach, H., Timmermans, M., \& Candel, I. (2004). De Nederlandstalige versie van de Psychopathic Personality Inventory [Dutch version of the Psychopathic Personality Inventory]. De Psycholoog, 39, 604-608.

Johansson, P., Hall, L., \& Sikström, S. (2008). From change blindness to choice blindness. Psychologia: An International Journal of Psychology in the Orient, 51, 142-155. doi:10.2117/psysoc.2008.142

Johansson, P., Hall, L., Sikström, S., \& Olsson, A. (2005). Failure to detect mismatches between intention and outcome in a simple decision task. Science, 310, 116-119. doi:10.1126/science.1111709

Johnson, M. B., \& Drucker, J. (2009). Two recently confirmed false confessions: Byron A. Halsey and Jeffrey M. Deskovic. The Journal of Psychiatry \& Law, 37, 51-72.

Juettner, J. (2009a, June 16). Bauer Rudi, ein grausiger Mord und das falsche Geständnis [Farmer Rudi, a cruel murder and the false confession]. Spiegel Online. Retrieved January 20th, 2010, from http://www.spiegel.de/panorama/justiz/0,1518,630648,00.html

Juettner, J. (2009b, November 26). Im Zweifel gegen den Angeklagten [When in doubt, against the defendant]. Spiegel Online. Retrieved January 20th, 2010, from http://www.spiegel.de/panorama/justiz/0,1518,663299,00.html

Jung, I., \& Lemmer, C. (2013). Der Fall Peggy. Die Geschichte eines Skandals. [The case Peggy. The story of a scandal]. München: Droemer.

Kahn, J. (2005). Deep flaws, and little justice, in China's court system. The New York Times, September 21, 2005.

Karlsen, C. F. (1989). The devil in the shape of a woman: Witchcraft in colonial New England. New York: Vintage.

Kassin, S. M. (1997). The psychology of confession evidence. American Psychologist, 52, 221-233.

Kassin, S. M. (2005). On the psychology of confessions. Does innocence put innocents at risk? American Psychologist, 60, 215-228. doi:10.1037/0003-066X.60.3.215

Kassin, S. M. (2007). Expert testimony on the psychology of confessions: A pyramidal framework of the relevant science. In E. Borgida \& S. T. Fiske's Beyond common sense: Psychological science in the courtroom (pp. 195-218). Blackwell Publishing.

Kassin, S. M. (2008a). Confession evidence: Commonsense myths and misconceptions. Criminal and Justice Behavior, 35, 1309-1322. doi: 10.1177/0093854808321557

Kassin, S. M. (2008b). False confessions. Causes, consequences, and implications for reform. Current Directions in Psychological Science, 17, 249-259. doi:10.1111/j.1467-8721.2008.00584.x

Kassin, S. M. (2012). Why confessions trump innocence. American Psychologist, 67, 431-445. doi: $10.1037 / \mathrm{a} 0028212$

Kassin, S. M., Drizin, S. A., Grisso, T., Gudjonsson, G.H., Leo, R.A., \& Redlich, A.D. (2010). Police-induced confessions: Risk factors and recommendations. Law and Human Behavior, 34, 3-38. doi:10.1007/s10979-009-9188-6

Kassin, S. M., Fein, S., \& Markus, H. R. (2008). Social Psychology (7th ed.). New York: Houghton Mifflin Company.

Kassin, S. M., \& Gudjonsson, G. H. (2004). The psychology of confession evidence: A review of the literature and issues. Psychological Science in the Public Interest, 5, 35-69.

Kassin, S. M., \& Kiechel, K. L. (1996). The social psychology of false confessions: Compliance, internalization, and confabulation. Psychological Science, 7,125-128. doi:10.1080=1068316021000057631

Kassin, S. M., Leo, R. A., Meissner, C. A., Richman, K. D., Colwell, L. H., Leach, A. M., \& La Fon, D. (2007). Police interviewing and interrogation: A self-report survey of police practices and beliefs. Law and Human Behavior, 31, 381-400. doi:10.1007/s10979-006-9073-5

Kassin, S. M., Meissner, C. A., \& Norwick, R. J. (2005). "I'd know a false confession if I saw one": A comparative study of college students and police investigators. Law and Human Behavior, 29, 211-227.

Kassin, S. M., \& Neumann, K. (1997). On the power of confession evidence: An experimental test of the 'fundamental difference' hypothesis. Law and Human Behavior, 21, 469-484. doi:10.1023/A:1024871622490

Kassin, S. M., \& Norwick, R. J. (2004). Why suspects waive their Miranda rights: The power of innocence. Law and Human Behavior, 28, 211-221. 
Kassin, S. M., \& Sukel, H. (1997). Coerced confessions and the jury: An experimental test of the "Harmless Error" rule. Law and Human Behavior, 21, 27-46. doi:10.1023/A:1024814009769

Kassin, S. M., \& Wrightsman, L. S. (1980). Prior confessions and mock juror verdicts. Journal of Applied Social Psychology, 10, 133-146. doi: 10.1111/j.1559-1816.1980.tb00698.x

Kassin, S. M., \& Wrightsman, L. S. (1985). Confession evidence. In S. Kassin \& L. Wrightsman (Eds.), The psychology of evidence and trial procedure (pp. 67-94). Beverly Hills, CA: Sage.

LaPiere, R. T. (1934). Attitudes vs. actions. Social Forces, 13, 230-237.

Leo, R. A. (1996a). Inside the interrogation room. Journal of Criminal Law and Crimonology, 86, 266-303.

Leo, R. A. (1996b). Miranda's revenge: Police interrogation as a confidence game. Law and Society Review, 30, 259-288.

Leo, R. A. (2001). False confessions: Causes, consequences, and solutions. In S. D. Westervelt, \& J. A. Humphrey (Eds.), Wrongly convicted: Perspectives on failed justice (pp. 36-54). Newark: Rutgers University Press.

Leo, R. A. (2008). Police interrogation and American justice. Cambridge, MA: Harvard University Press.

Leo, R. (2009). False confessions: Causes, consequences, and implications. The Journal of the American Academy of Psychiatry and the Law, 37, 332-342.

Leo, R. A., \& Liu, B. (2009). What do potential jurors know about police interrogation techniques and false confessions. Behavioral Sciences and the Law, 27, 381-399. doi:10.1002/bsl.872

Leo, R., \& Ofshe, R. (1998). The consequences of false confessions: Deprivations of liberty and miscarriages of justice in the age of psychological interrogation. Journal of Criminal Law \& Criminology, 88, 429.

Leo, R. A., \& White, W. S. (1999). Adapting to Miranda: Modern interrogators' strategies for dealing with the obstacles posed. Minnesota Law Review, 84, 397-472.

Lerner, M. J. (1980). The belief in a just world: A fundamental delusion. New York: Plenum Press.

Levesque, R. J. R. (2006). The psychology and law of criminal justice processes. New York: Nova Publishers.

Ley de Enjuiciamiento Criminal, art. 520.2, 1982 [Law of Criminal Procedure - Spain].

Lilienfeld, S. O., \& Byron, R. (2013). Your brain on trial. Lessons learned from psychology could greatly improve courtroom decision making, reducing racial bias, eyewitness errors and false confessions. Scientific American Mind, 23, 46-53. doi: 10.1038/scientificamericaninmind0113-44.

Lilienfeld, S. O., \& Landfield, K. (2008). Science and pseudoscience in law: A user-friendly primer. Criminal Justice and Behavior, 35, 1215-1230. doi: 10.1177/0093854808321526

Lilienfeld, S. O., Lynn, S. J., Ruscio, J., \& Beyerstein, B. L. (2010). 50 great myths of popular psychology. Shattering widespread misconceptions about human behavior. West Sussex, United Kingdom: WileyBlackwell.

Madden, T . J., Ellen, P. S., \& Ajzen, I. (1992). A comparison of the theory if planned behavior and the theory of reasoned action. Personality and Social Psychology Bulletin, 18, 3-9.

Magner, E. S., Markham, R., \& Barnett, C. (1996). Would reading an account of an event refresh your memory? Journal of Applied Psychology, 81, 769-776. doi:10.1037/0021-9010.81.6.769

Maio, G. R., \& Haddock, G. (2012). The psychology of attitudes and attitude change. London: SAGE Publications Ltd.

McCrae, R. R., \& Costa, P. T. (1997). Personality trait structure as a human universal. American Psychologist, 52, 509-516. doi:10.1037/0003-066X.52.5.509

Meissner, C. A., Horgan, A. J., \& Albrechtsen, J. S. (2009). False confessions. In R. Kocsis' (Ed.), Applied criminal psychology: A guide to forensic behavioral sciences (pp. 191- 212). Springfield, IL: Charles C. Thomas Publisher, LTD.

Meissner, C. A., \& Kassin, S. M. (2002). “He's guilty!": Investigator bias in judgments of truth and deception. Law and Human Behavior, 26, 469-480.

Meissner, C. A., \& Russano, M. B. (2003). The psychology of interrogations and false confessions: Research and recommendations. Canadian Journal of Police \& Security Services, 1, 53-64.

Memon, A., Vrij, A., \& Bull, R. (2003). Psychology and law: Truthfulness, Accuracy and Credibility. London: Jossey Bass. 


\section{REFERENCES}

Merckelbach, H., Jelicic, M., \& Pieters, M. (2011a). Misinformation increases symptom reporting--a testretest experiment. Journal of the Royal Society of Medicine, 2. doi:10.1258/shorts.2011.011062

Merckelbach, H., Jelicic, M., \& Pieters, M. (2011b). The residual effect of feigning: How intentional faking may evolve into a less conscious form of symptom reporting. Journal of Clinical and Experimental Neuropsychology, 33, 131-139. doi:10.1080/13903395.2010.495055

Merckelbach, H., Muris, P., Wessel, I., \& van Koppen, P. (1998). The Gudjonsson Suggestibility Scale (GSS): Further data on its reliability, validity, and metacognition correlates. Social Behavior and Personality, 26, 203-210. doi:10.2224/sbp.1998.26.2.203

Miranda v. Arizona, 384 U.S. 336 (1966).

Mokhtar, F. (2011, July 6). Man jailed for 6 years acquitted of murder charges. Singapore Scene. Retrieved from https://sg.news.yahoo.com/blogs/singaporescene/man-jailed-6-years-acquitted-murdercharges-055338858.html

Moore, T. E., \& Gagnier, K. (2008). "You can talk if you want to": Is the police caution on the 'right to silence' understandable? Criminal Reports, 51, 233-249.

Mordfall Peggy wird neu aufgerollt [Murder case will be reopened]. (December, 9). Spiegel Online. Retrieved from http://www.spiegel.de

Moston, S., Stephenson, G. M., \& Williamson, T. M. (1992). The effects of case characteristics on suspect behavior during police questioning. British Journal of Criminology, 32, 23-40.

Neubauer, D. (1974). Confessions in Prairie City: Some causes and effects. Journal of Criminology and Criminal Law, 65, 103-112.

Nickerson, R. S. (1998). Confirmation bias: A ubiquitous phenomenon in many guises. Review of General Psychology, 2, 175-220.

Oberlander, L. B., \& Goldstein, N. E. (2001). A review and update on the practice of evaluating Miranda comprehension. Behavioral Sciences and the Law, 19, 453-471. doi: 10.1002/bsl.453

Ogloff, J. R. P. (Ed.). (2002). Taking psychology and law into the twenty-first century. New York: Kluwer Academic / Plenum Publishers.

Olson, E. A., \& Charman, S. D. (2012). "But can you prove it?” Examining the quality of innocent suspects' alibis. Psychology, Crime \& Law, 18, 453-471. doi: 10.1080/1068316X.2010.505567

Onishi, N. (2007, May 7). Pressed by police, even innocent confess in Japan. The New York Times.

Otto, H. D. (2003). Das Lexicon der Justizirrtümer: Skandalöse Fälle, unschuldige Opfer, hartnäckige Ermittler [The lexicon of errors of justice: Scandalous cases, innocent vicitims, persistent investigators]. Vierkirchen: Buch Vertrieb Blank.

Otto, H. D. (2006). "Im Namen des Irrtums!" Fehlurteile in Mordprozessen ["In the name of error!" Miscarriages of justice in murder trials]. München: F.A. Herbig.

Perillo, J. T., \& Kassin, S. M. (2011). Inside interrogation: The lie, the bluff, and false confessions. Law and Human Behavior, 35, 327-337. doi 10.1007/s10979-010-9244-2

Perez, D. A. (2010). The (in)admissibility of false confession expert testimony. Touro Law Review, 26, 23 52.

Peterhans, S. (2011, January 12). Verbotene Vernehmungsmethoden [Forbidden interrogation methods]. Donaukurier. Retrieved from http://www.donaukurier.de/

Peters, K. (1970). Fehlerquellen im Strafprozess: Eine Untersuchung der Wiederaufnahmeverfahren in der Bundesrepublik Deutschland [Sources of error in criminal trials: An investigation of appellate cases in Germany]. Karlsruhe: C. F. Müller.

Quintieri, P., \& Weiss, K. J. (2005). Admissibility of false-confession testimony: Know thy standard. J Am Acad Psychiatry Law, 33, 535-538.

Rahn, K. (2008, November 30). Man cleared of murder charge after 36 years. The Korea Times, retrieved from http://koreatimes.co.kr

Rastam, H. (2013). Thomas Quick: The making of a serial killer. Edinburgh, Scotland: Canongate Books.

Redlich, A. D., Ghetti, S., \& Quas, J. A. (2008). Perceptions of children during a police interview: A comparison of suspects and alleged victims. Journal of Applied Social Psychology, 38, 705-735. doi: 10.1111/j.1559-1816.2007.00323.x

Redlich, A. D. \& Goodman, G. S. (2003). Taking responsibility for an act not committed: The influence of age and suggestibility. Law and Human Behavior, 27, 141-156. 
Rentschler, R. (2007). Verhören ist Beziehungsarbeit [Interrogating is like working on a relationship]. Gehirn \& Geist (1-2). p. 20.

Richardson, G. (1991). A study of interrogative suggestibility in an adolescent forensic population. Unpublished M.Sc. Thesis, University of Newcastle.

Rimer, S. (2002, February 6). Convict's DNA sways labs, not a determined prosecutor. The New York Times, p. A14.

Rogers, R. (2011). Getting it wrong about Miranda rights: False Beliefs, impaired reasoning, and professional neglect. American psychologist 66 728-736. doi: 10.1037/a0024988

Rogers, R., Fiduccia, C. E., Drogin, E. Y., Steadham, J. A., Clark, J. W., III, \& \& Cramer, R. J. (2013). General knowledge and misknowledge of Miranda rights: Are effective Miranda advisements still necessary? Psychology, Public Policy, and Law, 19, 432-442. doi: 10.1037/a0033964

Rogers, R., Rogstad, J. E., Gillard, N. D., Drogin, E. Y., Blackwood, H. L., \& Shuman, D. W. (2010). "Everyone knows their Miranda rights." Implicit assumptions and countervailing evidence. Psychology, Public Policy, and Law, 16, 300-318. doi: 10.1037/a0019316

Russano, M. B., Meissner, C. A., Narchet, F. M., \& Kassin, S. M. (2005). Investigating true and false confession within a novel experimental paradigm. Psychological Science, 16, 481-486.

Sagana, A., Sauerland, M., \& Merckelbach, H. (2013). Witnesses' blindness for their own facial recognition decisions: A field study. Behavioral Sciences and the Law, 31, 624-636. doi:10.1002/bsl.2082

Saks, M. J., \& Koehler, J. J. (2005). The coming paradigm shift in forensic identification science. Science, 309, 892-895. doi:10.1126/science.1111565

Salduz v. Turkey, (2009) 49 EHRR 19.

Sangero, B., \& Halpert, M. (2011). Proposal to reverse the view of a confession: From key evidence requiring corroboration to corroboration for key evidence. Michigan Journal of Law Reform, 511, Spring.

Santtila, P., Alkiora, P., Ekholm, M., \& Niemi, P. (1999). False confessions to robbery: the role of suggestibility, anxiety, memory disturbance and withdrawal symptoms. The Journal of Forensic Psychiatry, 10, 399-415. doi:10.1080/09585189908403692

Sauerland, M., Sagana, A., \& Otgaar, H. (2013). Theoretical and legal issues related to choice blindness for voices. Legal and Criminological Psychology. 18, 371-381. doi:10.1111/j.2044-8333.2012.02049.x

Sauerland, M., Schell, J. M., Collaris, J., Reimer, N. K., Schneider, M., \& Merckelbach, H. (2013). "Yes, I have sometimes stolen bikes": Blindness for norm-violating behaviors and implications for suspect interrogations. Behavioral Sciences and the Law, 31, 239-255. doi:10.1002/bsl.2063

Schell, J. M. (2010). False confessions and its pitfalls: The dilemma of applying research findings to practice. In P. Santtilla (Ed.), The applicability of psycho-legal research: Sexual interest, deception and suggestibility. Proceedings of the Third Joint Nordic PhD course in Legal and Investigative Psychology (pp. 73-88). Oslo: Nordforsk.

Schell, J. M., \& Kassin, S. M. (2009). Common sense of confessions: What do people believe? Manuscript in preparation.

Schell-Leugers, J. M., \& Kassin, S. M. (2014). Police practices and beliefs: A survey of European investigators. Manuscript in preparation.

Schell-Leugers, J. M., Kassin, S. M., Merckelbach, H., \& Hospers, H. J. (2014). Not acting according to our beliefs: The dangers of waiving your right to remain silent. Manuscript submitted for publication.

Schell, J. M., \& Merckelbach, H. (2011, May). Falsche Geständnisse: Warum unschuldige Menschen Verbrechen gestehen, die sie nicht begangen haben [False confessions: Why innocent people confess to crimes they have not committed]. In-Mind Magazine, 1/2011. Retrieved from http://de.in-mind.org/

Schell-Leugers, Merckelbach, H., \& Kassin, S. M. (2014). "I would never do that"!

Schmidt, M. S. (2014, May 22). In policy change, justice dept. to require recording of interrogations. The New York Times.

Schwarz, N., Groves, R. M., \& Schuman, H. (1998). Survey methods. In D. T. Gilbert, D. T. Fiske, \& G. Lindzey (Eds.), The Handbook of Social Psychology, Fourth edition, (pp. 143-179). New York: Oxford University Press.

Sherrer, H. (2005). Murdered woman's innocent boyfriend exonerated after bizarre "confession" is exposed as false. Justice: Denied, January 2005. 


\section{REFERENCES}

STPO: Strafprozessordnung: mit Einfuehrungs, GerichtsverfassungG, EGGVG, Jugendgerichtsgesetz, Strassenverkehrs. (2008). Muenchen: Verlag DTV-Beck.

Softley, P. (1980). Police interrogation: An observational study in four police stations (Home Office Research Study No. 61). London: Her Majesty's Stationery Office.

Soree, N. (2005). When the innocent speak: False confessions, constitutional safeguards, and the role of expert testimony. American Journal of Criminal Law, 191, 227-255.

State v. Cobb, 43 P. 3d 855, 869 (Kan. Ct. App. 2002).

State v. Davis, 32 S.W. 3d 603, 609 (Mo. Ct. App. 2000).

State v. Free, 798 A.2d 83 (N. J. Super Ct. App. Div. 2002).

State v. Ritt, 599 N.W.2d 802, 812 (Minn. 1999).

Symposium: An international exploration of wrongful conviction. (2013). University of Cincinnati Law Review, 80 (4), 1067-1526.

Thomas III, G. C. (1996). Plain talk about the Miranda empirical debate: A "steady- state" theory of confessions. UCLA Law Review, 43, 933-959.

Tourangeau, R., Rips, L. J., \& Rasinski, K. (2000). The psychology of survey response. New York: Cambridge University Press.

Van Bergen, S., Jelicic, M. \& Merckelbach, H. (2008). Interrogation techniques and memory distrust. Psychology, Crime \& Law, 14, 425-434. doi:10.1080/10683160701822533

Van Bergen, S., Horselenberg, R., Merckelbach, H., Jelicic, M. \& Beckers, R. (2010). Memory distrust and acceptance of misinformation. Applied Cognitive Psychology, 24, 885-896. doi:10.1002/acp.1595

Van de Laar, T. A. H. M., \& de Graaff, R. L. (2011). Salduz and Miranda: Is the US Supreme Court pointing the way? European Human Rights Law Review, 3, 304-317.

Von Hippel, W., \& Trivers, R. (2011). The evolution and psychology of self-deception. Behavioral and Brain Sciences, 34, 1-56. doi:10.1017/S0140525X10001354

Van Koppen, P. J., Merckelbach, H. L. G. J., Jelicic, M., \& de Keijser, J. W. (2010). Reizen met mijn Rechter: Psychologie van het Recht. Deventer: Kluwer.

Vrij, A. (2008). Nonverbal dominance versus verbal accuracy in lie detection: A plea to change police practice. Criminal Justice and Behavior, 35, 1323-1336. doi:10.1177/0093854808321530

Vrij, A., Granhag, P. A., \& Porter, S. (2010). Pitfalls and opportunities in nonverbal and verbal lie detection. Psychological Science in the Public Interest, 11, 89-121. doi:10.1177/1529100610390861

Wagenaar, W.A. (2002). False confessions after repeated interrogations: The Putten murder case. European Review, 10, 519-537.

Witt, J. W. (1973). Non-coercive interrogation and the administration of criminal justice: The impact of Miranda on police effectuality. The Journal of Criminology and Criminal Law, 64, 320-332.

Wrightsman, L. S., \& Pitman, M. L. (2010). The Miranda ruling. Its past, present, and future. New York: Oxford University Press.

Zimbardo, P. G., \& Leippe, M. R. (1991). The psychology of attitude change and social influence. New York: Mcgraw-Hill Book Company. 


\section{Summary}

The main aim of this dissertation is to examine common sense beliefs and misconceptions about false confessions. In the last decade, overturned wrongful conviction cases around the world have shown that false confessions are not a rare phenomenon (e.g., Huff \& Killias, 2008). Various research and case studies have investigated risk factors and provided recommendations on how to avoid false confessions (e.g., Drizin \& Leo, 2004; Kassin \& Gudjonsson, 2004; Kassin \& Kiechel, 1996; Kassin et al., 2010; Russanon, Meissner, Narchet \& Kassin, 2005). Admitting to a crime one has not committed is seen as counter-intuitive by many people (Leo \& Liu, 2009) and most people believe that it could not happen to them (Henkel, Coffman, \& Dailey, 2008). Overall, studies have shown that the average person is not well informed about the possibility (and risk) of a false confession. The present dissertation attempts to further investigate what the average person knows about false confessions and whether misbeliefs and misconceptions pose a risk factor for innocent suspects. The research goals are threefold: to address common sense beliefs and police practices about confession-related legal issues; to examine how misbeliefs about false confessions pose a risk for innocent suspects; and to investigate the relationship between people's beliefs and their behavior during police custody. Additionally, a new direction for future research is presented by linking the phenomenon of choice blindness to false confessions.

Chapter 1 presents the case of Ulvi Kulac, who got convicted based on a false confession for the murder of a little girl and acquitted for this crime 13 years later. It illustrates the danger of coercive police interrogation techniques, especially for vulnerable suspects. In Chapter 2, two more case vignettes of false confessions are described. These cases are followed by a review of the current state of literature in the field of false confession research offering an overview of research findings, risk factors, and recommendations on how false confessions can be avoided. It also addresses the difficulty of applying research findings to practice.

The literature review on false confession research showed that not much research has been done on examining laypeople's beliefs about confession issues and whether those beliefs are universal or specific to culture. Therefore, the survey in Chapter 3 used an online questionnaire to collect data across seven different countries about laypeople's beliefs about deception detection capabilities, the use of the right to remain silent, and the likelihood of true and false confessions. The findings of this survey show that participants overall overestimated their own deception detection skills and rated those of trained police investigators even higher, display- 
ing a common misconception that training improves deception detection. Furthermore, participants underrated their waiver rates to remain silent and overrated their own confession rates. Overall, these results revealed that participants universally exhibited a relative lack of knowledge about confessions and the factors that put innocent people at risk.

In an effort to shed light on how investigators in Europe approach the processes of interviewing and interrogation, Chapter 4 presents the results of a survey covering various police practices and beliefs of police. By replicating the self-report survey of North American police practices (Kassin et al., 2007), an adapted version of their questionnaire was used. This survey covered European investigators' beliefs and practices about deception detection accuracy, Miranda waiver rates, the interrogation process, rates of true and false confessions, and their practices of recording interrogations and confessions. Results displayed several similarities with the original study and consistencies with research findings, while some results deviated from the findings of the original study that was conducted by Kassin and colleagues (2007) in North America.

As stated above, the study described in Chapter 3 has shown that laypeople's beliefs about various confessions issues are incorrect, including the right to remain silent. In the multinational survey, participants indicated lower waiver rates than actual waiver rates of innocent suspects' right to remain silent and reported waiver rates of innocent suspects by police. To examine whether laypeople can use their common sense to predict the extent to which people would waive their rights to silence and that innocent suspects are particular likely to do so, Chapter 5 described two experiments that were conducted. In the first experiment, a mock theft paradigm was used, which had been developed by Kassin and Norwick (2004), to test how many innocent participants would give up their right to remain silent compared to guilty participants after being accused of a theft by a disguised police detective. The second experiment employed a thought experiment in which participants had to predict their waiver rates and those of innocent and guilty participants in the mock theft paradigm described in the first experiment. Results displayed a discrepancy between actual waiver rates obtained in experiment 1 compared to the predicted waiver rates in experiment 2 . These findings indicate that people are not aware of the innocence effect of waiver rates as a matter of common sense.

To further investigate the discrepancies found in Chapter 5 , the study presented in Chapter 6 examined whether participants are able to correctly predict their behavior and that of others in a typical false confession paradigm. A self-report study based on the results of the classic ALT key paradigm by Kassin and Kiechel (1996) was used. Participants were asked to read a description of this paradigm and had to predict confession rates for themselves and others. In line with our hypothesis, participants overall were poor at predicting confession rates. Furthermore, our findings confirmed that the average person clearly neglects the powerful effect false evidence can have and hence the power of such an influence is not a matter of common sense. The results of Chapter 5 and Chapter 6 demonstrate that 
false confession issues are not a matter of common sense knowledge and that judges and juries can benefit greatly from expert testimony on false confessions in court.

Chapter 7 explored a future avenue for research by linking the phenomenon of choice blindness to the risk of the occurrence of false confessions. Across two experiments we examined choice blindness in participants' accounts of their own history of norm-violating behaviors. Participants were asked to indicate how often they had committed specific norm-violating behaviors in the past. Consistent with our hypothesis, a substantial amount of participants was blind for manipulated answers of their own reports. The current results display implications for false confessions elicited in interrogation and further strengthen several recommendations that have already been given to avoid false confessions.

Finally, the last chapter includes a general discussion integrating all findings of this dissertation. It starts with analyzing the case of Ulvi Kulac based on all the information provided in previous chapters. Furthermore, we conclude that false confessions are a threat to innocent suspects and that certain changes in the process of police custody can make interrogations a safer place for innocent suspects. This dissertation shows that common sense knowledge about confession related issues is not so common and therefore we argue that expert witnesses should be allowed to testify in court to aid judges and juries. Chapter 8 also discusses methodological shortcomings and future directions. 



\section{Valorization}

In the following valorization addendum, five issues will be addressed regarding the current dissertation 'The Danger of Innocence. Common Sense Beliefs and Misconceptions about False Confessions'. The first one concerns the relevance of the present dissertation. The second point elaborates on the target groups. The third issue deals with specific activities and services that may be derived based on the research results presented in this thesis. The fourth matter describes the innovative approach and results. The fifth and last section explains how the results of this thesis can be implemented in practices and what market opportunities there are.

\section{Relevance}

Marty Tankleff spent 17 years in prison for a crime he did not commit. He had falsely confessed to murdering his parents under police pressure and was convicted despite a recanted confession and no other evidence. During his time in prison he maintained his innocence and fought for his freedom (Firstman \& Salpeter, 2008). He was finally released from prison in 2007 and in 2014 he won a 3.4 million settlement in a lawsuit against the state of New York (Zimmerman, 2014).

Marty's story is one of many. He is not the only innocent person who had been imprisoned wrongfully because of a false confession. According to the US based innocent project, which has to date exonerated 321 innocent people, around a quarter of these cases involved a false confession as a contributing factor to the wrongful conviction (http:/innocenceproject.org). As a result of the advancement in the field of forensic science, such as DNA profiling, the innocence project was able to help innocent people who were wrongfully convicted. Even though these numbers show that Marty's case is not a rare one, it is impossible to estimate how many more false confessors are unfairly behind bars. Based on the work of the innocent project, and its many highly publicized cases in the media, but also due to research studies, many scholars have argued that these uncovered and proven cases are only the tip of the iceberg (e.g., Drizin \& Leo, 2004).

However, wrongful convictions have not only occurred in the United States of America. Huff and Killias (2008), who define wrongfully convicted persons as "those who have been arrested on criminal charges, who have either pleaded guilty to the charges or have been found guilty, and who have, notwithstanding their 
guilty plea or verdict, are innocent" (p. 5) have studied wrongful convictions across different nations. They rightly argue that more can be learned about one's own justice system, by studying and comparing it to those of others.

Specifically, false confession cases have been documented around the world, for example in Australia (Egan, 2006), Canada (Meissner, Horgan, \& Albrechtsen, 2009), China (Kahn, 2005), Finland (Santtila, Alkiora, Ekholm, \& Niemi, 1999), Germany (Otto, 2006), Ireland (Inglis, 2004), Japan (Onishi, 2007), the Netherlands (Wagenaar, 2002), New Zealand (Sherrer, 2005), Norway (Gudjonsson, 2003) and Singapore (Mokhtar, 2001). Despite documented cases, and organizations such as the innocent project in the US and the Criminal Case Review Commission for England, a prevalence rate of false confession is not known. Furthermore, it is problematic that not all cases involve physical evidence. Hence, it is often impossible to establish the 'truth' and exonerate innocent prisoners. If the uncovered cases of wrongfully convicted false confessors, such as the one of Marty Tankleff and others describe in this dissertation, are only the tip of the iceberg, there could be still thousands of innocent persons in prison today. This clearly poses a societal problem that needs attention.

The goal of false confession research, including the research presented in this dissertation, is to raise awareness of the risk of innocent suspects falsely admitting to a crime they have not committed. The aim, in the long run, is to change the system, improve police custody for (innocent) suspects and hence reduce the risk that innocent people admit to crimes they were not involved in. Ultimately, we hope that our research can save innocent people from spending years and decades in prison and being robbed of their freedom. Hence, the importance and relevance of researching the risks factors of false confessions, as the current dissertation did, to reduce wrongful convictions is obvious. The above mentioned statistics and the case of Marty Tankleff illustrate the need for this research and as Gail Zimmerman (2014) correctly stated "false confessions benefit no one. Innocent people go to prison. As this case shows, there may ultimately be a hefty financial price to pay. Last - but not least - it means people get away with murder. Whoever did kill Seymour and Arlene Tankleff got away with it -- so far" (last paragraph).

\section{Target Groups}

Even though the academic community is an evident target audience for our research, it should be emphasized that the research angle we have approached in this thesis is in its 'baby shoes'. Hence, other researchers in the field of false confessions are our prime target group because we hope they will replicate and extend our results presented in this thesis. In addition to other researchers, we also hope that our results will be used to educate the current students in the fields of psychology, law and forensic psychology. By raising awareness at a young educational stage of the new generation of psychologists, lawyers, judges, and forensic experts, we hope 
to create open mindsets that are aware of the risks of false confessions. We hope to motivate current students to help change and improve the system.

Once our research has been extended, replicated and verified, our main target group will be law enforcement officials: police, lawyers, and judged and furthermore the general population, especially jury eligible society members. The results obtained in this dissertation have demonstrated that the average person is not aware of the risk of falsely confessing when in police custody. Furthermore, we have shown that individuals are not able to use their common sense judgment to correctly foresee their own behavior and that of others while in police custody. This does not only mean that innocent suspects in police custody are put at risk just by being innocent, it also means that judges and juries are not able to fully understand the risk of false confessions and especially how they can be detected. Therefore, law enforcements and the general public are targeted to make them aware of these misconceptions and misbeliefs about false confessions that were researched in this thesis. One way to inform, for example, judges and juries is by routinely using false confession experts in court to educate judges and juries about all related problems of false confession. As mentioned earlier, such awareness can already be raised at an earlier stage during undergraduate and graduate studies for law enforcement officials.

As mentioned above, at the current state of this research the prime target audience is the scientific community, especially those involved in false confession research. In a later state, the target group shifts towards students on the hand and employed law enforcement officials, including jury members, on the other hand.

\section{Activities and Services}

In the current form, the results of the dissertation are relevant for the academic community in the field of psychology and law, therefore the first step should be to convert each chapter that has not be published yet, into a scientific publication. Through such publications the knowledge that has been gained during the research of this dissertation can be communicated to the relevant scientific community. Furthermore, the questionnaires that were developed for the studies described in Chapter 3 and Chapter 4 can be adapted and used by other researchers in order to extend and replicate our findings and hence our understanding of the issue of common sense knowledge about false confessions. The paradigm described in Chapter 7 opens up a whole new direction of research by linking the phenomena of false confessions to the choice blindness literature. This could inspire other researchers to further develop this research avenue.

Additionally, our results display potential to be translated into teaching sessions, such as seminars or workshops, for students and law enforcement officials. One idea, for example, could be to offer a summer school program for undergraduate and graduate students in which the issue of misconceptions and misbeliefs will 
be dealt with intensively, of course embedded in the overall risk factors of false confessions. Another possible service that could be developed out of this research (once it has been extended) could be novel teaching materials, such as a book, guidelines or presentations.

On top of that, a long term goal is to help improve the justice system in order to reduce the occurrence of false confessions. This can be done by writing a policy recommendation, including change suggestions for how the police should deal with suspects in custody. Our research could be the basis for such a policy in the following years.

Currently, the findings of this dissertation are at a premature level, but they already demonstrate the potential to be developed in activities, such as seminars, workshops and summer schools, and services, such as policy recommendations, books and other teaching materials.

\section{Innovation}

False confessions have been widely researched in the last two decades, through case studies of exonerations, through field observations of interrogations and experiments in research laboratories. As a result of these numerous studies, a solid scientific foundation on false confessions exists today ranging from various risk factors to manifold recommendations on how to reduce false confessions. The existing literature, however, has been primarily dealing with police custody of suspects, and especially interrogation techniques and their consequence. In contrast, the studies presented in the current dissertation focused largely on the preceding stage: the beliefs of people about false confessions and police custody before they enter such a situation. This dissertation investigated a novel perspective - what lay people's beliefs about false confessions are across different nations, with what beliefs people enter police custody, and how this influences their risk of falsely confessing to a crime they have not committed.

For example, in Chapter 3 we examined the lay people's beliefs and attitudes about false confession in seven different countries across the world. There have been several of such studies conducted in the United States, but not across nations. So, to the best of our knowledge our research approach to extend the American findings and compare and contrast them to several other countries is unprecedented. By using such a large sample of various countries we were able to show that most misbeliefs and misconceptions about confession related issues are universally accepted and not specific to the American culture. Furthermore, we did not only ask participants about their own behavior but also in comparison to that of others. Similarly, in Chapter 4 we used a questionnaire to survey police investigators across Europe. An earlier study had examined the beliefs and attitudes about police practices in North America (Kassin et al., 2007), but such a study had previously not been conducted in Europe which makes our approach innovative. 
Furthermore, the combination of using an established paradigm and pairing it with a prediction study, as we have done in Chapter 5 and Chapter 6, is a new approach to investigating misbeliefs about false confessions. It enabled us to demonstrate that innocent participants have problems in predicting how they and others will behavior in police custody. Such an uncovered discrepancy can pose a potential risk for innocent suspects to falsely confess in an interrogation. Finally, the study described in Chapter 7 presented for a newly developed paradigm, linking the risk of false confessions to the phenomenon of choice blindness.

Overall, most studies in this dissertation developed new approaches and examined the problem of false confessions from a new perspective, making the overall results innovative and valuable.

\section{Implementation}

As already mentioned previously, at the current state of this research, our primary target audience is the scientific community. Therefore, as a first step the results of Chapters 3, 4, 5, 6, and 7 have already been presented at various international conferences. Through these presentations, interest about the topics and approaches was sparked and has already led to networking with other researchers in the field. As a second step, the goal is to publish all studies that have not been published yet. The process of getting the individual research studies ready for publication and submitting them to journals in the field of psychology and law has already started and is currently an active process. Ultimately, the hope is that our research studies will be extended and replicated by other researchers.

In the long term, it is hoped that our research findings will be used to educate law enforcement officials, students and the population in general. As a future step, a seminar and/or workshop could be developed for undergraduate students. For example, by offering summer school courses. Starting with students, such workshops could be redefined and further develop to also fit graduate students and at some point law enforcement officials, such as police, lawyers and judges. Such trainings could be either offered as optional educational activities or even made mandatory for law enforcement officials, either during their training stages or as advanced training during the professional careers. Another idea could be to educate all jury members about the risks of false confessions, of course including our research direction of misbeliefs and misconceptions. To aid such trainings, guidelines or a book could be written or even other teaching materials such as case examples could be developed.

If at some point a policy recommendation would be written, it could as a first step make the appearance and admittance of false confession experts in court mandatory in order to ensure that all personnel involved in a court trial are properly informed. Furthermore, such a policy could suggest changes in police proceedings. However, as mentioned earlier already, the current findings are not at the level yet 
where such future plans can be implemented. Even though some of these ideas have the potential to be marketed into profits, it should be stressed that the main aim of this research is to reduce the occurrence of false confessions and to help decrease the risk that innocent people spend decades in prison.

\section{References}

Egan, C. (2006, February 22). A murderer no more. The Australian Newspaper, p. 13.

Firstman, R., \& Salpeter, J. (2008). A criminal injustice. A true crime, a false confession, and the fight to the free Marty Tankleff. New York, NY: Ballantine Books.

Gudjonsson, G. H. (2003). The psychology of interrogations and confessions: A handbook. Chichester, England: John Wiley \& Sons.

Huff, C. R., \& Killias, M. (Eds.). (2008). Wrongful conviction. International perspectives on miscarriages of justice. Philadelphia: Temple University Press.

Inglis, T. (2004). Truth, power and lies: Irish society and the case of the Kerry babies. Dublin: University College Dublin Press.

Kahn, J. (2005). Deep flaws, and little justice, in China's court system. The New York Times, September 21, 2005.

Kassin, S. M., Leo, R. A., Meissner, C. A., Richman, K. D., Colwell, L. H., Leach, A. M., \& La Fon, D. (2007). Police interviewing and interrogation: A self-report survey of police practices and beliefs. Law and Human Behavior, 31, 381-400. doi:10.1007/s10979-006-9073-5

Meissner, C. A., Horgan, A. J., \& Albrechtsen, J. S. (2009). False confessions. In R. Kocsis' (Ed.), Applied criminal psychology: A guide to forensic behavioral sciences (pp. 191- 212). Springfield, IL: Charles C. Thomas Publisher, LTD.

Mokhtar, F. (2011, July 6). Man jailed for 6 years acquitted of murder charges. Singapore Scene. Retrieved from https://sg.news.yahoo.com/blogs/singaporescene/man-jailed-6-years-acquitted-murdercharges-055338858.html

Onishi, N. (2007, May 7). Pressed by police, even innocent confess in Japan. The New York Times.

Otto, H. D. (2006). "Im Namen des Irrtums!" Fehlurteile in Mordprozessen ["In the name of error!" Miscarriages of justice in murder trials]. München: F.A. Herbig.

Rahn, K. (2008, November 30). Man cleared of murder charge after 36 years. The Korea Times, retrieved from http://koreatimes.co.kr

Santtila, P., Alkiora, P., Ekholm, M., \& Niemi, P. (1999). False confessions to robbery: the role of suggestibility, anxiety, memory disturbance and withdrawal symptoms. The Journal of Forensic Psychiatry, 10, 399-415. doi:10.1080/09585189908403692

Sherrer, H. (2005). Murdered woman's innocent boyfriend exonerated after bizarre "confession" is exposed as false. Justice: Denied, January 2005.

Wagenaar, W.A. (2002). False confessions after repeated interrogations: The Putten murder case. European Review, 10, 519-537.

Zimmerman, G. (2014, January 8). Marty Tankleff, wrongfully imprisoned, wins $\$ 3.4 \mathrm{M}$ settlement. CBS NEWS. Retrived October 26, 2014 from http://www.cbsnews.com/news/marty-tankleff-wins-3375million-for-wrongful-imprisonment/ 


\section{Acknowledgements}

I would like to thank my family, friends, colleagues and especially my supervisors for all their support during my PhD project. I couldn't have done it without you!

Harald, Harm and Saul - you are my three heroes! I could have not asked for a better trio of supervisors. I have learned so much from you during the last years and it is a great privilege to work with you.

Harald, not only did you accept me with open arms into your research group, you also always had an open ear for my concerns and worries. You were a great mentor from the beginning of my PhD journey till the end. You always managed to help me get back on the right track. When I was frustrated, you reminded me that writing a PhD is a once a life time opportunity which should be enjoyable and fun. When I was excited about a new project, you shared my enthusiasm. You taught me to have a critical eye on my work but also to trust in my work. I cannot put in words how thankful I am for all of your support!

Harm, my stats wizard. Thank you for all of your support, especially with my statistics related problems. Thank you for supporting my conference travels all over the world, each trip was very valuable and a great experience. Your door was always open for me, which I really appreciate. Thank you for believing in me.

Saul, I don't even know where to start thanking you. The one year internship in your lab inspired this project; you inspired me! I discovered my passion for false confession research and I am honored to have been able to work with you during the last few years. Your great ideas, your enthusiasm about my project and your valuable, critical feedback have helped me develop my research skills so much. I am eternally grateful for the experience and hope we will work on more projects together in the future.

Louis, I probably would not be where I am today if you had not believed in my PhD project and offered me a job at UCM. I am very grateful for the opportunity you provided. Thank you!

Melanie and Nicolai - my great paranimfen! Thank you very much for your support, your feedback, your motivation and for always believing in me during the last years.

Melanie, thank you for our small brainstorming sessions during our lunches, thank you for making our PEERS projects a success and thank you for being my 
friend! Working with you is fun and challenging. I have learned so much from you and I hope we will keep working together on projects.

Nick, what would I do without you? You are a great colleague, a great friend and I am grateful for always having someone around to share my gossip, my frustration and my good news with. Thank you for taking the time to read my whole thesis. I really appreciate your feedback and the fact that you can spot all typos and mistakes. Thank you for always having my back.

I would also like to thank my assessment committee for reading my thesis and for approving it.

My dear UCM colleagues - thank you for your support and your understanding when I did not have time to take over a class, an interview or said no to a new project. It is great to work in such a comfortable working environment and I am happy to be able to stay at UCM. I enjoy working together with all of you. Anouk, thank you for all of your support and help. It is good to know that I can always talk to you. Christoph, best office mate ever! Nina \& Wolfgang, sharing the long rides to and from work with you is great. Our chats make the commute so much more fun! Mark, it is always fun sharing shark news with you. Teun, thanks for your "it will always work out in the end" attitude. Kelly, sorry for always bothering you with tons of questions and thank you for always finding an answer. And a big THANK YOU to everyone else for making UCM the great place it is.

Ceren, it is so much more bearable to work on Saturdays if I know I am not the only one. Thanks for letting me crash in your office on various Saturdays. Thanks for your advice and our chats. It feels good talking to someone in the same position.

To all my colleagues in the section of Forensic Psychology of Maastricht University - thank you for letting me join your group. I enjoyed joining your Friday meetings and especially the retreat trips. I am grateful for all the inspiration and feedback you provided.

Julia, Annelies \& Ingo, my Master besties! What fun times we had together in class, critically discussing and evaluating all aspects of forensic psychology. I love our little reunions in which we reflect back on our time in grad school and swap stories of our daily lives, all revolving around our shared passion. Thank you for travelling to UCM to spread your research and job experiences with my students. Julia \& Annelies, my conference travel buddies - I enjoyed our trips so much and hope that I can soon join the travel conference fun again.

Last but not least I would also thank my family and friends. I would have been lost without all your support and understanding. Meine Mädels - danke, dass es euch gibt. Danke, dass ihr verstanden habt wenn ich mal wieder keine Zeit zum telefo- 
nieren oder treffen hatte, weil ich an meinem Schreibtisch saß und die Doktorarbeit vorging. Danke, dass ich weiss, dass ich immer auf euch zählen kann. Danke, dass ihr mich immer wieder auf den Boden der Tatsachen zurück holt.

I would also like to thank my parents-in-law and my siblings-in-law for welcoming me to the family with open arms. Thank you for always being interested in hearing about my research, my progress, my struggles and my achievements. Thank you for sending me links of articles, videos and radio series related to my research. It shows how much you care and I really appreciate it!

Mama und Papa, euch möchte ich von ganzem Herzen danken. Ohne euch hätte ich es nicht geschafft. Ihr habt mich ein Leben lang begleitet und unterstützt, ob in Deutschland oder weit weg in Amerika, ob finanziell oder mit viel Liebe. Ich habe alles bekommen von euch und es fällt mir schwer die richtigen Worte zu finden euch dafür zu danken. Ich bin froh, dass es euch gibt. Ohne euch hätte ich es nicht geschafft diese Doktorarbeit zu beenden. Ich weiss sehr zu schätzen, dass ich mich immer auf euch verlassen kann. Danke!

Auch dem Rest meiner Familie und vorallem meinem Bruder und meiner Schwägerin möchte ich auf diesem Weg danke. Es ist grossartig, dass ihr immer Interesse an meiner Arbeit gezeigt habt und nie an mir gezweifelt habt.

Andrew, my biggest thank you goes out to you. You have been by my side from the beginning of this project. You dried my tears of frustration and shared my tears of happiness. Thank you for always listening, for formatting my graphs, for helping me code my data, for endless proof reads, and for everything else. I love you!

Noah, you put a smile on my face every day and for that I love you. You have shown me what life is really about! You are going to be a great big brother. And I am thankful that I will not be alone during the defense since your sibling will be with me. 



\section{Curriculum Vitae}

Jennifer Schell-Leugers was born on November 22nd, 1982 in Aachen, Germany. After graduating from Städtisches Gymnasium Eschweiler in Germany in 2002, she attended a one year commercial college program in Economics and Business. From 2003-2004 she spent a year in Connecticut, USA as an Au Pair. She started her bachelor's at University College Maastricht (UCM) in August 2004. During her studies she spent a year abroad at Hobart and William Smith colleges in New York. She graduated cum laude in the summer of 2007 with a focus on Psychology and Law. Subsequently, she joined the Applied Cognitive Psychology Master (track: Psychology and Law) at the Faculty of Psychology and Neuroscience at Maastricht University. For her Master's thesis research, she spent one year at John Jay College of Criminal Justice in New York City, USA and conducted research under the supervision of Prof. Dr. Saul Kassin. She graduated cum laude in 2008 and received the top 3\% Master's scholarship. In January 2009, she started working at UCM as a lecturer and $\mathrm{PhD}$ candidate. During her PhD project, she has been teaching and coordinating a course in Psychology \& Law and in the field of Academic Skills. 


\section{Publications}

Sauerland, M., Schell, J. M., Otgaar, H., \& Meijer, E. H. (2013). Hoe misleiding tijdens het verhoor (valse) bekentenissen in de hand kan werken: Over keuzeblindheid in de verhoorkamer. [How deceptive interviewing techniques can put (innocent) suspects at risk of confessing: About choice blindness in the interrogation room]. Expertise en Recht, 5/2013, 210-214.

Sauerland, M., Schell, J. M., Collaris, J., Reimer, N., Schneider, M., \& Merckelbach, H. (2013). "Yes, I have sometimes stolen bikes": Blindness for norm-violating behaviors and implications for suspect interrogations. Behavioral Sciences and the Law, 31, 239-255.

Schell, J. (2012). False confessions. In J. Shaw (Ed.), Psychology and Law Factbook. Kelowna, Canada: European Association of Psychology and Law Publishing House.

Schell, J. M., \& Merckelbach, H. (2011). Falsche Geständnisse: Warum unschuldige Menschen Verbrechen gestehen, die sie nicht begangen haben [False confessions: Why innocent people confess to crimes they have not committee].The Inquisitive Mind, 1/2011.

Schell, J. M. (2010). False confessions and its pitfalls: The dilemma of applying research findings to practice. In P. Santtila (Ed.), The applicability of psycho-legal research: Sexual interest, deception and suggestibility (pp. 73-88). Oslo, Norway: Nordforsk.

\section{Manuscripts submitted for publication:}

Schell-Leugers, J . M., Kassin, S. M., Merckelbach, H., \& Hospers, H. J. (2014). Not acting according to our beliefes: The dangers of waiving the right to remain silent. Manuscript under review.

Sauerland, M., Schell-Leugers, J. M., \& Sagana, A. (2013). Fabrication puts suspects at risk: Blindness to changes in transgression-related statements. Manuscript under review.

\section{Conference presentations:}

Schell, J. M. (2013, September). Reden ist Silber, Schweigen ist Gold? Über den Nichtgebrauch des Schweigerechts von unschuldigen Verdächtigen. [Speech is silver, silence is golden? About non-usage of the right to remain silent of innocent suspects]. Paper presented at the $15^{\text {th }}$ biannual meeting of the Fachgruppe Rechtspsychologie of the DGPs in Bonn, Germany.

Schell, J. M. (2013, June). Common sense during interrogations. Paper presented at the $2^{\text {nd }}$ Forensic Psychology Update meeting in Maastricht, The Netherlands. 
Schell, J. M., \& Kassin, S. M. (2012, March). Police practices and beliefs: A survey of European investigators. Paper presented at the annual meeting of the American Psychology-Law Society in San Juan, Puerto Rico.

Schell, J. M., Kassin, S. M., Merckelbach, H., \& Hospers, H. (2011, March). "I would never do that!"...and then they do...Exploring inconsistencies between predicted and actual behavior in interrogation situations. Paper presented at the $4^{\text {th }}$ International Congress on Psychology and Law in Miami, USA.

Schell, J. M., \& Merckelbach, H. (2010, June). Guilty by exoneration: The danger of recanted (false) confessions. Paper presented at the 19th meeting of the European Association of Psychology and Law in Gothenburg, Sweden.

Schell, J. M., \& Kassin, S. M. (2009, September). The psychology of eyewitness testimonies. Poster presented at the $18^{\text {th }}$ meeting of the European Association of Psychology and Law in Sorrento, Italy.

Schell, J. M., \& Kassin, S. M. (2009, September). Welche Auswirkungen können Geständnisse haben?

Laien-Ansichten über Ermittlungsverfahren und deren Risiken [Which effects do confessions have? Lay peoples opinion about investigation procedures and their risks]. Paper presented at the $13^{\text {th }}$ biannual meeting of the Fachgruppe Rechtspsychologie of the DGPs in Giessen, Germany.

Schell, J. M., \& Kassin, S. M. (2009, March). Common sense of confessions: What do people believe? Poster presented at the annual meeting of the American Psychology - Law Society in San Antonio, Texas, USA.

Schell, J. M., \& Kassin, S. M. (2008, July). Common sense of confessions: What do people believe? Poster presented at the $17^{\text {th }}$ meeting of the European Association of Psychology and Law in Maastricht, The Netherlands. 